\title{
SURVEY PROTOCOLS FOR SURVEY \& MANAGE CATEGORY A \& C LICHENS IN THE NORTHWEST FOREST PLAN AREA
}

Bryoria tortuosa (G. Merr.) Brodo \& D. Hawksw. Leptogium cyanescens (Rabenh.) Körber

Lobaria oregana (Tuck.) Müll.

Niebla cephalota (Tuck.) Rundel \& Bowler

Platismatia lacunosa (Ach.) Culb. \& C. Culb.

Ramalina thrausta (Ach.) Nyl.

Teloschistes flavicans (Sw.) Norman

Usnea longissima Ach.

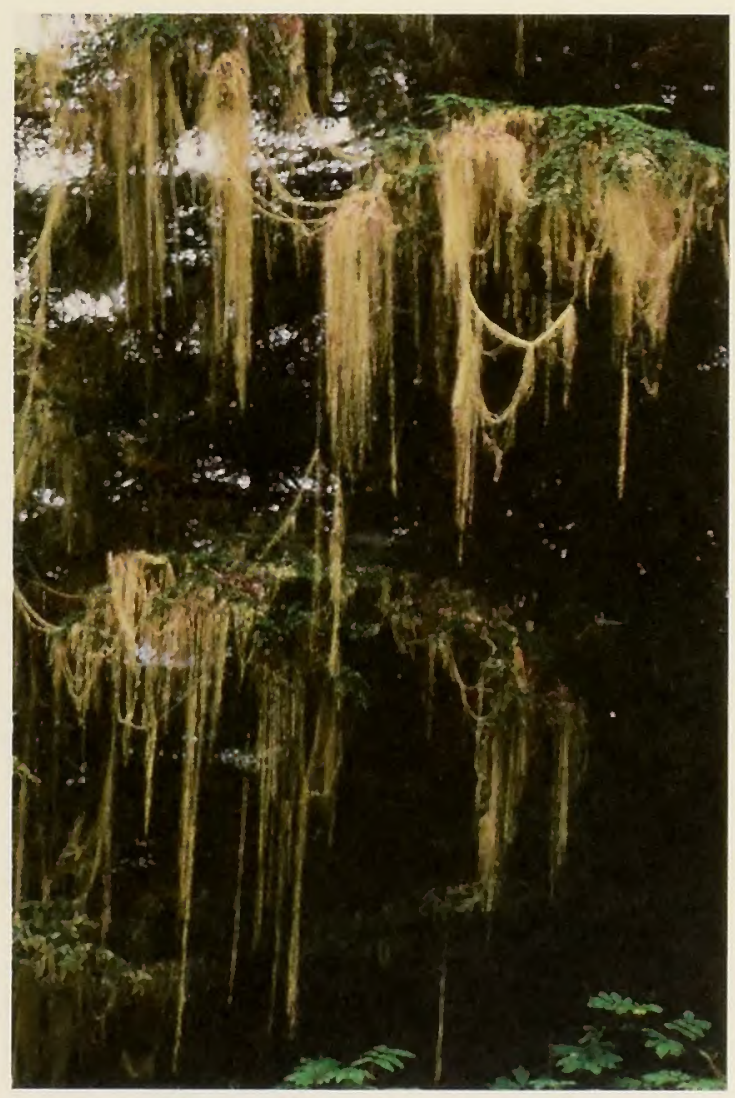

Usnea longissima Ach.

Version 2.1 (2003)

By: Chiska Derr, Richard Helliwell, Andrea Ruchty,
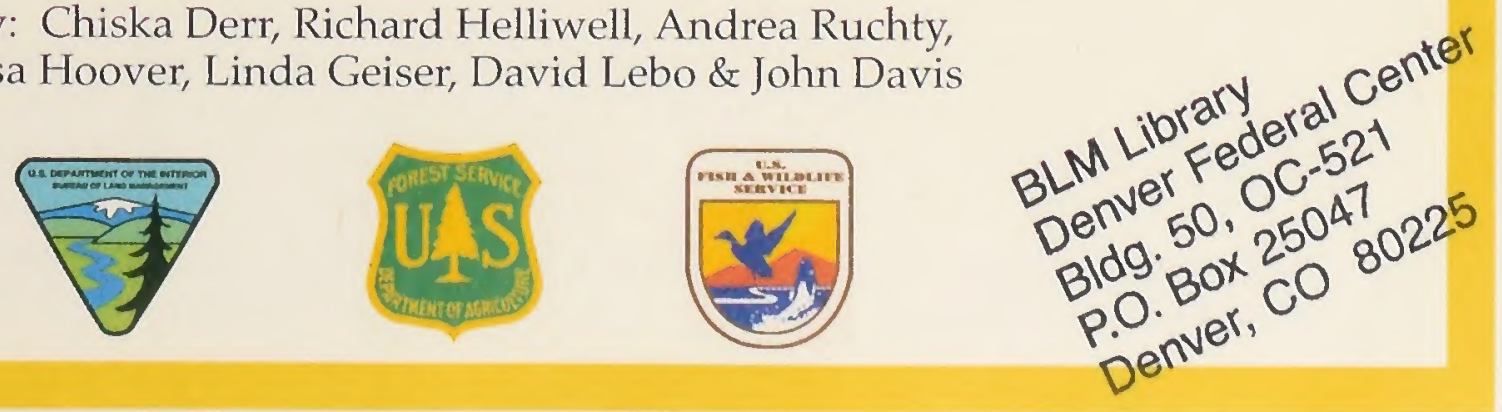
BLM/OR/WA/PL-02/045+1792

All photographs used in this document are copyrighted (c) by Sylvia and Stephen Sharnoff and are used with their permission. 


\section{TABLE OF CONTENTS}

INTRODUCTION

SECTION I: SURVEY PROTOCOLS ……………………………………….... 5

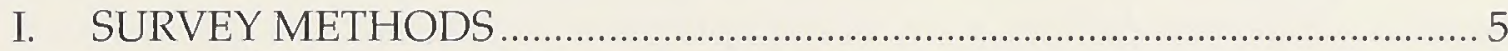

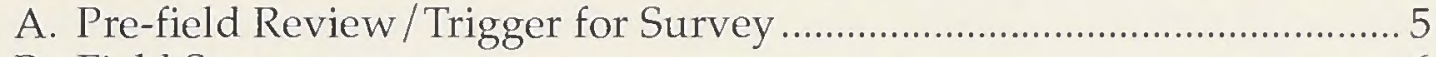

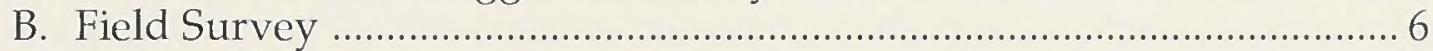

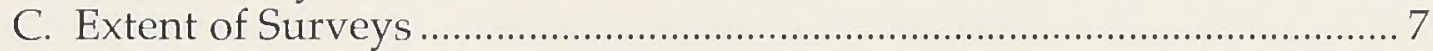

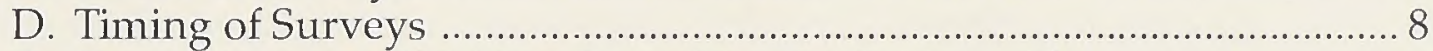

E. Determination of Habitat Disturbing Activities with Significant Negative Effects ………………………........................... 8

II. DATA COLLECTION AND DOCUMENTATION ……………………….... 9

A. Documenting the Presence of a Target Lichen Species ………………..... 9

B. Vouchering and Species Verification .................................................. 10

C. Monumenting a Known Site …………………………………………...... 11

D. Documenting the Non-Detection of a Target Lichen Species ................ 12

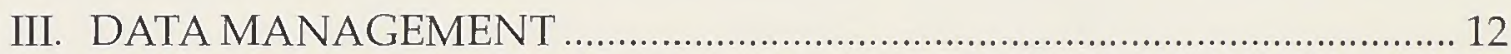

A. Data Storage and Quality Assurance ...................................................... 12

IV. SURVEYOR QUALIFICATIONS AND SKILLS ………………………....... 12

SECTION II: SPECIES INFORMATION …………………........................... 15

I. Bryoria tortuosa (G. Merr.) Brodo \& D. Hawksw. ................................... 17

II. Leptogium cyanescens (Rabenh.) Körber ……………………………...... 21

III. Lobaria oregana (Tuck.) Müll. ................................................................ 27

IV. Niebla cephalota (Tuck.) Rundel \& Bowler ................................................ 33

V. Platismatia lacunosa (Ach.) Club. \& C. Culb. ............................................ 37

VI. Ramalina thrausta (Ach.) Nyl. .............................................................. 43

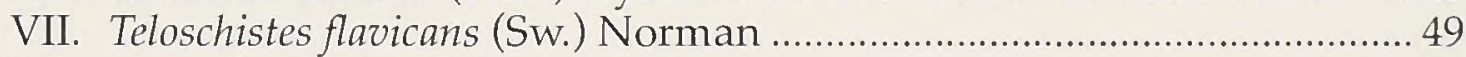

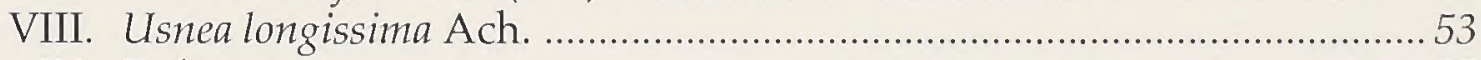

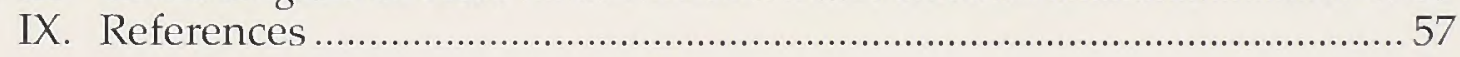

\section{APPENDICES}

Appendix A. Lichen \& Bryophyte Species Location Field Form \& Instructions ....... 61

Appendix B. Lichen \& Bryophyte General Survey Field Form \& Instructions ........... 69

Appendix C. Lichen \& Bryophyte Collection Packet Form for Voucher Specimens 75

Appendix D. Jan. 9, 2002 Memo: Centralized Process to Identify/Verify Survey \& Manage Specimens Collected While Conducting Surveys..... .79

\section{LIST OF FIGURES}

Figure 1. Example of a Complete Survey ……………………………………. 6

Figure 2. Example of an Intuitive-Controlled Survey ……………………..... 7

Figure 3. Bryoria tortuosa ..................................................................... 20

Figure 4. Bryoria fremontii ............................................................... 20

Figure 5. Bryoria tortuosa pseudocyphellae ..................................................... 20

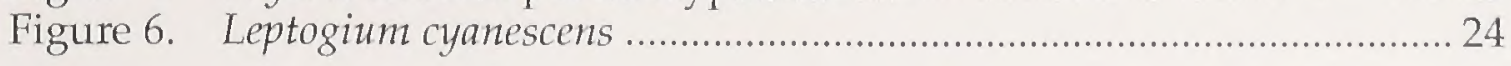




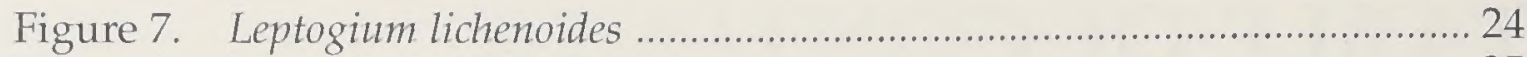

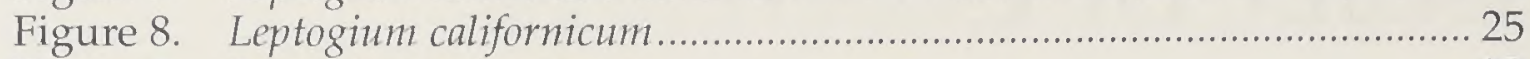

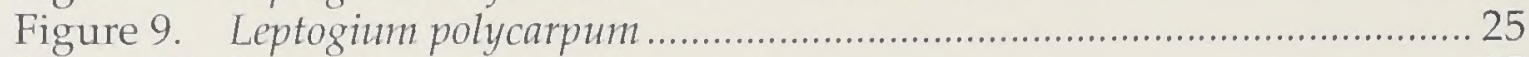

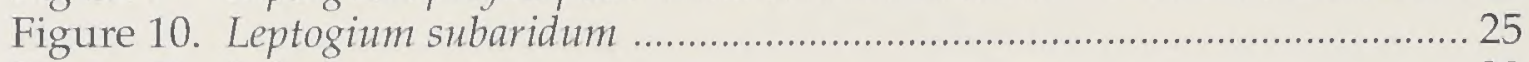

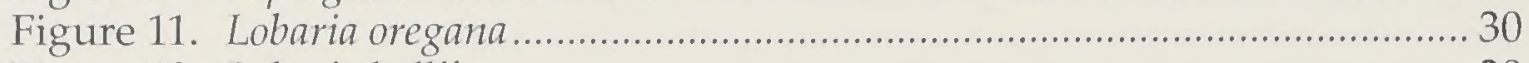

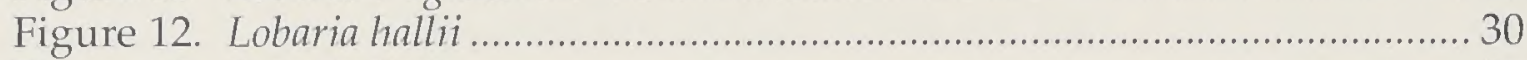

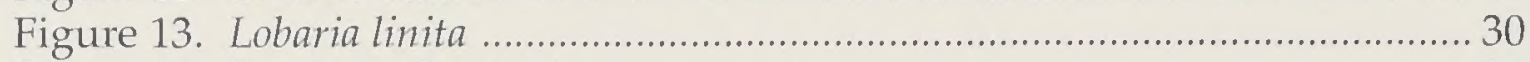

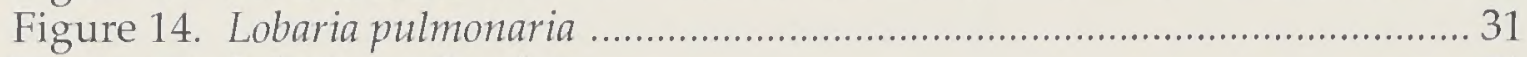

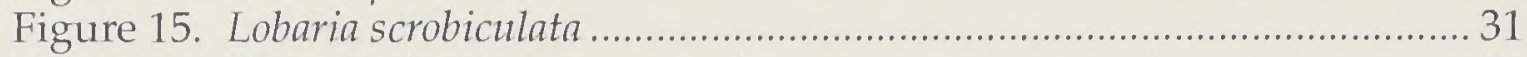

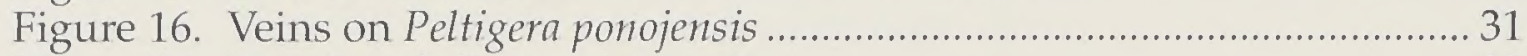

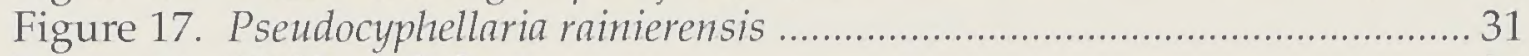

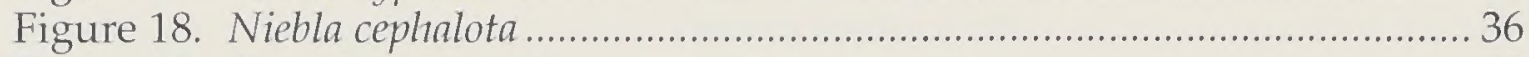

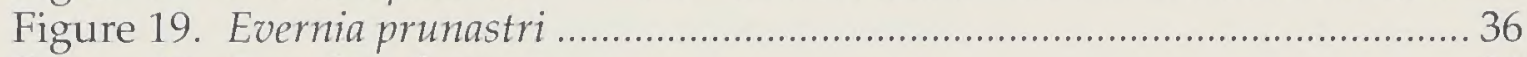

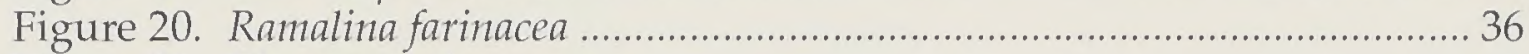

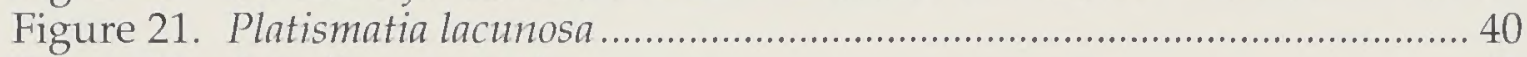

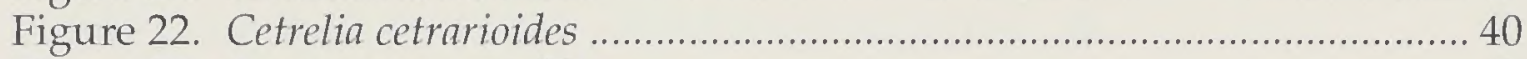

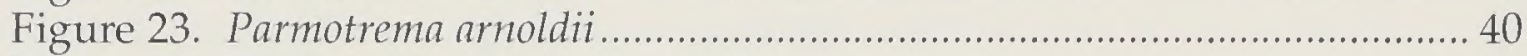

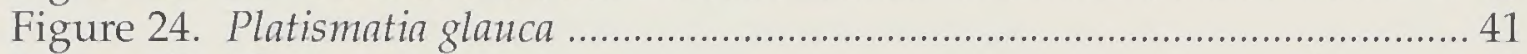

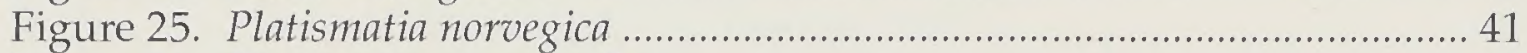

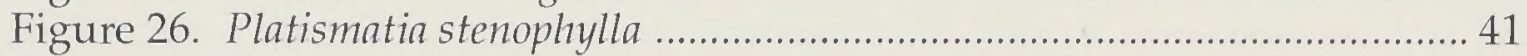

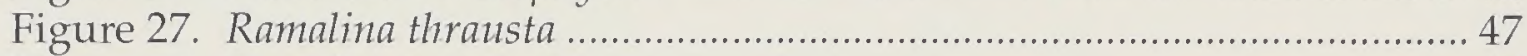

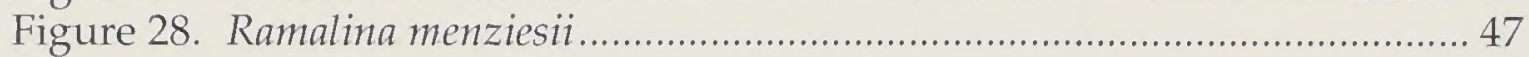

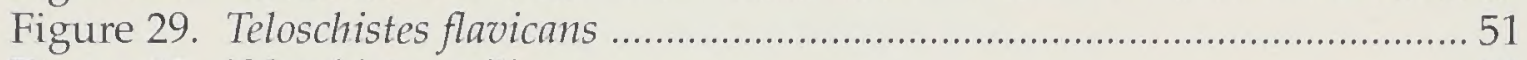

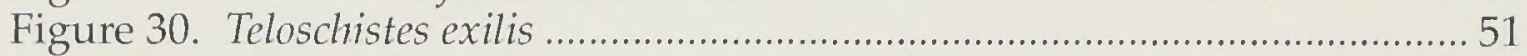

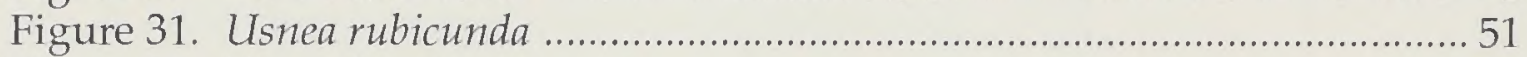

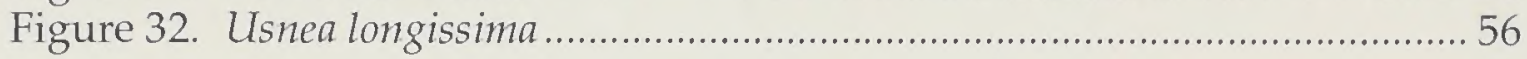




\section{INTRODUCTION}

This protocol provides a general overview of survey methods and requirements for the eight lichen species covered by this protocol. In Section I, a procedure is outlined that describes the circumstances that would trigger a need for survey. Survey methods, data collection, documentation, vouchering, and specimen verification procedures are also described. Section II provides the specific habitat and range information for individual species that should be used to focus survey efforts. Section II also provides detailed descriptions of each species including key identification features and how to distinguish them from similar-appearing lichens. The Standards and Guidelines for Amendments to the Survey and Manage Protection Buffer, and other Mitigation Measures Standards and Guidelines (USDA \& USDI 2001) provide the basis for this protocol and pages $21-26$ should be reviewed for background or additional guidance.

This survey protocol was prepared by the Lichen Taxa Team: Chiska Derr, Regional Interagency Lichen Taxa Expert, Richard Helliwell, Bryophyte and Lichen Taxa Lead, and John Davis, Linda Geiser, Lisa Hoover, David Lebo, and Andrea Ruchty, Lichen Taxa Team members. Comments, corrections, or additional information should be addressed to the current Lichen Taxa Lead.

\section{SECTION 1: SURVEY PROTOCOLS}

\section{SURVEY METHODS}

\section{A. Pre-field Review / Trigger for Survey}

A project will require survey for Category $\mathrm{A}$ or $\mathrm{C}$ species if all three of the following criteria are met:

1. The project lies within the known or suspected range for the species.

2. The project lies within, or could affect, suitable habitat for the species.

3. The project has the potential to cause a significant negative effect on the species habitat or the persistence of the species at the site.

The range and habitat for each species is described in Section II of this document. In most cases, the range is necessarily general, conforming to the physiographic provinces described in the Record of Decision (USDA \& USDI 2001). The range should be further refined by field units, using the habitat information provided for each species. Information on range and habitat represents the best available information to date. Additional surveys may modify this information in time, with range changes addressed during the Annual Species Review process. The survey requirement in the expanded range would apply to NEPA decisions or other decision documents signed in the calendar quarter following the first full survey season (USDA \& USDI 2001, Standards \& Guidelines p. 24).

The regional interagency lichen taxa expert is available to answer questions regarding range and habitat requirements of individual species. It is, however, ultimately the responsibility of the field unit, rather than the taxa expert, to determine whether survey is required in specific situations. The person on the field unit making this assessment must meet the qualifications described in Section IV. 
Habitat-disturbing types of activities are briefly addressed in Section E. Habitat-disturbing activities are not necessarily the same as grounddisturbing. A disturbance that is likely to have a "significant negative impact on the species' habitat, its life cycle, microclimate, or life support requirements" would qualify as a habitat-disturbing activity. "The evaluation of the scale, scope, and intensity of the anticipated negative impact of the project on habitat or life requirements should include an assessment of the type, timing, and intensity of the disturbing activity" (USDA \& USDI 2001, Standards \& Guidelines p. 22).

If no survey is required because the project did not meet one or more of the criteria listed above, then that should be documented along with a brief discussion of the reasons why.

\section{B. Field Survey}

The primary objective of a pre-disturbance survey is to identify locations of species that could be adversely affected by a project. However, there is tremendous benefit to gathering sufficient ecological data at new sites to allow for further assessment of habitat requirements, including latesuccessional/old-growth (LSOG) association. Ecological data can be used in the design of project mitigation as well as during the Annual Species Review process. These data are also useful in modification of future Management Recommendations and Survey Protocols.

Surveys should be conducted in such a manner as to ensure a high likelihood of locating the species where there is suitable habitat within the range of the species. Depending upon the size of the proposed project area, use one of the following two survey methods:

\section{Complete Survey}

For small areas of one hectare (2.47 acres) or less conduct a complete survey. A complete survey involves a 100 percent visual examination of the proposed project area (Figure 1). Distance between survey lines should be close enough to maintain sight distance between transects.

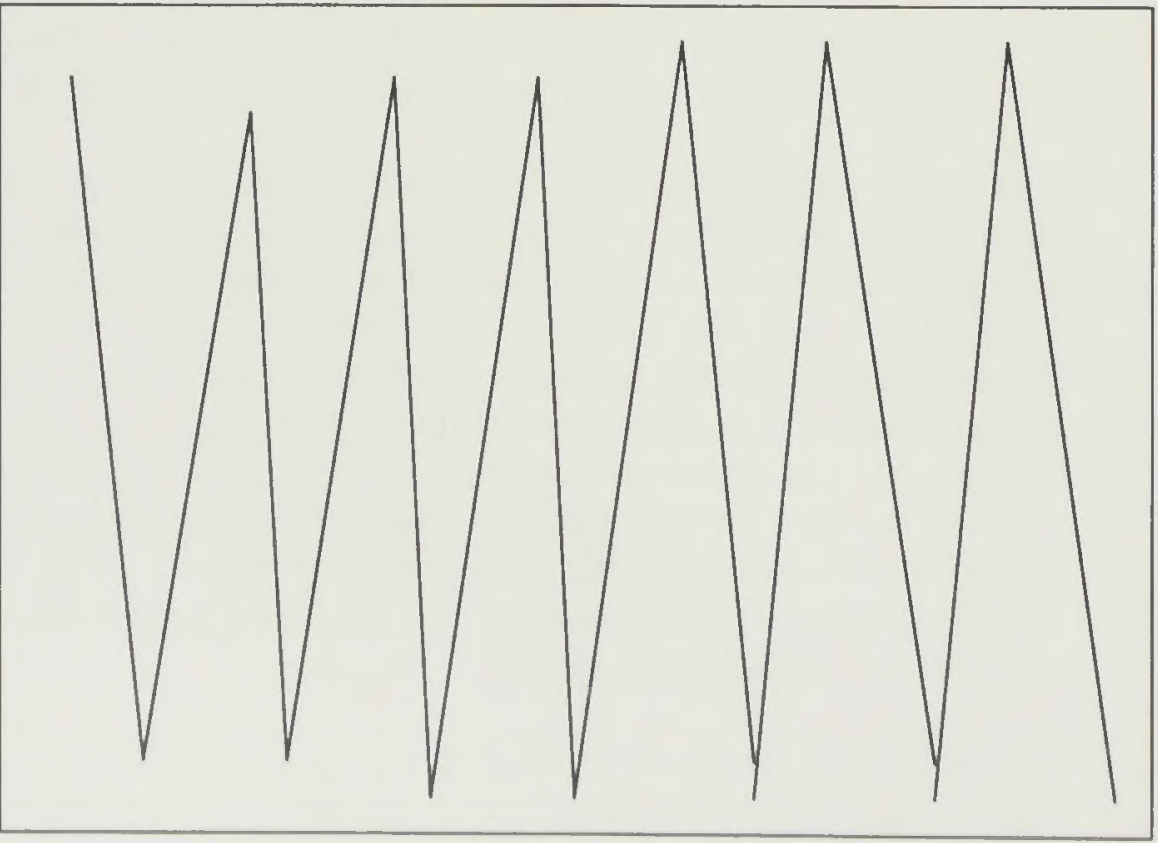

Figure 1. Example of a Complete Survey. Distance between survey lines would depend upon sight distance. 


\section{Intuitive-Controlled Survey}

For large areas (greater than one hectare) it can be more difficult to determine from the pre-field review the extent and distribution of the suitable habitat for a species. For this reason, an intuitive-controlled survey is conducted on large areas. This survey method requires that the surveyor(s) be knowledgeable enough of the species and its habitat to distinguish areas of likely habitat on the ground. Enough of the proposed project area is traversed that all the major habitats and topographic features have been, at least briefly, investigated (Figure 2). Any suitable habitat that is found receives a complete survey. The survey intensity should be thorough enough to have a reasonable assurance of detecting the target species in atypical habitat as well.

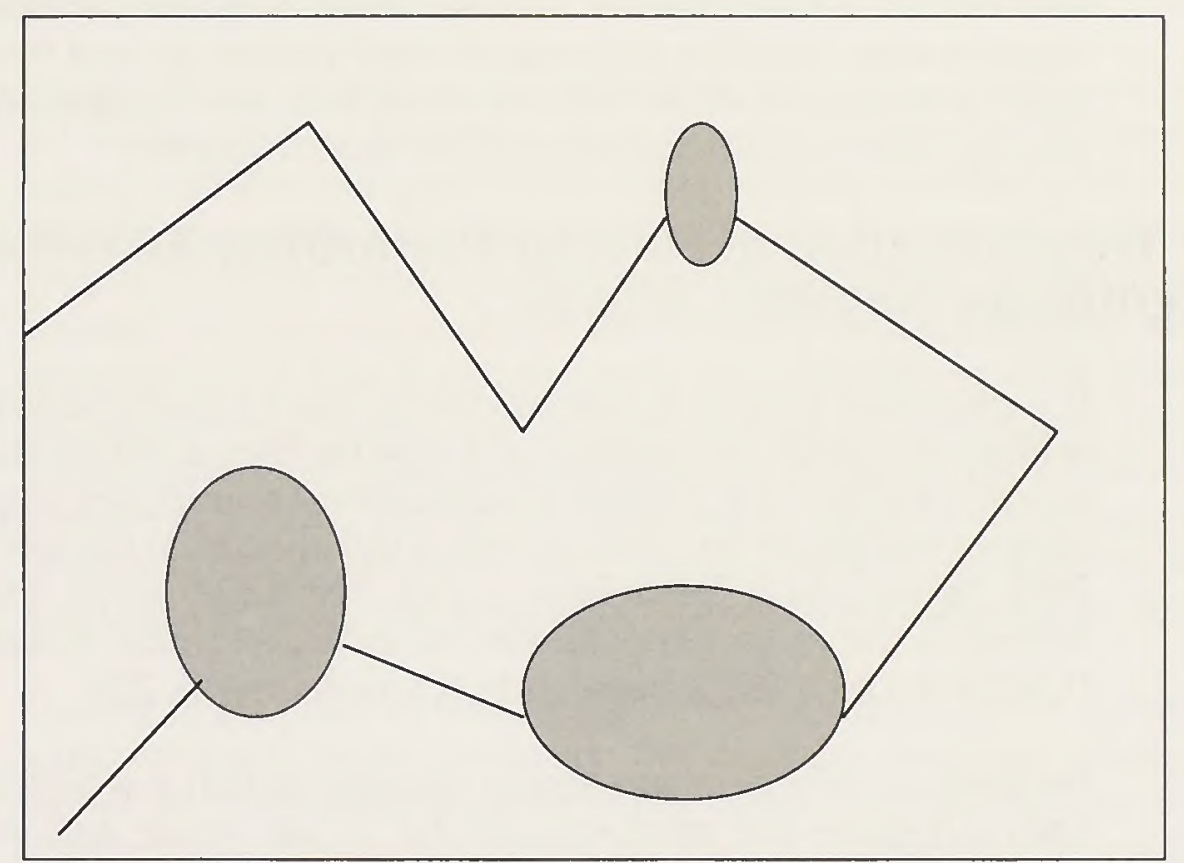

Figure 2. Example of an Intuitive-Controlled Survey. Shaded blocks represent areas of suitable habitat.

\section{Extent of Surveys}

In either a complete or intuitive-controlled survey, if there is habitat adjacent to the proposed project, and the proposed project could significantly affect that habitat or the persistence of the species at the site, then that habitat should be surveyed in addition to the proposed project area itself. For example, some projects may affect microclimatic conditions immediately adjacent to the project boundary. Although the effect of created forest edges on microclimatic conditions has been the subject of much recent research, impacts to individual species are poorly understood (Sillett 1994, Esseen \& Renhorn 1998, Hilmo \& Holien 2002).

When surveying for epiphytic lichens, recently fallen lichen litter, trees and branches should be investigated, however there is no requirement to climb trees. Comparison of tree climbing and ground survey methods for Nephroma occultum concluded that ground survey alone was an effective and more efficient method than tree climbing alone. The primary drawback of using only ground surveys is that it doesn't provide an accurate assessment of the distribution of this species within the stand (Rosso et. al. 2000). All of the epiphytes considered in this protocol can commonly be found in the lower canopy or bole and shrubs as well as on litterfall. Although some people 
have found them useful, the use of binoculars to search the upper canopy is not considered to be a reliable survey method and does not allow for ready collection or verification of vouchers.

\section{Timing of Surveys}

There is no seasonal restriction on the implementation of this protocol. Lichens are present and identifiable year-round. They can be surveyed for any time, although they tend to be more common in litterfall following storm events. Size, color, and texture all vary depending on the hydration level of the lichen. Lichen color in particular can change dramatically depending on whether the lichen is wet or dry, and surveyors need to be aware of and consider these color changes. Also, lichens can increase dramatically in size and texture when they are wet and fully hydrated, occasionally doubling or more in size. Smaller individuals tend to curl up and become concealed by tuffs of mosses or other lichens when they are dry, therefore survey intensity during drier conditions needs to be more rigorous.

\section{E. Determination of Habitat Disturbing Activities with Significant Negative Effects}

If a proposed project is determined to have a reasonable probability of being within the range and habitat of a species then a determination should be made whether "the project would cause a significant negative effect on the species habitat or the persistence of the species at the site" (USDA \& USDI 2001, Standards \& Guidelines p. 22). The scale, scope, intensity, type and timing of the project should also be included in the assessment process (USD A \& USDI 2001, Standards \& Guidelines p. 22).

Because most lichens are sessile organisms that are highly dependent upon their substrate and microclimate the "scale, scope, and intensity" may be very local and still have significant negative affect upon species persistence at a given site. Because of this, the scale or scope of a proposed project, in and of itself, will only occasionally be limited enough to exclude survey based on potential affect to organisms or their habitat. However, the scale and scope of a proposed project can affect the likelihood of an area being occupied which is one of the survey criteria for line officers to consider (USDA \& USDI 2001, Standards \& Guidelines p. 22). That is to say, that all else being equal, a very small area has a lower likelihood of being occupied than a large area.

Removal of trees in a second-growth stand could be an example of a situation not requiring survey if the trees are considered to be only marginal habitat or have a small likelihood of being occupied. On the other hand, removal of only a few trees in a riparian old-growth stand, which are considered to have a high likelihood of being occupied because of the quality of the habitat, may potentially have a significant negative effect. This would particularly be true if there are known sites of the species in the immediate area.

The type of a proposed project is more likely to be a consideration in evaluating survey needs based on potential significant negative effect upon a species. Since these species are all considered to be associated with latesuccessional/old-growth forest, projects that would alter late-successional / old-growth stands or specific old-growth components will trigger a need for survey. This can be a difficult evaluation to make because the association between lichens, particularly epiphytic lichens, and old-growth is complex. 
Because epiphytic lichen association with old-growth stands is highly complex it has been the subject of much study in recent years. Lichens differ in their old-growth association from some wildlife species in that their dispersal mechanisms, though typically varied and abundant, do not allow them to move very far (Sillett et. al. 2000a, Keon \& Muir 2002). McCune (1993) described a vertical gradient of epiphytic lichen and bryophyte species within forest canopies of different ages. He found that as stands age, functional groups of lichens (alectorioid, cyanolichens, and others) and bryophytes tend to migrate upward in the canopy. Since old-growth dependent lichens do not readily migrate to suitable habitat, they are dependent upon remnants and temporal substrates, sometimes called "hot spots", to bridge the gaps. These "hot spots" include wolf trees, old shrubs, hardwoods, and canopy gaps (Neitlich \& McCune 1997). Hot spots need to be considered for individual species when evaluating the need for survey.

Young, dense stands of timber ( $<25$ years-old) generally provide poor habitat for these species. Activities, such as pre-commercial thinning, in stands this young without old-growth remnants would not need to be surveyed. If oldgrowth remnants are present in the stands, but would be unaffected by the project, surveys would generally not be required. If old-growth remnants are deemed to have a reasonable likelihood of being occupied and would be impacted such that it would cause a significant negative effect upon species persistence at the site, then survey should be conducted. Because epiphytic lichens often have dispersal limitations (Keon \& Muir 2002, Rosso et al. 2000, Sillet et al. 2000b), habitat in stands older than 25 years but younger than 80 years will largely depend upon the presence of old-growth legacies, particularly large, old trees in or immediately adjacent to the project area.

Timing of projects, in some cases, may be significant in determining whether a project needs to be surveyed. For example, because lichens are sensitive to air-borne pollutants, underburning around a potential site when lichens are dormant (i.e. when conditions are very dry) may not be a significant effect but underburning when they are moist could be if the scope of the project is large enough.

Activities proposed in non-suitable habitat would not need to be surveyed. Tree planting, manual noxious weed treatments, and rock quarry operations (that do not involve quarry expansion) are examples of projects that normally occur in non-habitat.

\section{DATA COLLECTION AND DOCUMENTATION}

\section{A. Documenting the Presence of a Target Lichen Species}

Sites should be documented in the field using the "Species Location Field Form" (Appendix A) and Collection Packet Form (Appendix C). The form should be filled out as completely as possible. For ease of data entry into ISMS, observers need to be aware of the fields with "pick lists" in ISMS in which only pre-established terms may be entered. A specimen should be collected and sent to the interagency taxa expert for verification. See Appendix D for the specimen verification policy.

To the degree practicable, the extent of each site should be determined, mapped, and marked in the field for future re-location. Because thalli of Survey \& Manage lichens may be variously scattered throughout a stand, defining the perimeter of a site can be challenging. In general, a minimum 
distance of $100 \mathrm{~m}$ between individuals has been used to define a site (USDA \& USDI 2001, Standards \& Guidelines p. 71). In practice, observers will need to use their best judgment to decide what distinguishes a site on the ground. Thalli regularly distributed throughout relatively homogenous, contiguous habitat should be considered a single site. Contiguous habitat is defined as an area of suitable habitat with adequate substrates without barriers to growth, reproduction, or dispersal of the species. In most cases, a forest road would not qualify as a barrier while a clearcut or young stand lacking legacy old-growth components would be a barrier for lichens. Where there are multiple occurrences at a single location, a polygon connecting "nearby or functionally contiguous detections" would comprise a single "occupied" site (USDA \& USDI 2001, Standards \& Guidelines p. 83). Polygons outlining sites should only connect multiple detections within functionally contiguous habitat; they should not attempt to include all suitable or potential habitat in the vicinity.

Accurately delineating the perimeters of the site and recording abundance greatly increases the understanding of the biological significance of the location. Abundance should be recorded using the ranking system on the field form (see Appendix B).

\section{B. Vouchering and Species Verification}

All sites with sufficient numbers and/or biomass of a suspected Survey \& Manage lichen should have a voucher collection made and sent to the taxa expert for verification (see Appendix D); a blank vouchering packet is included in Appendix C. However, several factors need to be carefully evaluated in determining when and how much material to voucher. In no cases should a population be extirpated or threatened with extirpation by over-collecting.

If the suspected Survey \& Manage lichen is present as litterfall (loose on the ground, on a fallen branch, or in a downed tree), collect voucher material from the litterfall. Avoid samples that have begun to decompose.

If the suspected Survey \& Manage lichen is fairly abundant at the site, collect a small, representative sample that has enough diagnostic characteristics present so it can be verified by the lichen taxa expert. Try to use the "one in 20 rule" when vouchering, meaning evaluate the number of individuals present and leave enough so that a reproductive population remains.

Unless the lichen is obviously abundant at a site, always collect the smallest sample possible while ensuring that there is enough material to correctly identify the species. This can vary depending on species; a species with many morphological characteristics will need a larger voucher than one that only requires a chemical determination. However, be realistic about vouchering, refraining from collecting mere fragments.

If only one thallus is encountered during the survey, increase the survey intensity near that thallus. Look for more thalli in litterfall and on the same substrate at locations in the survey area with similar habitat conditions.

If no more thalli can be located, consider the following to determine if it should be collected:

a) How does the site compare with other known sites for this species?

Are there sites nearby, or does this find represent a substantial range 
extension? Is it a first record for the field unit? Is the habitat within the suspected range of habitat characteristics, or is this habitat previously unknown for the taxon? If there are other sites nearby, to the north and south, in similar habitat, it may be appropriate to voucher. The lichen taxa expert should be consulted to evaluate these considerations.

b) How big is the thallus? If it is sufficiently large, and is representative of the suspected species, collect a small piece for the lichen taxa expert. Collect enough material so that the taxa expert can either confirm the species or say with certainty that it is not the species.

c) Flag the site without vouchering, and revisit with the lichen taxa expert. The taxa expert may be able to do a field identification, or determine conclusively that it is not the species in question. In some instances, the taxa expert may identify someone else with expertise for that particular taxon to visit the site.

d) If someone else with expertise for that particular taxon is identified by the taxa expert to visit the site and he/she can't do a field identification, have them evaluate the feasibility of collecting just enough material to confirm identification and leave the rest. The authority will have the expertise necessary to know if appropriate morphological characteristics are present.

e) If a field identification is needed, consider documenting the site with several digital photos.

In a situation where a species is locally well distributed, it may not be necessary to collect from each individual site. In these cases, one collection per section, or roughly every square mile, is generally adequate. Generally this would only be the case with uncommon, as opposed to rare species. It is recommended that a surveyor have at least one specimen of the target species verified by the taxa expert before deciding not to collect additional vouchers at nearby sites. Unusual, atypical, or otherwise uncertain specimens should continue to be verified as necessary. The taxa expert is always available to verify any collection of a potential Survey \& Manage species upon request.

Standards for voucher verification are outlined in the Jan. 9, 2002 memo, Centralized Process to Identify / Verify Survey and Manage Specimens Collected While conducting Surveys (Appendix D.). Basically, these standards state that all material will be vouchered (unless a situation like that described above is encountered), these vouchers will be sent, along with appropriate survey forms, to the lichen taxa expert for verification, and the vouchers will be deposited with the appropriate regional herbarium. These standards are to be followed at all times.

\section{Monumenting a Known Site}

A site should be adequately marked in the field so it can be relocated for at least the next five years. If possible, the precise location should be recorded using a GPS unit. The type of GPS unit should be noted on the field form along with other information that would be useful in assessing the precision of the reading. If a site is flagged, the color of flagging should be recorded on the site form. Other markers that are occasionally used include plastic flashers and tags, and pin flags. At least one unit has had success with colored Tyvek signs labeled "PLANT SITE" that are stapled to adjacent trees. Runoff from galvanized metal markers can damage or kill lichens and should 
be avoided when possible. If they are used, make certain that they are not directly above a thallus. If a site is in an area that may be difficult to relocate, recording the distance and azimuth to a readily identifiable feature is recommended.

\section{Documenting the Non-detection of a Target Lichen Species}

If no Survey \& Manage species are encountered during the field survey then lack of species detection should be documented by entering the required data on the flora general survey form in the Interagency Species Management System (ISMS). General Survey information to be documented includes: where a survey was done, the date, by whom, and the species surveyed for including presence or absence (See Appendix B, General Survey Field Form).

\section{DATA MANAGEMENT}

\section{A. Data Storage and Quality Assurance}

Each administrative unit (National Forest or BLM District Office) is responsible for entering and managing data for Survey \& Manage species locations on their unit. All data should be entered into the Interagency Species Management System (ISMS) in a timely manner although records should not be entered until the voucher is verified. Data entry is an integral part of the survey protocol and needs to be factored into project planning and budgeting. The designated data steward for each administrative unit is responsible for the quality and completeness of their survey data.

\section{SURVEYOR QUALIFICATIONS AND SKILLS}

Personnel conducting surveys should have successfully completed an accredited lichen course, the regional interagency lichen training, or the Northwest Lichenologists or Region 6 air quality lichen monitoring certification process. It is recommended that seasonal personnel doing lichen surveys have the above training as well as permanent and year-round employees. It is recognized that this may not always be possible so the Forest or BLM District botanist will often have to be responsible for training and evaluation of seasonals. It is always best to have less qualified personnel working with trained or experienced surveyors until sufficient confidence and proficiency is developed. As much as possible, surveyors should also have the opportunity to see known sites of target species in the field. Personnel conducting surveys for lichens need to be experienced with the following:

- Skilled in the recognition and identification of the Category A and C lichens and similar species, including:

- collection methods used for lichens,

- microscope and micro-dissection techniques,

- safe use of chemical spot tests used in lichen identification,

- ability to distinguish different species that are often growing together,

- ability to use the dichotomous lichenological keys for the Pacific Northwest.

- Experienced in field techniques to be able to locate and document the locations surveyed for and occupied by Survey \& Manage lichens; 
- Education and/or experience in plant taxonomy and plant ecology within the range of the Northwest Forest Plan;

- Ability to accurately identify associated species and characterize the ecological conditions of the local population;

- Competence in off-trail navigation using topographic maps, compass, and aerial photos; and

- Ability to perform surveys on steep, rugged, densely vegetated terrain. 


\section{SECTION II: SPECIES INFORMATION}

I. Bryoria tortuosa (G. Merr.) Brodo \& D. Hawksw.

II. Leptogium cyanescens (Rabenh.) Körber

III. Lobaria oregana (Tuck.) Müll.

IV. Niebla cephalota (Tuck.) Rundel \& Bowler

V. Platismatia lacunosa (Ach.) Culb. \& C. Culb.

VI. Ramalina thrausta (Ach.) Nyl.

VII. Teloschistes flavicans (Sw.) Norman

VIII. Usnea longissima Ach.

IX. References 
2003 Survey Protocols for Category A \& C Lichens 


\section{Bryoria tortuosa (G. Merr.) Brodo \& D. Hawksw.}

\section{A. Identification in the Field}

Bryoria tortuosa (Figure 3) is a filamentous dull red-brown to dusky yellowbrown, or occasionally bright greenish yellow lichen that looks like long, matted auburn hair on the boles and branches of trees and shrubs, and on the ground or other substrates it has fallen on or been blown onto. It often grows intermingled with other Bryorias. Because of the presence of vulpinic acid, $B$. tortuosa often has a greenish-yellow to chartreuse color from a distance. It frequently has tiny greenish-yellow stripes (pseudocyphellae) that can be visible with the naked eye or hand lens.

\section{B. Technical Description}

\section{Morphology}

Bryoria tortuosa is a pendent, filamentous lichen, 10-30 $(-40) \mathrm{cm}$ long. The color is dull, dark, reddish-brown to dusky yellow-brown, occasionally becoming bright yellow in thalli having heavy concentrations of vulpinic acid. Branching is mainly anisotomic dichotomous; angles between the dichotomies are acute with frequent, slender, perpendicular side branches arising from the axes. Branches are uneven in diameter, strongly twisted and tortuous, foveolate and often flattened; 0.4-1 $\mathrm{mm}$ in diameter (Brodo et al. 2001). Spinules and isidia are absent; soredia are exceedingly rare (known only from one specimen), and are bright yellow when present. The conspicuous, yellow pseudocyphellae are diagnostic. Pseudocyphellae are usually abundant, occasionally rare, bright yellow, linear or sometimes short fusiform, slightly raised, twisting around filaments in long yellow spirals. Pycnidia are unknown (Brodo \& Hawksworth 1977, Brodo et al. 2001).

\section{Chemistry}

All spot tests are negative (Brodo \& Hawksworth 1977), but vulpinic acid may be extracted by acetone, leaving a visible vulpinic acid yellow color around the rim of a spot plate or on a piece of blotter paper.

\section{Reproductive Structures}

Bryoria tortuosa relies predominantly on thallus fragmentation, a form of vegetative propagation, for reproduction and probably disperses effectively over short distances (within a few hundred meters). It may be locally abundant, and $B$. tortuosa can be the dominant epiphyte on trees in some locations. Dispersal over long distance is poorly understood but, in general, lichens that rely on thallus fragmentation produce many fewer propagules, of much greater mass, than species with smaller, or specialized propagules (for example, soredia or isidia). Apothecia are rare, lateral, with a raised, persistent, thalline exciple; the disc is strongly yellow pruinose. Spores are 7.5-8.7 $\times$ 4.7-5.0 $\mu \mathrm{m}, 8$ per ascus, and hyaline ellipsoid. Sexual reproduction in $B$. tortuosa is presumably rare because of the rarity of apothecia. In very rare cases, individuals may also propagate asexually by soredia (Brodo \& Hawksworth 1977). 


\section{Look-alikes}

McCune and Geiser (1997) provide a user-friendly key for the Bryoria in the Pacific Northwest, complete with a description of the technique for doing chemical tests based on acetone extract. Goward (1999) also has good keys that take a slightly different approach to the group, and include very useful line drawings. Brodo et al. (2001) provide updated keys to all the Bryoria and related species in North America, with a wealth of photographs. Brodo \& Hawksworth's monograph (1977) is the definitive technical treatment of all Bryoria and related genera; this reference can be hard to locate.

Bryoria fremontii (Figure 4): Specimens with low concentrations of vulpinic acid or sparse pseudocyphellae may be easily confused with the closely related species, $B$. fremontii. Bryoria fremontii may have yellow soredia that could be mistaken at first glance for the yellow pseudocyphellae (Figure 5) of $B$. tortuosa. Thin-layer chromatography always reveals vulpinic acid in $B$. tortuosa, but it is only found associated with soralia and apothecia in B. fremontii. Brodo \& Hawksworth (1977) or White and James (1985) can be consulted for thin layer chromatographic methods for lichen substances. Vulpinic acid concentration varies considerably, and pale and dark individuals often grow intermixed.

\section{Range}

The current known and suspected range of Bryoria tortuosa in the Northwest Forest Plan area includes all of Washington, Oregon and Northern California. In some parts of the Northwest Forest Plan area, namely parts of the Eastern Washington and Oregon Cascades, and the Oregon Klamath Physiographic Provinces, $B$. tortuosa can be common and abundant in suitable habitat. To date, there are no known sites in the Oregon Coast Physiographic Province, however there is at least one site in the Willamette Valley, within a mile of the Oregon Coast Physiographic Province boundary. This species is not yet reported from the Western Washington and Western Oregon Physiographic Provinces. Globally, B. tortuosa occurs in western North America (Brodo \& Hawksworth 1977), and central Norway (Holien 1986).

In the Puget Trough area of Washington (Washington Western Lowlands Physiographic Province), Bryoria tortuosa is known from Deception Pass State Park, Goose Hill, and Pt. Colville, Lopez Island, in BLM tract E (Island County); Mt. Erie, Fidalgo Island, Phoebe Lake, and Cypress Island (Skagit County); the University of Washington Pack Forest and along the White River (Pierce County), and from state land in the Bald Hill Natural Area Preserve (Thurston County). It is also known from three sites in the southern tip of the Willamette Valley Physiographic Province. There are no known sites in the Olympic Peninsula Physiographic Province reported in ISMS at this time, although it may occur in drier areas influenced by the rain shadow effect. It is known from a few sites on the Shasta-Trinity National Forest in the California Klamath Physiographic Province, and from several sites in the California Coast and California Cascades Physiographic Provinces that were reported in the 1993 Known Site Database. Very few specific site locations are listed, but there are historic sites from Siskiyou, Humboldt, Mendocino, Modoc, Shasta and Plumas Counties. Two of the Humboldt records may not be valid because there is reference in the database to the presence of white pseudocyphellae, which means this would not be B. tortuosa. 


\section{Habitat}

Generally speaking, Bryoria tortuosa grows on trees in well-lit, open stands, most frequently on oaks and pines, although it has been collected on a large variety of trees and shrubs (Brodo \& Hawksworth 1977). It apparently prefers the drier habitats of the Pacific Northwest, where it achieves its greatest biomass in semi-open conifer stands in low-elevation transitional areas between wet coastal forests and drier inland forests (McCune \& Geiser 1997).

In the Olympic Peninsula, Western Washington Lowlands, Washington and Oregon Western Cascades, and Oregon Coast Range Physiographic Provinces of the Northwest Forest Plan area, B. tortuosa is found in several habitats at low elevations. In the Puget Sound area it has been found on grand fir (reported in Brodo \& Hawksworth 1977, however they may have meant Douglas-fir), ocean spray and other shrubs, and on shore pine. On Lopez Island it occurs in the Olympics rain shadow, at Pt. Colville, near the town of Richardson where annual precipitation is $<19^{\prime \prime}$ per year (J. Harpel pers. comm.). At the Bald Hill Natural Area Preserve, near Yelm, Washington, it occurs on mock orange and Oregon white oak in an oak bald.

In the Willamette Valley Physiographic Province, it is known from three low elevation sites west of Eugene, close to the Oregon Coast Physiographic Province boundary. Although habitat information for these historic sites is unknown, two of the sites are probably fairly dry since the vouchers were collected from oaks; the third voucher was growing on the twigs of a huge old yew tree, and there is no further habitat information. Bryoria tortuosa is currently not known from the Sitka Spruce and Western Hemlock zones of the Coast Range and western Cascades of Oregon and Washington, or the high elevation areas dominated by true fir and mountain hemlock in the Cascade Mountains.

In the Washington and Oregon Eastern Cascades Physiographic Provinces, where it is more abundant and widespread, it occurs on conifers and hardwoods in mid-elevation conifer stands where it receives a fair amount of light. In southern Oregon, especially Jackson County, the species can be very abundant and widespread, particularly in old (i.e. 100 years or more) firesuppressed white-leaf manzanita stands where it festoons the manzanita. It also occurs on other hardwoods, Douglas-fir and ponderosa pine where either manzanita is present or there is sufficient light.

Very little is known about $B$. tortousa's habitat requirements or distribution in California. This species has been found a few times, on large "old-growth" (fire suppressed) manzanita in chaparral habitat on the Shasta-Trinity National Forest (S. Erwin, pers. comm.). While manzanita chaparral is common in parts of the Klamath province, $B$. tortuosa's range and distribution within this habitat is unknown. There is very little specific habitat data for the California sites in the Known Site Database. The best information is from a Shasta County site, near Burney, where it was found in a mixed stand of Oregon white and black oak, ponderosa pine and manzanita. On the Klamath National Forest, Siskiyou County, it was growing on a Douglas-fir in an undescribed stand, and an additional site near Weaverville reported it "hanging from trees". Two of the three records for Humboldt County note that white pseudocyphellae were present, indicating these vouchers were not $B$. tortuosa, but there is an additional record from Humboldt County, in an unspecified habitat, in the database. 


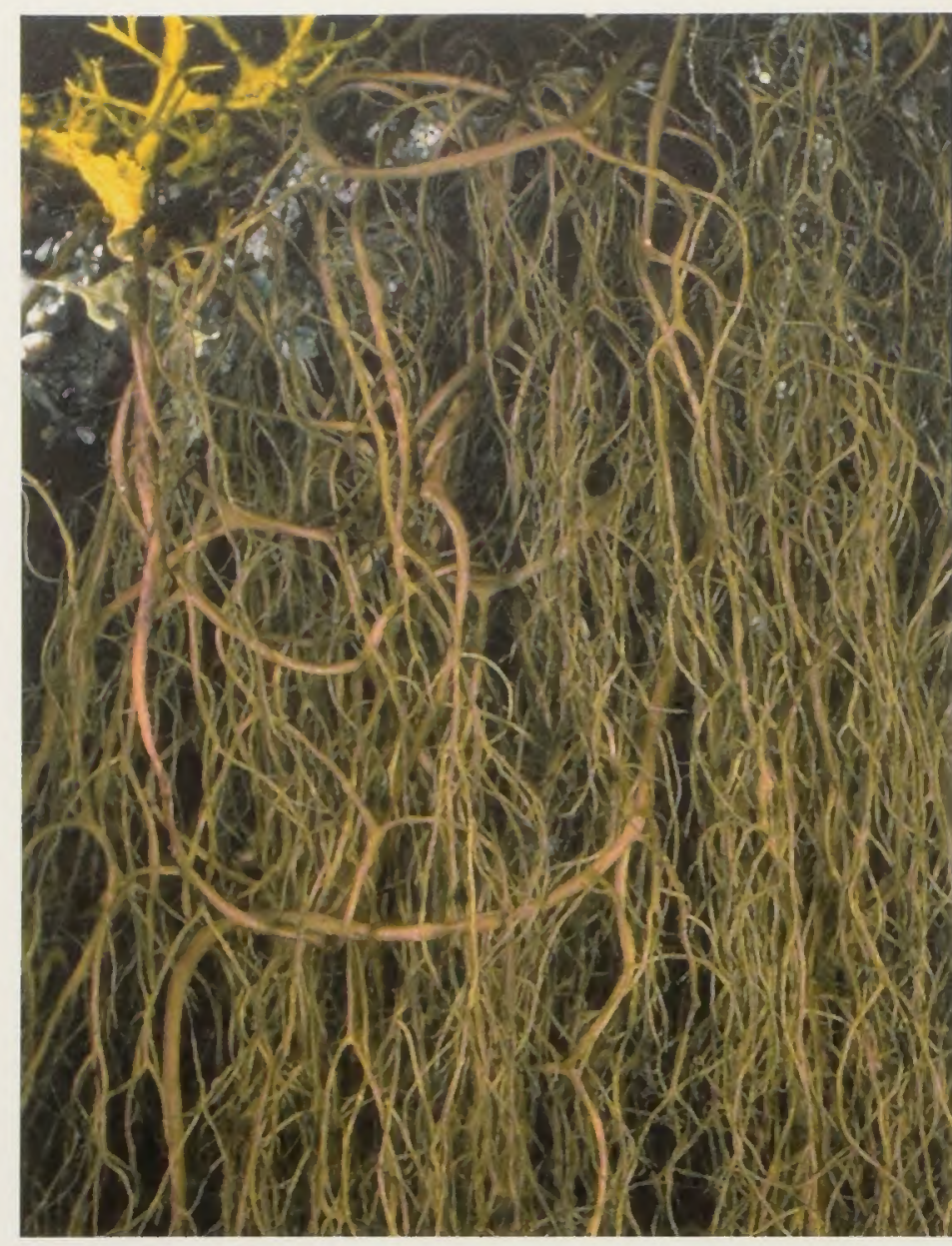

Figure 3. Bryoria tortuosa

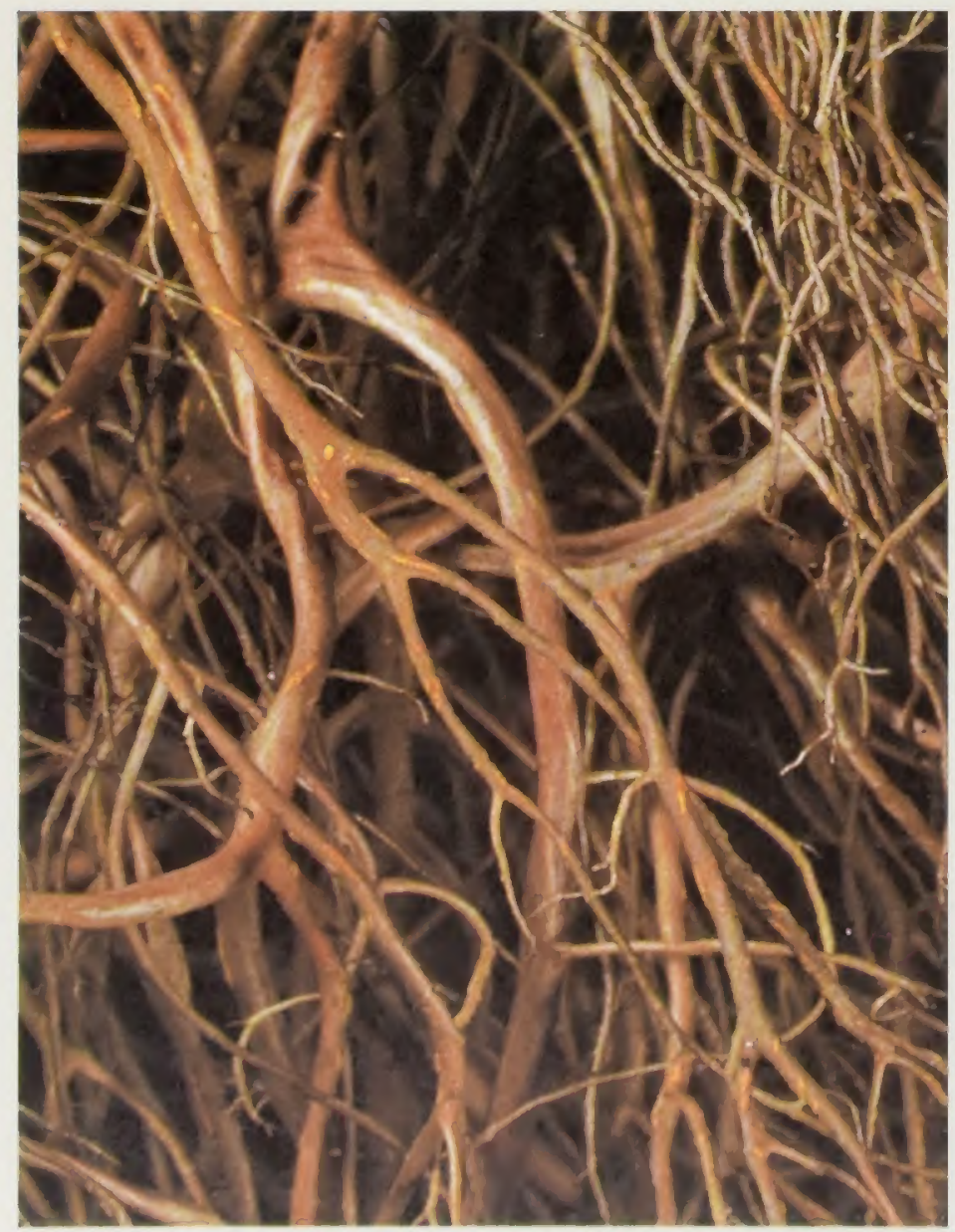

Figure 5. Bryoria tortuosa pseudocyphellae

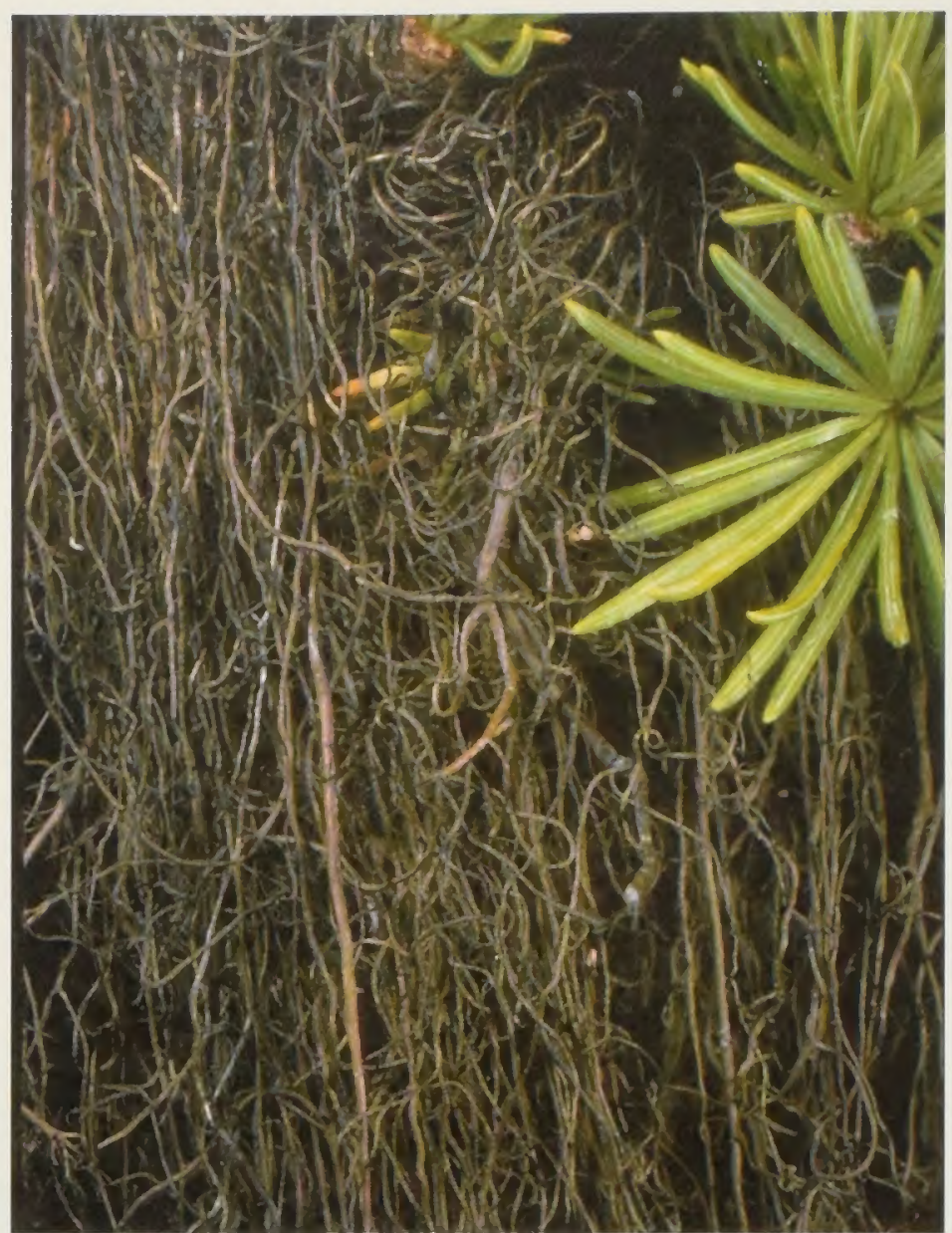

Figure 4. Bryoria fremontii 


\section{Leptogium cyanescens (Rabenh.) Körber}

\section{A. Identification in the Field}

Thalli of Leptogium cyanescens (Figure 6) can be difficult to spot, especially when they are dry and shriveled. Look for thin, wrinkled, crispy tatters of lead gray film clinging to branches and usually nestled among or on top of moss. With a hand lens you may see finger-like gray isidia that seem remarkably long. The edges of the lichen may be curled in on themselves, in which case the underside, which may have little tufts of white hairs on it, would be more obvious. If the site is moist, or it has recently rained, look for a rubbery-textured dark lead gray lichen with isidia.

\section{B. Technical Description}

\section{Morphology}

Thallus foliose, smooth to occasionally slightly roughened, but not deeply wrinkled; $1-5 \mathrm{~cm}$ in diameter, more or less flat, spreading, dark lead gray to blue-gray, matt to shining. Lobes orbicular, $2-4 \mathrm{~mm}$ broad, margins entire to dentate to isidiate or lobulate; isidia commonly abundant on the upper surface, cylindrical (often branched) to clavate to lobulate, concolorous with the thallus; thallus attached to substrate by scattered tufts of hairs (Brodo et al. 2001, Jorgensen \& James 1983, McCune \& Geiser 1997, Sierk 1964).

\section{Chemistry}

Chemistry unknown; spot tests are not used with this genus.

\section{Reproductive Structures}

Apothecia uncommon, sessile to short stipitate on the upper surface of the thallus, $0.5-2.0 \mathrm{~mm}$ broad, disc slightly concave to plane to convex, light brown to red-brown, thalloid exciple entire to isidiate, light gray to creamcolored. Spores eight per ascus, monostichous to irregular, ellipsoid with apices rounded to pointed, 18-23 X 6-10 microns, 3-septate transversely, 0-1septate longitudinally (Sierk 1964). This species also reproduces asexually by the production of isidia, which are described above.

\section{Look-alikes}

McCune \& Geiser (1997) provide a good key to the Leptogium of the Pacific Northwest; Goward et al. (1994) also have a good key with line drawings of distinguishing characteristics. The North American monograph for Leptogium (Sierk 1964) is also valuable. Jorgensen has done extensive taxonomic work with the genus (Jorgensen 1973, 1975, 1994, 1997; Jorgensen \& Goward 1994; Jorgensen \& James 1983; Jorgensen \& Tonsberg 1999). Color photos of many Leptogium species are shown in the lichen guides Macrolichens of the Pacific Northwest (McCune \& Geiser 1997) and Lichens of North America (Brodo et al. 2001).

The genus Leptogium can be challenging to identify to species, and positive species identification sometimes requires microscopic examination of internal thallus structure or spores. Interior thallus structure can be examined by making thin-sections and observing them under a light microscope (McCune \& Geiser 1997). The interior of some thalli have a cellular structure 
(parenchyma-like) throughout; others are composed of loosely or compactly interwoven hyphae (McCune \& Geiser 1997). L. cyanescens has a thallus interior with elongate, loosely interwoven hyphae. This characteristic may sometimes help to distinguish the species from look-alikes.

Leptogium cyanescens is normally a straightforward species to identify, based on its bluish-grey color and the presence of abundant elongate laminal isidia. Nevertheless, stunted or young specimens with few isidia may be difficult to distinguish from some other Leptogium look-alike species (see below).

Leptogium lichenoides (Figure 7), like L. cyanescens, has cylindrical isidia and an internal thallus structure of loosely interwoven hyphae. However, $L$.

lichenoides is brownish in color and holds its lobes erect to form a cushionlike thallus (in contrast to the more or less flat, spreading thallus of $L$. cyanescens). Leptogium lichenoides lobes are more often wrinkled, isidia are more often marginal, and red-brown, concave apothecia are fairly common on the lobe surface. Leptogium lichenoides can be quite variable in form but always has dissected lobes with isidiate or fringed margins (McCune \& Geiser 1997).

Leptogium californicum (Figure 8) is reported to be similar in size to $L$. cyanescens, but its isidia become partly flattened and lobulate at maturity (Goward et al. 1994). However, McCune and Geiser (1997) state "the separation of L. californicum from L. lichenoides is unclear at present", and Brodo et al. (2001) concur by saying "perhaps the species [L. californicum] should not be recognized as distinct".

Leptogium polycarpum (Figure 9) is distinguished by the presence of abundant, partially sunken apothecia, absence of isidia, and a brownish-gray (to reddish brown in exposed sites) color. When dry, the thallus is conspicuously wrinkled. Leptogium polycarpum is also unique among other local Leptogium species in producing asci with just four spores, in contrast to the normal eight (Brodo et al. 2001, Goward et al. 1994, Jorgensen \& Goward 1994, McCune \& Geiser 1997).

Leptogium subaridum (Figure 10) is similar to L. cyanescens in that it also produces laminal, cylindrical to club-shaped isidia, but its upper cortex is smooth to weakly wrinkled (a characteristic which can overlaps with $L$. cyanescens's slightly roughened but not deeply wrinkled upper cortex), and the thallus color is dark greenish-brown (as opposed to bluish gray). This species tends to occur in more arid habitats than L. cyanescens, on soil or mosses over soil or rock (Goward et al. 1994, Jorgensen \& Goward 1994; McCune \& Geiser 1997).

\section{Range}

The current known and suspected range of L. cyanescens in the Northwest Forest Plan area is all Physiographic Provinces with the exception of the California Cascades and Eastern Oregon and Washington Cascades Physiographic Provinces. It is known from the Mount Baker-Snoqualmie National Forest in Washington, and the Willamette, Umpqua and Siskiyou National Forests and Roseburg District BLM in Oregon. It was recently confirmed for Northern California, where it was found on the Six Rivers National Forest in the California Coast Range. It is not yet known from the California Klamath Physiographic Province, where it could occur in suitable moist habitat, most likely at higher elevations. 
Although Sierk (1964) considered L. cyanescens to be one of the most abundant Leptogium species in North America, that statement is qualified by McCune \& Geiser (1997) who note that it is common in eastern North America but rare in the Pacific Northwest. Globally, this is a temperatesubtropical, widely distributed suboceanic species (Jorgensen \& James 1983; Krog 1968).

\section{Habitat}

Leptogium cyanescens was originally thought to be a riparian species (USDA \& USDI 1994, 2001). Recent information has revealed that the species has a broader ecological amplitude, and occurs in mixed conifer and Douglas-fir stands, and in maple and willow thickets in both riparian and upland habitats.

In the Northwest Forest Plan area, L. cyanescens is rare on bark (especially tree bases), rotten logs, and rocks (Brodo et al. 2001, McCune \& Geiser 1997). This species is found in the Western Hemlock and Pacific Silver Fir Zones from 1400-4600' elevation in mixed conifer stands, mature big leaf maple and Douglas-fir stands (USDA 1998). On the Mount Baker-Snoqualmie National Forest, it occurs at a cool moist site on vine maple at the toe of an old avalanche chute that extends into an undisturbed old-growth stand near a stream (E. Burnett pers. comm.). On the Willamette National Forest it occurs at the base of a $4^{\prime \prime}$ diameter big leaf maple on an old skid road in a 41 yearold Douglas-fir plantation at 2300' (A. Smith pers. comm.). On the ShastaTrinity National Forest it was found at about 4100' elevation in a stand of predominantly mid-mature Douglas-fir and Oregon white oak where it was growing in moss on an oak. The site is characterized as dry with a sparse understory of salal beneath a $95 \%$ closed canopy. Apparently the high canopy cover and northeastern exposure provide sufficient moisture for the species. The rare occurrences of this species in British Columbia are reported from trees at lower elevations in sheltered forests in humid intermontane localities (Goward et al. 1994). In Southeast Alaska it is infrequent to uncommon on alder and willow and rarely occurred on Sitka spruce in the floodplains of the large, glacial mainland rivers (Geiser et al. 1998). 


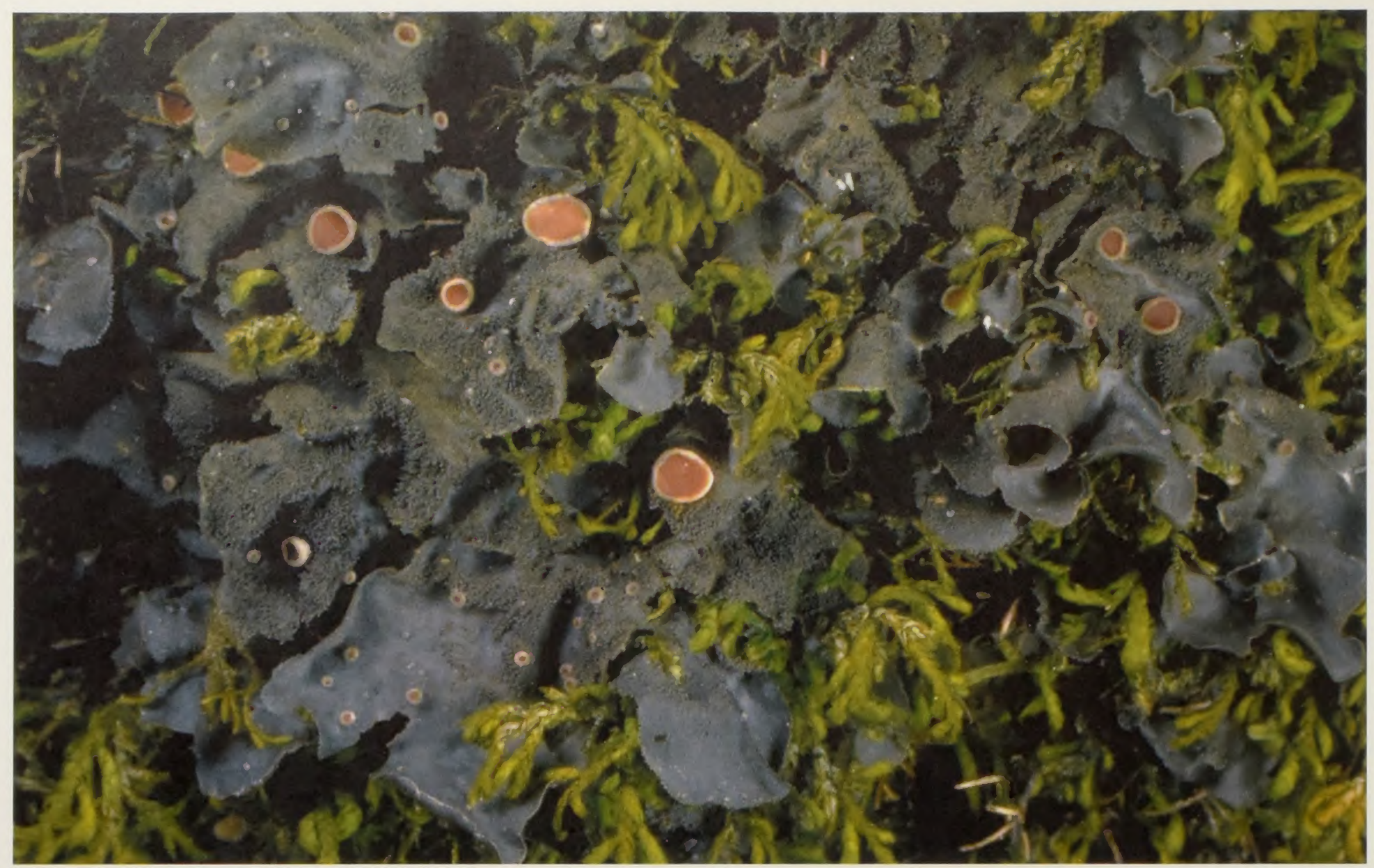

Figure 6. Leptogium cyanescens

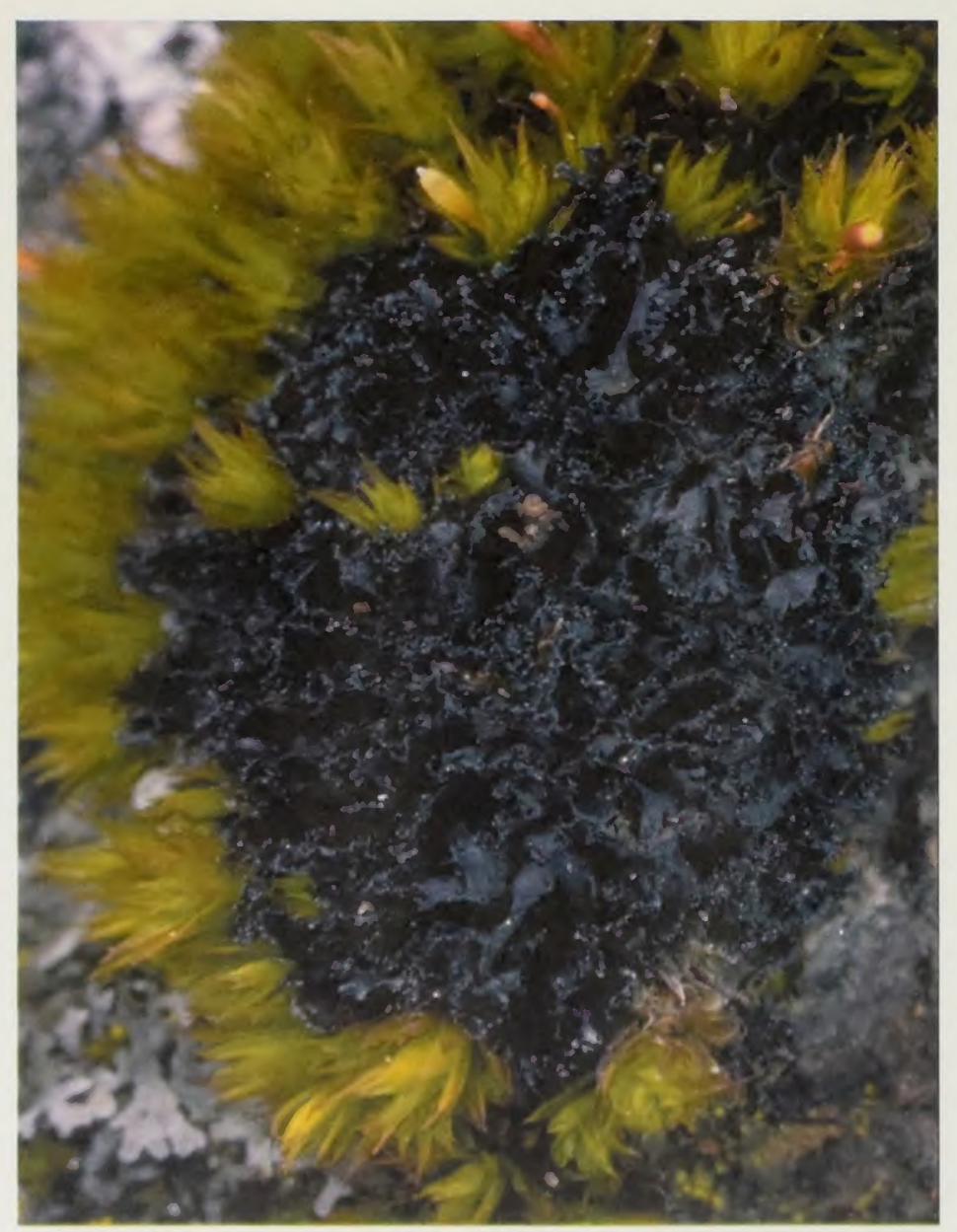

Figure 7. Leptogium lichenoides 


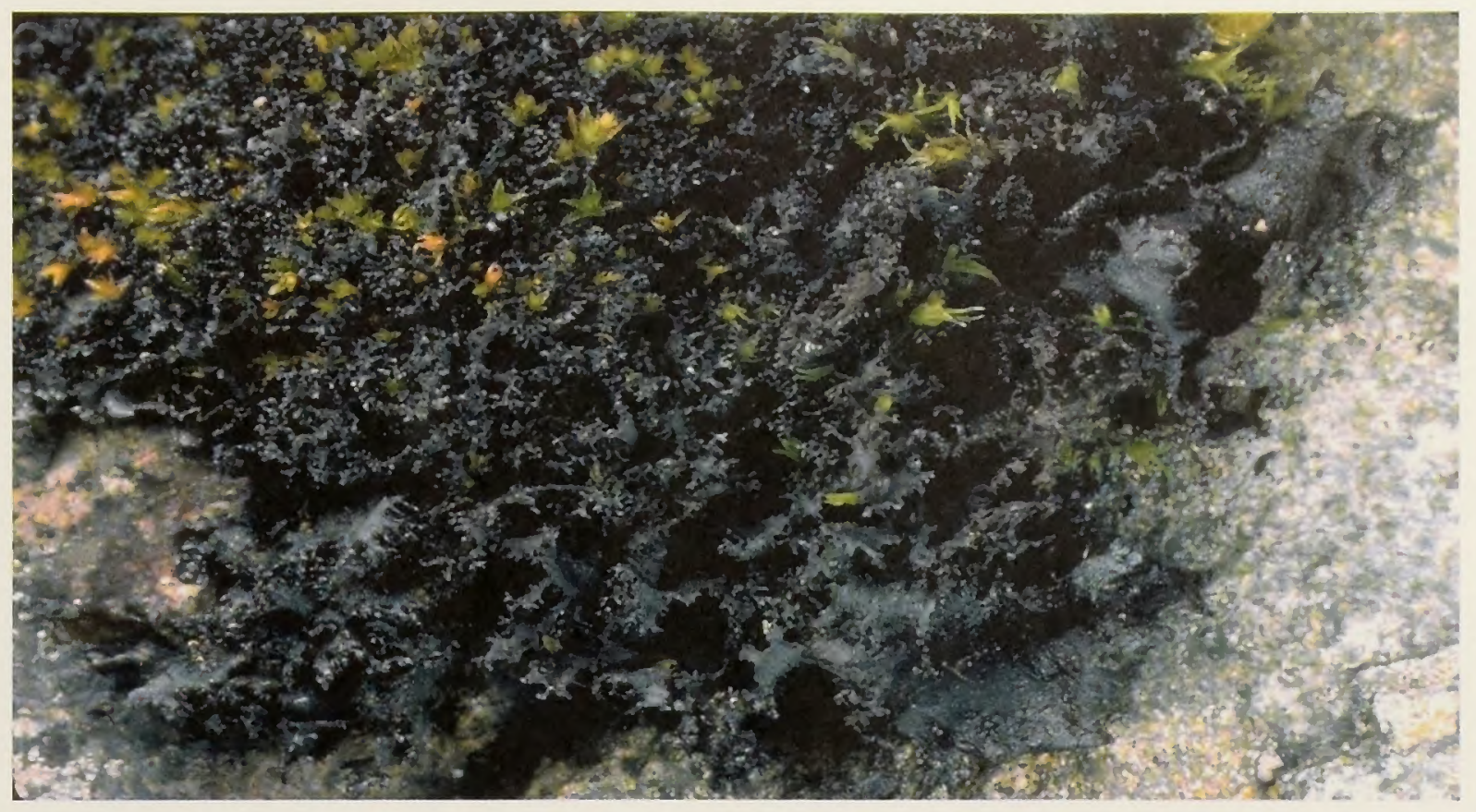

Figure 8.

Leptogium

californicum

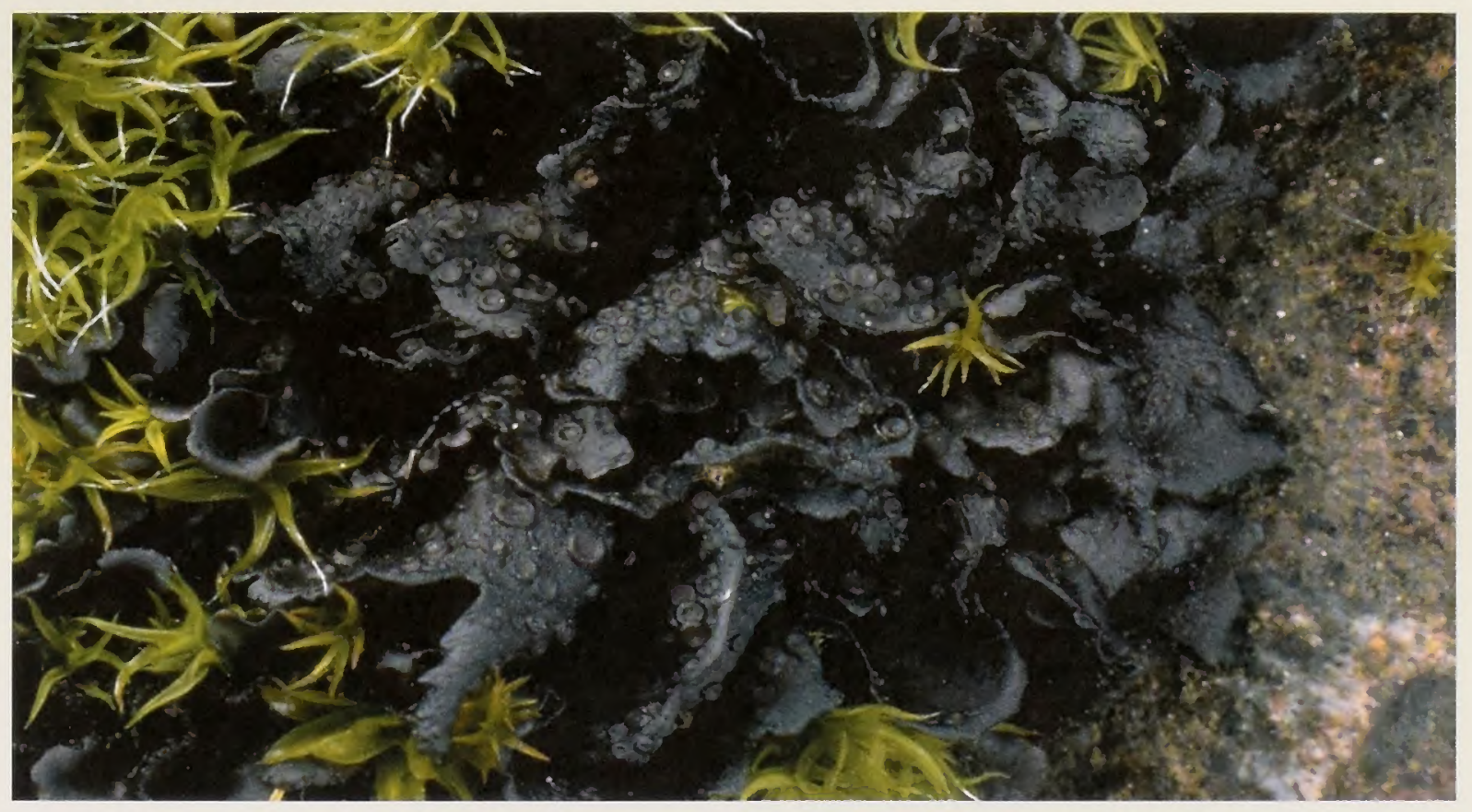

Figure 9.

Leptogium

polycarpum

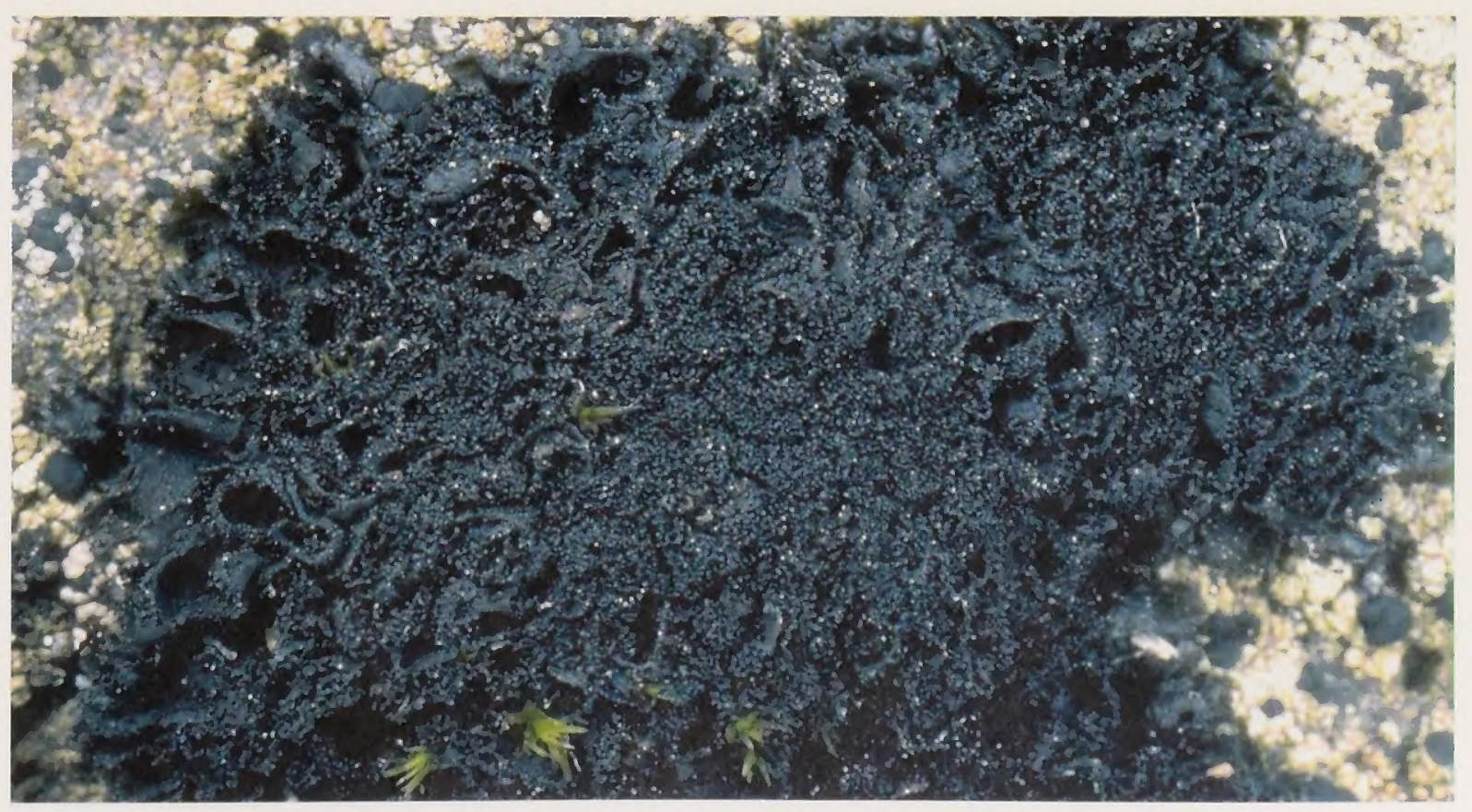

Figure 10.

Leptogium

subaridum 
2003 Survey Protocols for Category A E C Lichens 


\section{Lobaria oregana (Tuck.) Müll.}

\section{A. Identification in the Field}

Lobarin oregana (Figure 11) is a distinctive, easily recognizable large yellowish green lichen that is hard to mistake for anything else. Look for what appear to be great big pieces of iceberg lettuce draped over conifer branches and boles and scattered on the ground, especially following a storm event; in California the pieces may not be as large as they are in other parts of its range. The color of dry L. oregana is unlike that of any other lungwort (Lobaria), with a dusty grey-green cast to it (Brodo et al. 2001). Biomass can be quite high at some sites.

\section{B. Technical Description}

\section{Morphology}

Thallus foliose, large, mostly $5-20(30) \mathrm{cm}$ broad, often becoming pendent when large, lobes generally $1-5 \mathrm{~cm}$ broad. Upper surface greenish or yellowish green (usnic acid present), with a shallow network of ridges overall. Lower surface generally tomentose, often patchy-mottled or with a dark network of furrows surrounding pale, less tomentose areas. Lobules usually present that can be isidia-like and are mainly marginal. Primary photobiont green but with a blue-green photobiont in internal cephalodia that form very small warts on the lower and occasionally upper surface (Brodo et al. 2001, McCune \& Geiser 1997).

\section{Chemistry}

Medulla $\mathrm{K}+\mathrm{Y}$ darkening to red, $\mathrm{PD}+\mathrm{O}, \mathrm{C}-, \mathrm{KC}$-. Contains stictic, constictic, cryptostictic, norstictic, and usnic acids and one unknown (Brodo et al. 2001, Goward et al. 1994).

\section{Reproductive Structures}

Lobaria oregana's primary form of reproduction is asexual, through the production of lobules that are occasionally isidia-like; these lobules are mostly marginal and are also occasionally laminal. It occasionally reproduces sexually through the production of apothecia, which are lecanorine (surrounded by a rim that is the same color as the thallus) with reddish brown disks. The apothecia of $L$. oregana are frequently parasitized by a nonlichenized fungus, resulting in black apothecial disks.

\section{Look-alikes}

Brodo et al. (2001), McCune \& Geiser (1997) and Goward et al. (1994) provide good keys, descriptions and pictures of L. oregana and look-alikes. The Air Quality Database (USDA 1998) contains a wealth of specific site habitat information from hundreds of sites where L. oregana is found; most of these sites are in Oregon and Washington.

Lobaria hallii (Figure 12) is much smaller than L. oregana, lacks lobules, and is a blue-green color rather than grass green when wet. It also produces tiny white hairs that may or may not persist on the tops of the lobe tips. 
Lobaria linita (Figure 13) looks more like L. pulmonaria than L. oregana, with a thicker thallus and no lobules; like L. pulmonaria it turns lime green when wet.

Lobaria pulmonaria (Figure 14) has a more deeply ridged thallus that usually has abundant soredia along the ridges and lobe margins, and lacks lobules; it turns bright lime green when wet. The thallus is also thicker, and is aptly described by one of its common names, "monster skin". Lobaria oregana looks more like iceburg lettuce than monster skin.

Lobaria scrobiculata (Figure 15) has the same growth form as L. oregana but with a bluish coloration due to the cyanobacterial primary photobiont ( $L$. oregana has an algal primary photobiont with cyanobacteria confined to internal cephalodia). The former almost never gets as large or has as much biomass at a site as L. oregana.

Peltigera are large, foliose lichens with veins on the undersurface (Figure 16). Sometimes the network of furrows on the underside of Lobarias are mistaken for the veins of Peltigeras; it helps to remember that veins are raised, while furrows are indented. Most species of Peltigera have rhizines on the underside (sometimes reaching over $1 \mathrm{~cm}$ in length); Lobaria oregana is not rhizinate. Most Peltigeras are terrestrial, anchored to their mossy substrates by rhizines; if Lobaria oregana is present on the ground, it arrived there as litterfall from surrounding trees.

Pseudocyphellaria rainierensis (Figure 17) could be mistaken for L. oregana, or (more likely) go unnoticed among the L. oregana it is often found with. P. rainierensis has a slightly more bluish color, and a thinner, droopier thallus that tends to have longer lobes. On closer inspection, it usually has abundant lobules that tend to be smaller than those of L. oregana, and always has small white raised blips (pseudocyphellae) on the underside. Pseudocyphellaria rainierensis frequently has a distinctive fishy or shrimpy smell, especially when wet.

\section{Range}

The current known and suspected range of L. oregana in the Northwest Forest Plan area includes all Physiographic Provinces except the California Cascades. It is not yet reported for the Washington and Oregon Eastern Cascades Physiographic Provinces, where it would most likely be confined to wet forested sites just east of the crest. It also occurs in northern Idaho and British Columbia (McCune \& Geiser 1997). This species is a Pacific North American endemic.

Lobaria oregana is considered to be rare in California, where its range is the California Coast and California Klamath Physiographic Provinces. It is currently known from Six Rivers National Forest and other locations in Humboldt County, and Arcata Field Office BLM.

\section{Habitat}

Lobaria oregana occurs in moist forests of western North America. It reaches maximum dominance in mid-elevation old-growth Douglas-fir and western hemlock forests on the west slope of the Cascades, and is occasional in moist low-elevation forests in the foothills. Although L. oregana can occur in younger stands, especially moist sites where it has blown in from adjacent 
colonized areas, it reaches its greatest biomass in sites greater than 200 years of age (McCune 1993). Its distribution in the canopy will vary based on stand age and moisture gradient at the site, with L. oregana occurring higher in the canopy in wetter and older sites, and lower in the canopy (if present at all) in younger drier sites (McCune 1993). It usually grows on conifers and is also sporadic on hardwoods including alder, Oregon ash and shrubs (McCune \& Geiser 1997).

In Northern California, L. oregana occurs sporadically in coastally influenced, moist old-growth redwood forests (D. Glavich pers. comm., J. McFarland pers. comm., D. Wright, pers. comm.), in old-growth stands dominated by Port Orford Cedar (E.B. Peterson, pers. comm.), and at moist tanoak-Douglas fir sites. It also occurs on Sitka spruce in redwoods stands along the coast (L. Larsen pers. comm.). On the Six Rivers National Forest it occurs between 1350 and $2200^{\prime} \mathrm{ft}$. in elevation in northwest facing mature stands of tanoakDouglas fir, and in a late-mature northwest facing stand of port-orford cedar/Douglas fir (L. Hoover pers. comm.). At the tanoak-Douglas fir sites where L. oregana occurs, the presence of big leaf maple and other moist site indicators suggests that the site is relatively moist. On Arcata BLM lands it occurs at several sites ranging from 400-3500 feet in elevation (J. McFarland pers. comm.). Abundance at known sites varies from low to high. Habitat requirements for $L$. oregana could be present in other types of tree dominated plant communities in the survey Physiographic Provinces where site conditions are cool and moist; these sites should also be surveyed. 


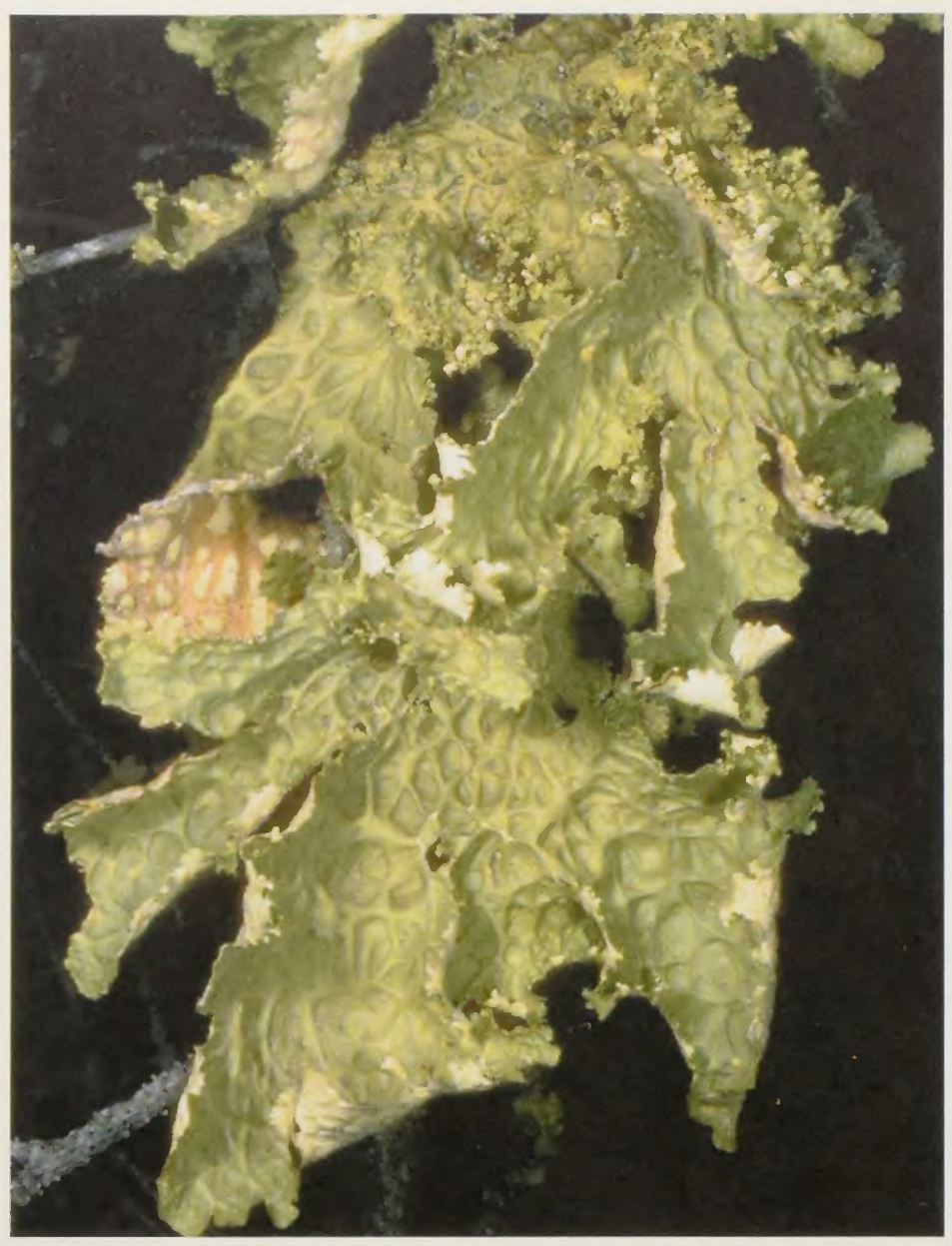

Figure 11. Lobaria oregana

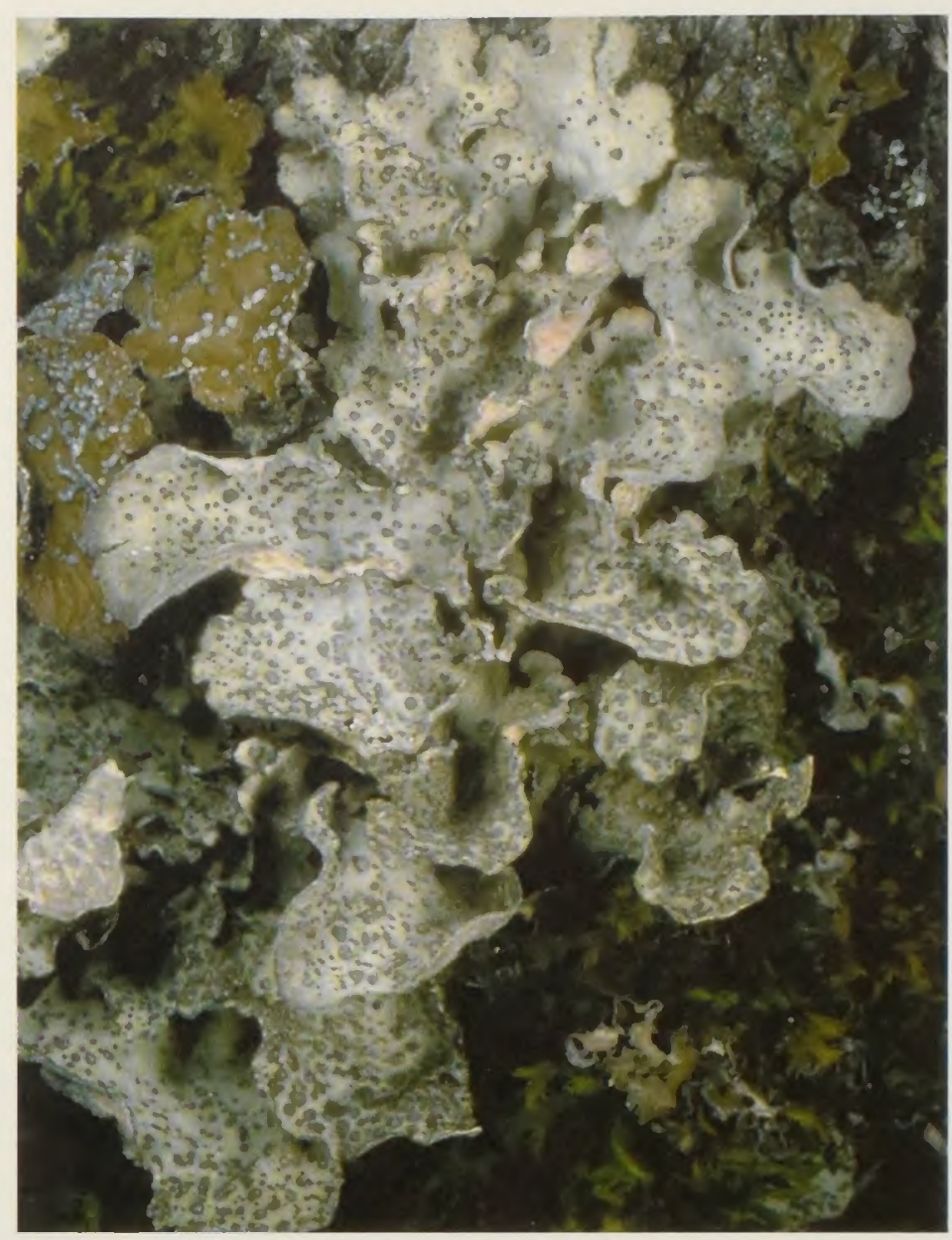

Figure 12. Lobaria hallii

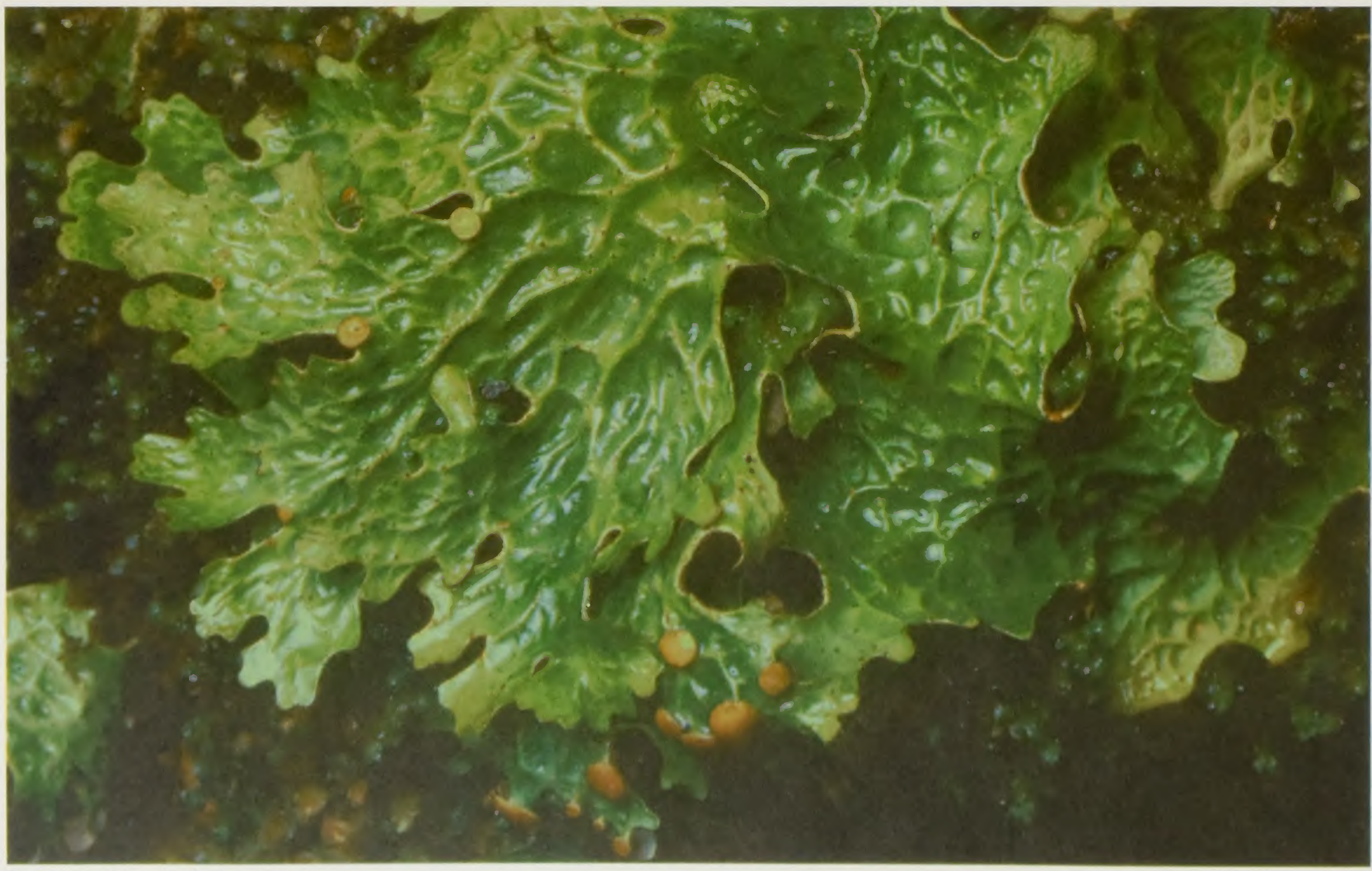




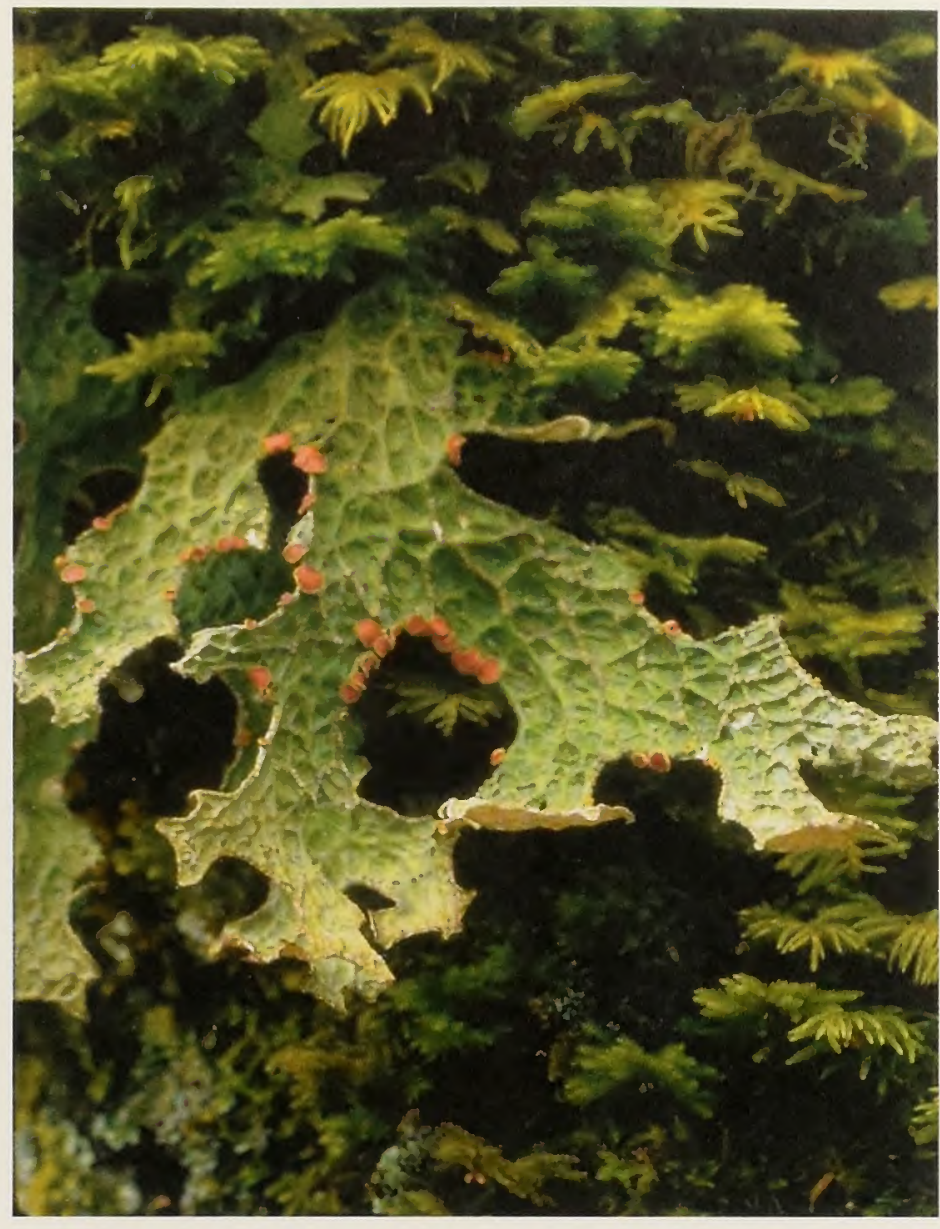

Figure 14. Lobaria pulmonaria

Figure 16. Veins on Peltigera ponojensis

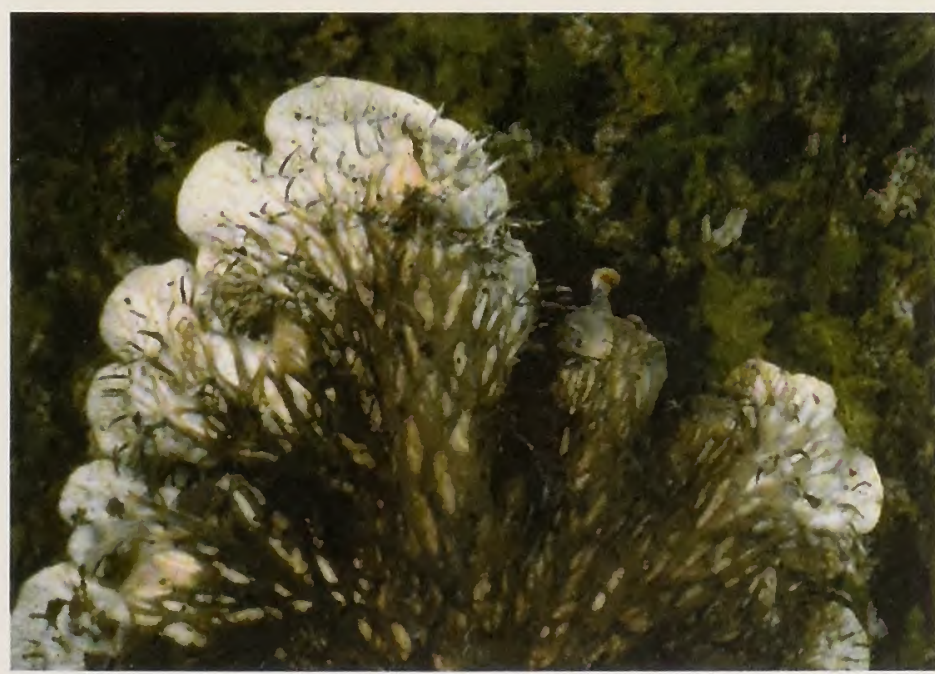

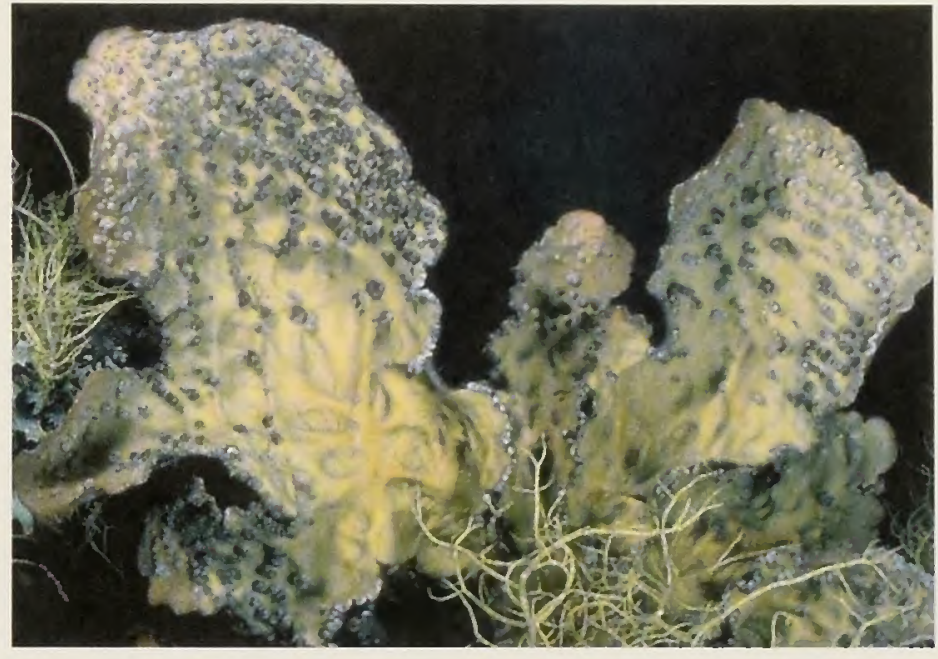

Figure 15. Lobaria scrobiculata

Figure 17. Pseudocyphellaria rainierensis

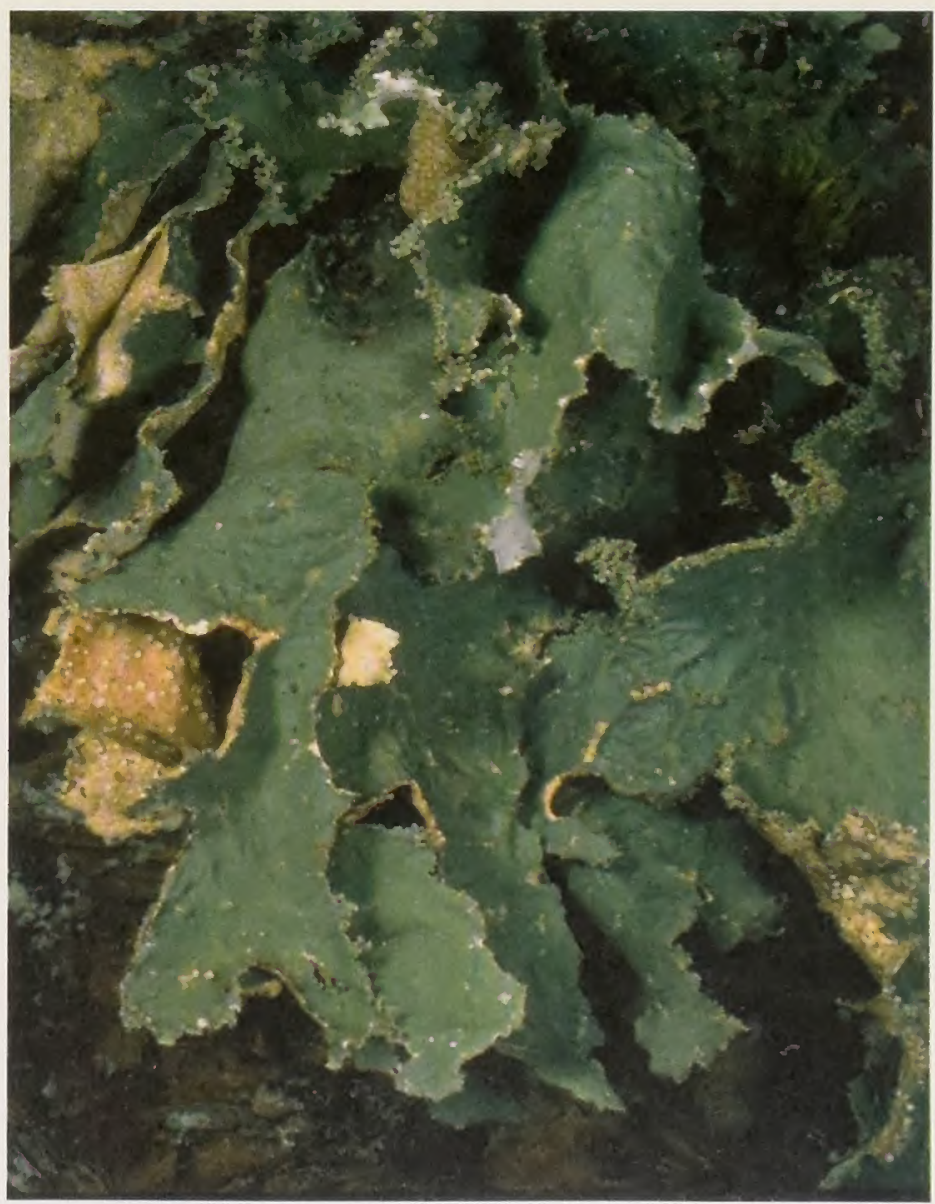


2003 Survey Protocols for Category A \& C Lichens 


\section{Niebla cephalota (Tuck.) Rundel \& Bowler}

\section{Synonym: Vermilacinia cephalota (Tuck.) Spjut \& Hale}

Taxonomic Note: Niebla, and the closely related genus Ramalina, have been the subject of several recent taxonomic revisions based on cortical and chemical characteristics (Rundel \& Bowler 1978, Bowler \& Riefner 1995). In 1996 the genus Niebla was further split, creating the new genus Vermilacinia. At this time Niebla cephalota became Vermilacinia cephalota, again based on cortical characteristics and chemistry (Spjut 1995 \& 1996). Although many distinguishable entities in the genus Niebla (in the broad sense) have been assigned species names (Brodo et al. 2001), this leads to confusion while studies continue. The current Checklist for North American Lichens (Esslinger 1997) uses the new name, Vermilacinia cephalota, however Brodo et al. (2001) suggest a conservative approach while studies of the group are still in progress. Therefore, this entity will be referred to in this document as Niebla cephalota.

\section{A. Identification in the Field}

Niebla cephalota (Figure 18) is a small $(2-4 \mathrm{~cm})$ fruticose tufted or drooping pale yellow to greenish yellow lichen that often has black spots. It also has lateral blue-gray soralia. It superficially resembles a diseased Ramalina covered with black spots that could be mistaken for a fungal parasite.

\section{B. Technical Description}

\section{Morphology}

Thallus fruticose, $2-4 \mathrm{~cm}$, tufted to drooping, pale yellow to greenish yellow but often black spotted, in the herbarium becoming covered with filamentous crystals (that have the appearance of mold); branches mostly $<2 \mathrm{~mm}$ diameter, roundish and pitted with depressions and wrinkles, dull to shiny, corticate, solid, sparsely to occasionally richly branched, branching uneven. Soredia large, convex, lateral, containing bluish grey soredia, pycnidia black, dotlike, conspicuous (Brodo et al. 2001, Goward 1999, McCune \& Geiser 1997). Morphology is variable; see look-alikes section. Based on microscopic cortical characteristics and chemistry, this species was recently placed in the genus Vermilacinia (Spjut 1995 \& 1996). However, for the reasons described in the taxonomic note above, it will continue to be treated with Niebla in this document.

\section{Chemistry}

Most individuals have negative spot tests in the medulla, except for rare populations with salazinic or norstictic acid ( $\mathrm{K}+\mathrm{red}$ ) (Brodo et al. 2001). McCune \&Geiser 1997 note that the cortex is KC+Y. Usnic acid and numerous other lichen substances present; these lichen substances are used as distinguishing characteristics in Spjut's treatment (Spjut 1995 \& 1996).

\section{Reproductive Structures}

Apothecia are unknown for Niebla cephalota. Asexual reproduction occurs by soredia, which are described above. The microscopic size of the reproductive propagules should enable them to be carried long distances by wind, 
animals, or birds, however dispersal and establishment rates for lichen propagules are largely unknown. Birds in particular are thought to enhance arrival rates of rare oceanic species like $N$. cephalota by dispersing lichen propagules along coastal migratory routes of the Pacific Northwest (McCune et al. 1997).

\section{Look-alikes}

Niebla cephalota can be highly variable in morphology, leading to confusion with other species and even genera. It resembles an Evernia or Ramalina, but has angular to almost rounded branches and a soft, cottony interior (Brodo et al. 2001). This is the only sorediate Niebla (Brodo et al. 2001).

Evernia prunastri (Figure 19) has a foliose thallus that is generally green above and paler below (ours is colored alike above and below), is never black spotted ( $N$. cephalota is black spotted), and has dichotomously forked branch tips.

Ramalina are similar, but never have scattered black pycnidia (they may have black fungal parasites). Ramalina don't produce external filamentous crystals in the herbarium.

Ramalina farinacea (Figure 20) is a common species that also produces marginal soralia, but they are not tinged blue-gray as soralia in $N$. cephalota are.

Brodo et al. (2001), Goward (1999) and McCune and Geiser (1997) provide readily available keys, descriptions and illustrations of this species.

\section{Range}

The current known and suspected range of $N$. cephalota in the Northwest Forest Plan area is the entire coastal strip in the Washington Olympic Peninsula and Western Lowlands, the Oregon and California Coast Range, and the Oregon Klamath Physiographic Provinces, from shoreline to about 15 miles inland.

Niebla cephalota is a North American coastal endemic, ranging from Baja California north to southern Southeast Alaska (Dillman pers. comm.). It is not yet known from British Columbia (Goward 1999), but does occur in northern Washington. In the Northwest Forest Plan area it is known from three locations in Washington (the San Juan Islands), and five or six in Oregon. Numbers of known sites in California have recently increased; in 2000 the coastal lichen study discovered nearly a dozen new populations (Glavich et al. 2000). Niebla is a tropical genus with high species diversity and biomass along the coasts of southern California, the Channel Islands, and Baja California (Bowler \& Riefner 1995). Niebla cephalota is the only species in this genus to range north to the Pacific Northwest, where it is rare.

\section{Habitat}

Niebla cephalota is a strictly coastal species, known from exposed trees (less often rocks), usually within sight or sound of the ocean (McCune \& Geiser 1997). Coastal Washington, Oregon and northern California are in the northern-most part of this species global distribution, and its habitat characteristics and requirements there are probably different than those of 
populations farther south, where it is more common. Most known sites within the Northwest Forest Plan area are less than $75 \mathrm{~m}(250 \mathrm{ft})$ elevation and within a few kilometers of the Pacific Ocean, or within the coastal fog zone, which may extend as far as 15 miles inland. The genus Niebla is particularly well adapted to low annual rainfall, frequent overcast and fog with associated high humidity. Niebla is the Spanish word for "fog" or "mist", a suitable epithet for the habitat of this species.

In the Northwest Forest Plan area, N. cephalota grows in high precipitation areas on forested edges of windswept headlands and sand dunes; at the edge of tree islands surrounded by moving dunes; as well as in sparsely forested estuaries and willow-dominated marshy areas. It has been found most often on exposed boles and branches of Sitka spruce and shore pine, but is also known from Monterey cypress, shore pine and willow. At one site it occurs on an old shore pine on the seaward edge of an old-growth Sitka spruce forest (McCune et al. 1997). At another it occurs at 700' elevation about three miles from the ocean, in a young Douglas-fir and western hemlock stand with closed canopy on most of the stand and a stream along one side (USDA 1998). Two populations are known that are slightly farther inland, but evidently within the coastal fog zone. One of these is in Tillamook County, Oregon where it was found at 700' elevation three miles from the ocean (USDA 1998), and the other is at Stafford Lake Park, near Novato, California, where it is about 12 miles from the ocean (D. Wright, pers. comm.). In Mendocino County, California, the riparian/estuarine community where $N$. cephalota occurs was described as having quite old/ decadent plant growth (T. Sholars, pers. comm.). Preliminary data from the coastal lichen study indicate that it occurs in older, well-established stands, with the maximum age of conifers ranging from 50 to 150 years (Glavich et al. 2000). Species abundance at known sites varies; it can be extremely rare at northern sites (Dillman pers. comm), and apparently can reach higher biomass at more typical, southern sites. 


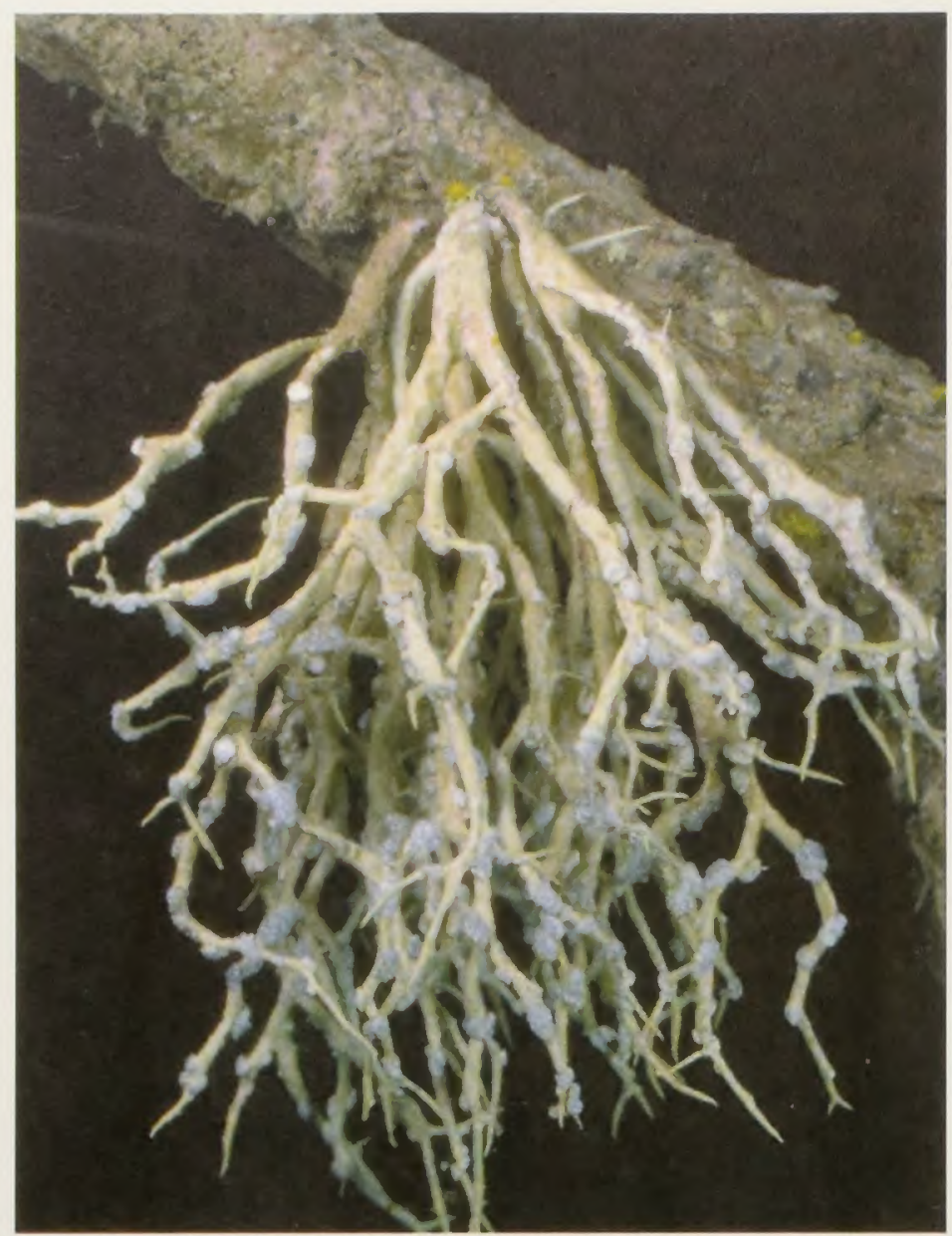

Figure 18. Niebla cephalota

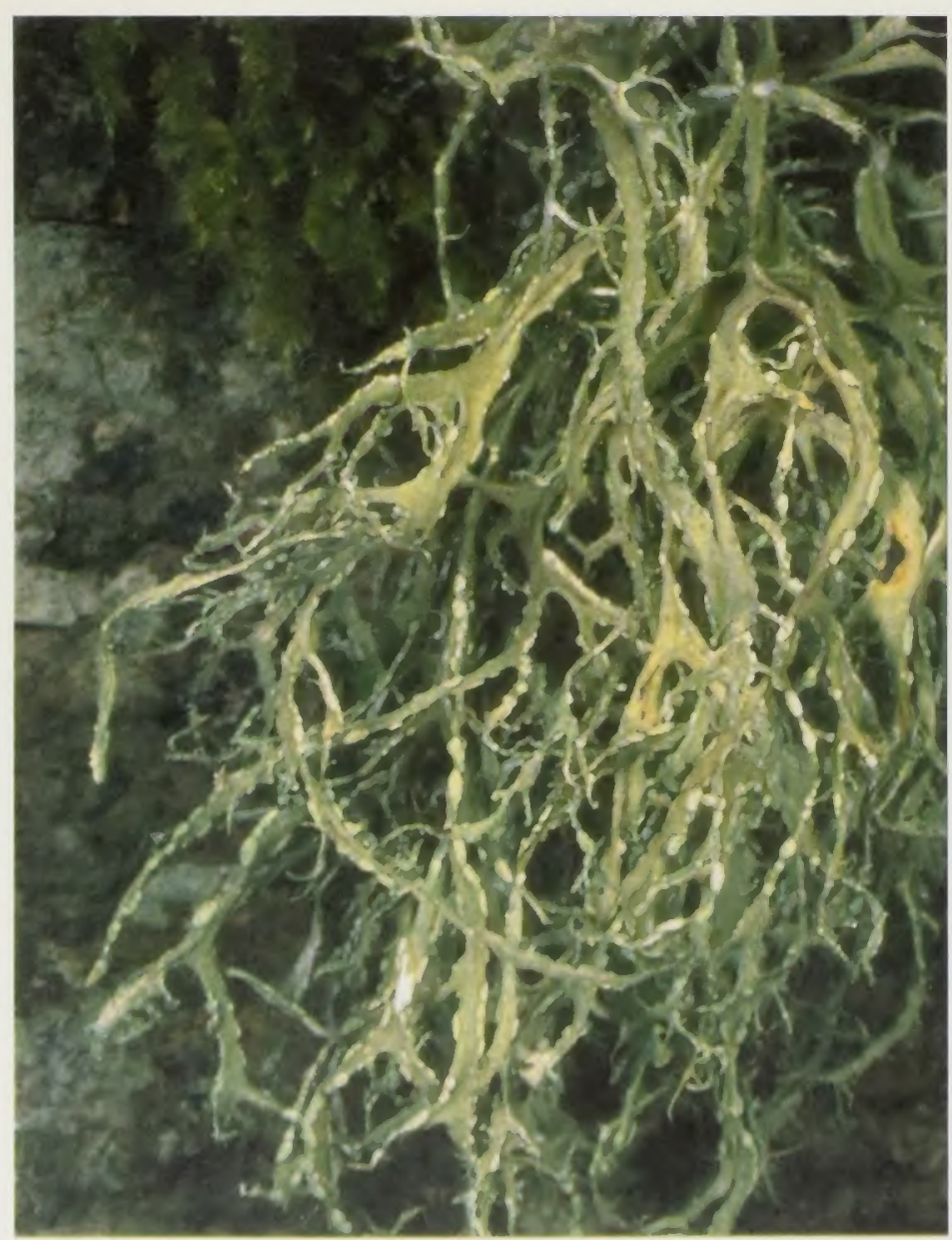

Figure 20. Ramalina farinacea

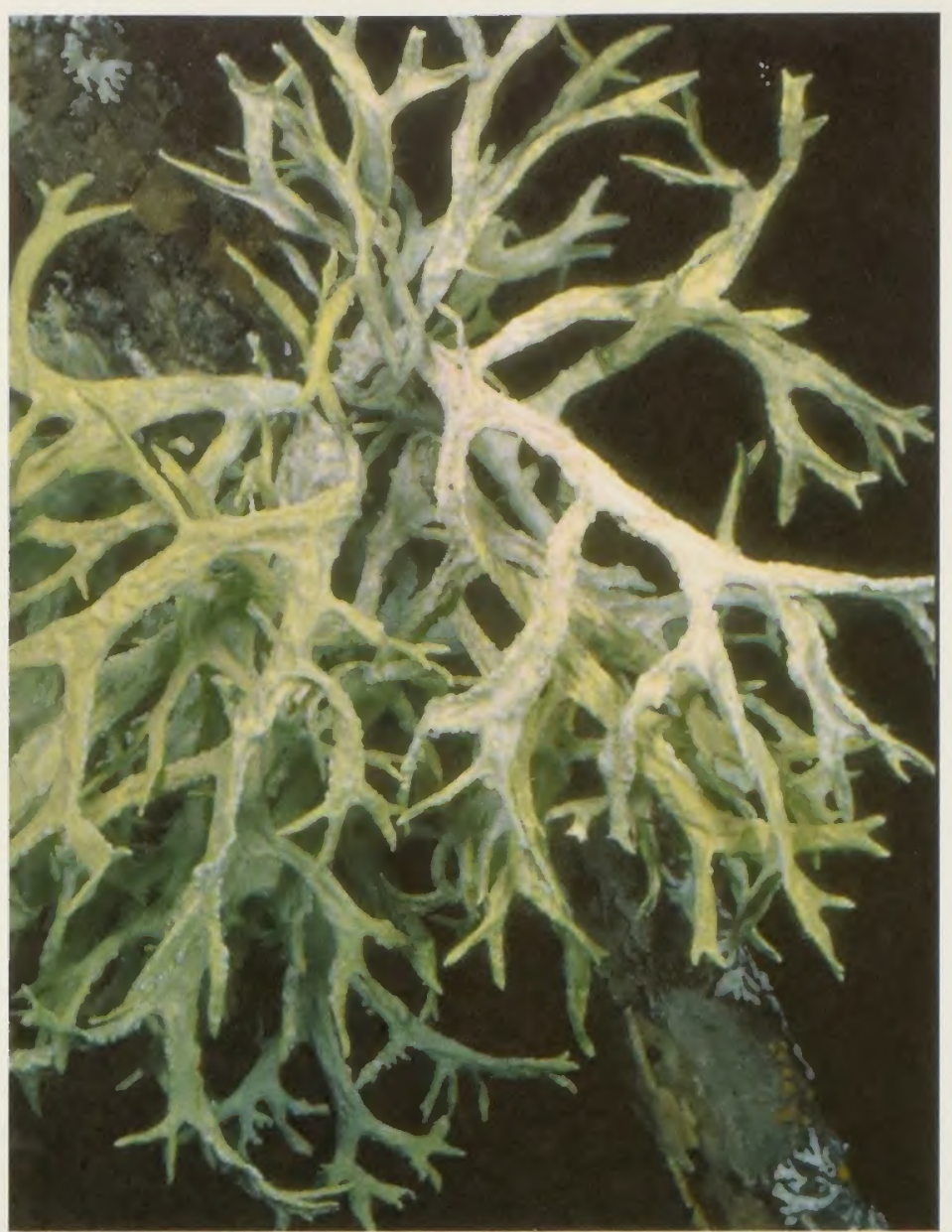

Figure 19. Evernia prunastri 


\section{Platismatia lacunosa (Ach.) Culb. \& C. Culb.}

\section{A. Identification in the Field}

Platismatia lacunosa (Figure 21) is a medium to large, roundish, appressed, foliose lichen that is whitish or grayish but can become browned at exposed sites. It is often on the branches, and occasionally the boles of conifers and hardwoods. From several feet away, the pronounced network of ridges and depressions is obvious. This species is usually more appressed to the substrate than other Platismatia. The lichens Menegazzia terebrata and Hypotrachyna sinuosa, on red alder and other hardwoods as well as conifers, can be good indicators of $P$. lacunosa habitat.

\section{B. Technical Description}

\section{Morphology}

Thallus small to large, $5-16 \mathrm{~cm}$. broad; lobes $0.6-1.5 \mathrm{~cm}$. broad. Upper surface very pale greenish-gray to almost white in the field (uniformly brown or tan in old herbarium specimens), the margins conspicuously blackening, prominently ridged by strong reticulations rising at right angles to the surface, not pseudocyphellate. Lower surface black at the center, chestnut brown at the margins, somewhat reticulately wrinkled; not punctate; rhizines few, black (Brodo et al. 2001, Culberson \& Culberson 1968). McCune \& Geiser (1997) make these additional comments: the foliose thallus is suberect or appressed but with the edges free; the upper surface has a pronounced network of ridges and depressions and is whitish, grayish, or browned in exposed sites; the lower surface is black, brown, white, or with patches of these colors; isidia and soredia are lacking; and apothecia are common.

\section{Chemistry}

Cortex K+ Y (McCune \& Geiser 1997); medulla K-, C-, KC-, PD+ orange-red. Contains fumarprotocetraric acid, caperatic acid (at least in some specimens), and atranorin (Culberson \& Culberson 1968).

\section{Reproductive Structures}

Apothecia occasional, marginal to submarginal, with large, folded, brown disks 4-20 mm in diameter; spores eight per ascus, ellipsoid to ovoid, 7-10 $\mathrm{x}$ 3-4.5 microns. Pycnidia marginal to submarginal or even superficial (on the crests of the reticulations), the ostiole round to irregular at maturity (Brodo et al. 2001, Culberson \& Culberson 1968).

\section{Look-alikes}

The genus Platismatia is closely related to and could be mistaken for several genera in the large and diverse family Parmeliaceae (Brodo et al. 2001); these genus splits are included in the general key sections in most references, and are summarized below. Brodo et al. (2001), Goward et al. (1994) and McCune \& Geiser (1997) all provide good keys, photographs, descriptions and line drawings of this species and look-alikes. The Air Quality Database (USDA 1998) contains site-specific habitat information. 
Platismatia lacunosa is distinctive with its strong network of ridges and depressions, combined with the absence of isidia and soredia. The pycnidia, however, which can be either protruding or stalked, are sometimes mistaken for isidia (McCune \& Geiser 1997). Less well-defined or immature specimens are sometimes confused with the following:

Cetrelia (Figure 22) always have pseudocyphellae, are usually sorediate, and usually react $\mathrm{C}+$ or $\mathrm{KC}+(P$. lacunosa medulla is $\mathrm{C}$ - and $\mathrm{KC}-$ ). Cetrelia also never have the strong network of ridges and depressions characteristic of P. lacunosa.

Platismatia lacunosa could be mistaken for a Lobaria based on its slightly thicker, glossier texture that is more common in Lobaria (other Platismatia tend to have a paper-like texture). Check the underside for the white/ tan/brown mottling typical of Platismatia; Lobaria will have characteristic more or less tomentose furrows surrounding raised white patches.

Parmotrema (Figure 23) is a genus that could be mistaken for Platismatia; the former lacks rhizines at the lobe margins but usually has marginal cilia, which are never present in Platismatia. (Brodo et al. 2001).

Platismatia glauca (Figure 24) can resemble P. lacunosa, but has a less appressed growth form than our species. Platismatia glauca is "fluffy and disheveled" looking (McCune \& Geiser 1997, p. 242), and often has soredia or isidia or both. Platismatia glauca occasionally has a weakly ridged upper surface.

Platismatia norvegica (Figure 25) is most easily confused with P. lacunosa; both have an appressed growth form, but the ridges in $P$. lacunosa are always stronger, and $P$. lacunosa is often almost white, where $P$. norvegica almost always has a green tinge. The distinction between the ridges becomes apparent after seeing several thalli of both species. Platismatia norvegica almost always has at least a few (more frequently many) isidia, predominantly on the ridges; pycnidia are not seen in the Northwest Forest Plan area (McCune \& Geiser 1997). Finally, P. norvegica is PD-, while P. lacunosa is PD+ orange to red.

Platismatia stenophylla (Figure 26), like P. norvegica, also lacks isidia or soredia, but has consistently narrower lobes (0.5-4 mm wide) that lack a network of ridges.

\section{Range}

The current known and suspected range of P. lacunosa in the Northwest Forest Plan area includes all Physiographic Provinces except Washington Eastern Cascades, Oregon Eastern Cascades and California Cascades. Although it is not yet known from the California Coast Range or Klamath Physiographic Provinces, it may occur there, particularly in Del Norte County, in the Russian Wilderness Area and other moist sites where microclimate conditions are met (J. McFarland pers. comm.). Its global range is from the Aleutian Islands south through coastal Alaska to northern California (Brodo et al. 2001), however there are currently no ISMS records for this species in California.

In Washington it is known from the Olympic, Mount Baker-Snoqualmie, and Gifford Pinchot National Forests, and in Oregon it occurs on the Mount 
Hood, Willamette, Siuslaw, Umpqua and Siskiyou National Forests and Salem, Eugene, Roseburg, and Coos Bay District BLM.

\section{Habitat}

Although Platismatia lacunosa was originally thought to be a riparian species (USDA \& USDI 1994, 2001), recent information has revealed that the species has a broader ecological amplitude. In the Northwest Forest Plan area it is uncommon on the boles and branches of hardwoods and conifers in moist, cool upland sites as well as moist riparian forest in the Coast Range and Cascades, at sites ranging from sea level to 3500 feet in elevation. At one site in western Washington it occurs on vine maple on a steep slope in a mixed old-growth forest. It also occurs on western hemlock, Sitka spruce, alder, cherry and maple (USDA 1998), and occasionally on rocks in coastal forests (Brodo et al. 2001). Most sites in the Air Quality Database are primarily in the Western Hemlock Zone, but it also occurs in coastal stands (USDA 1998). This species is never abundant at sites where it does occur.

Platismatia lacunosa often grows on the upper side of horizontal branches, especially hardwoods, adjacent to wetlands or lakes, and it also occurs on vine maple in second growth with old-growth remnants present. During a climbing survey in the Cobble Knob area of Roseburg District BLM, it was found high in the canopy of an old-growth conifer in a relatively cool, moist canyon near a riparian area (A. Ruchty pers. comm.). Habitat requirements for P. lacunosa could be present in other types of tree dominated plant communities in areas where site conditions are cool and moist. 


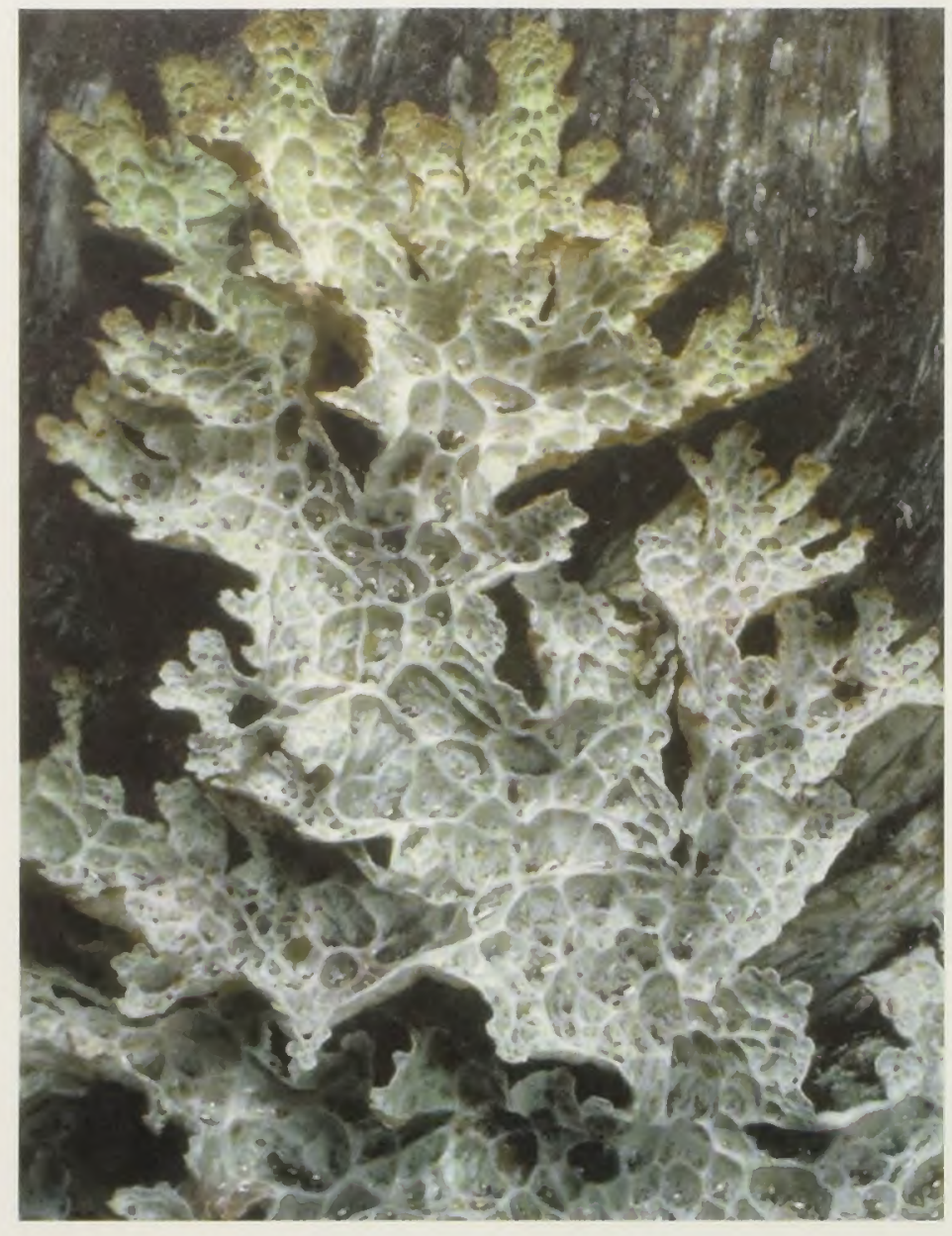

Figure 21. Platismatia lacunosa

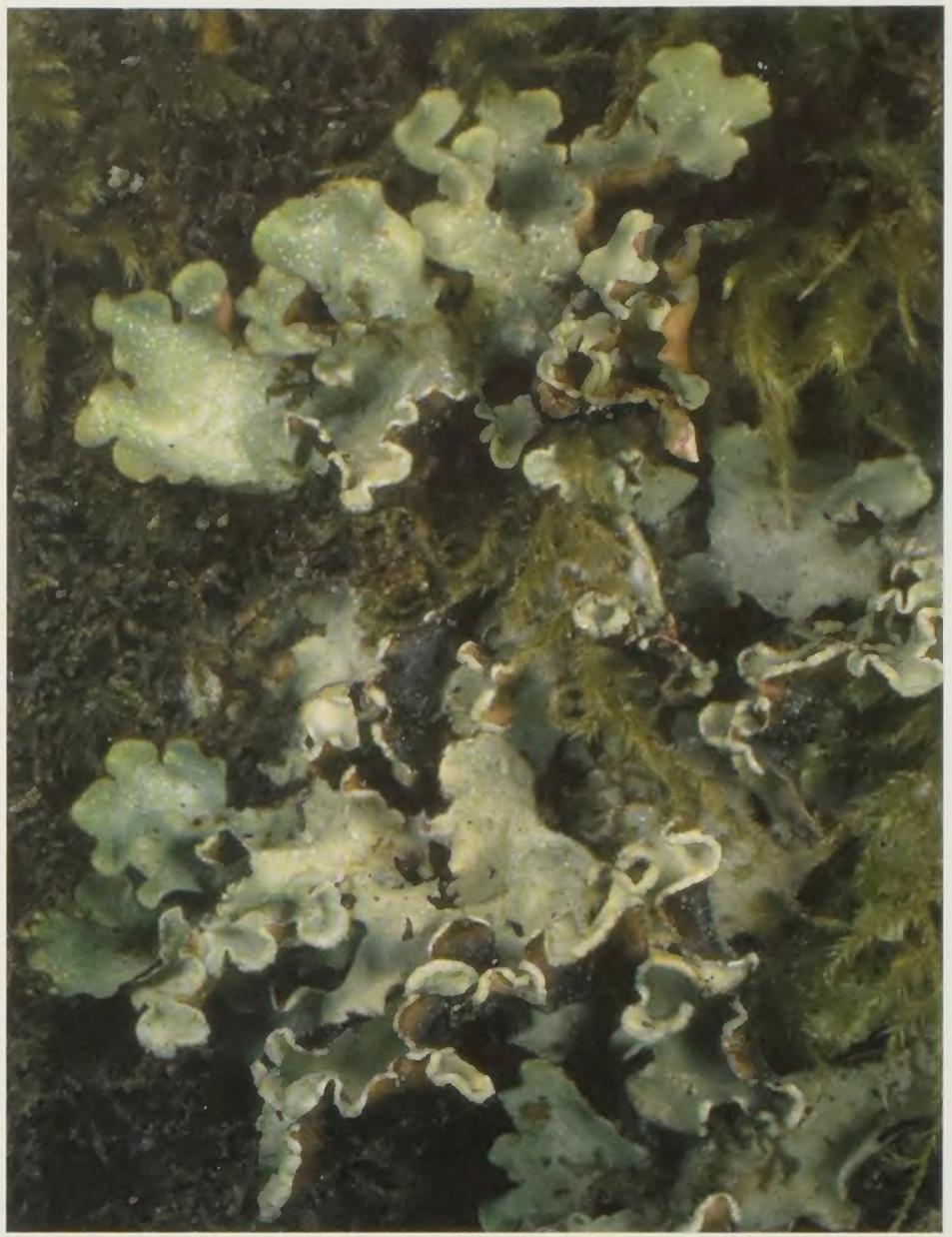

Figure 22. Cetrelia cetrariodides

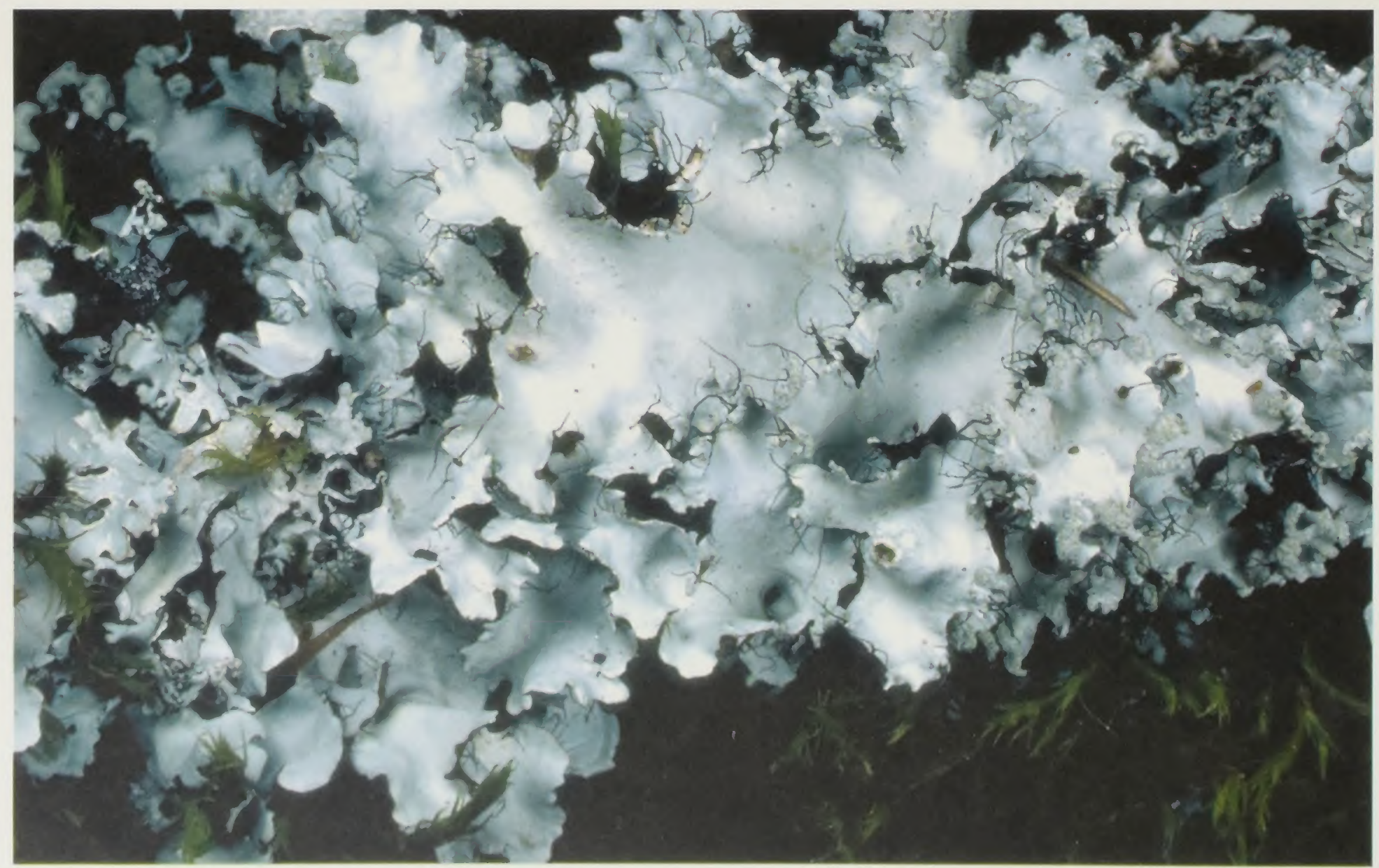

Figure 23. Parmotrema arnoldii 


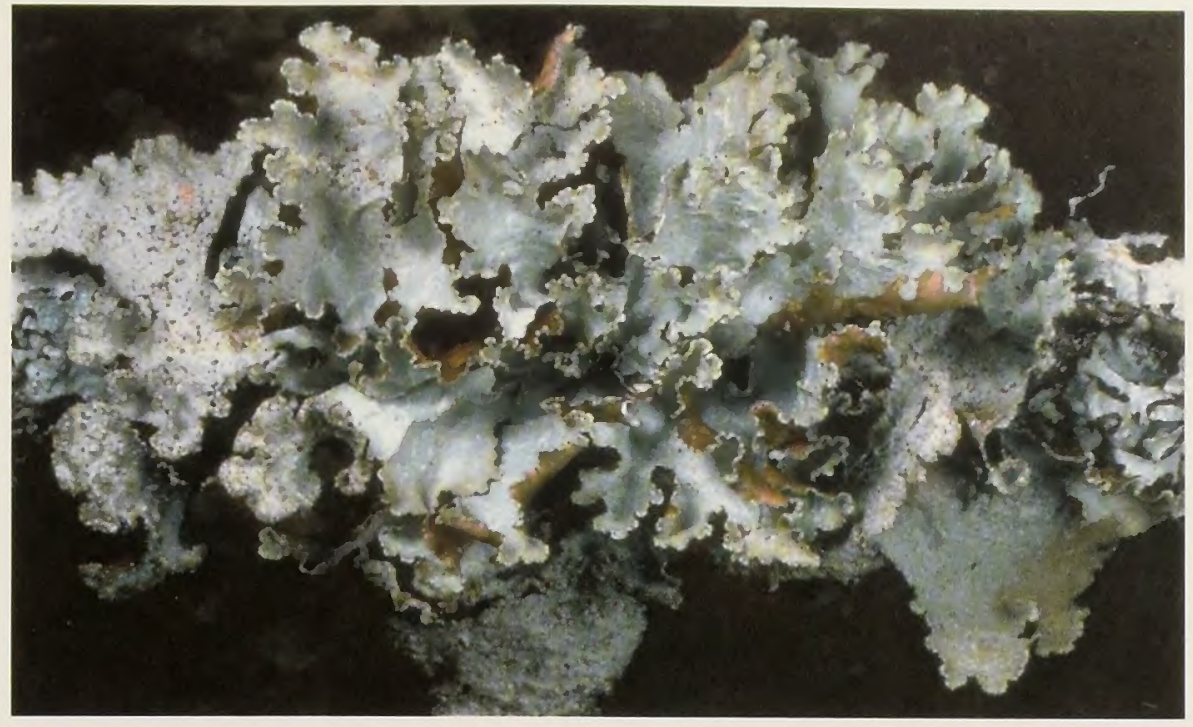

Figure 24. Platismatia glauca

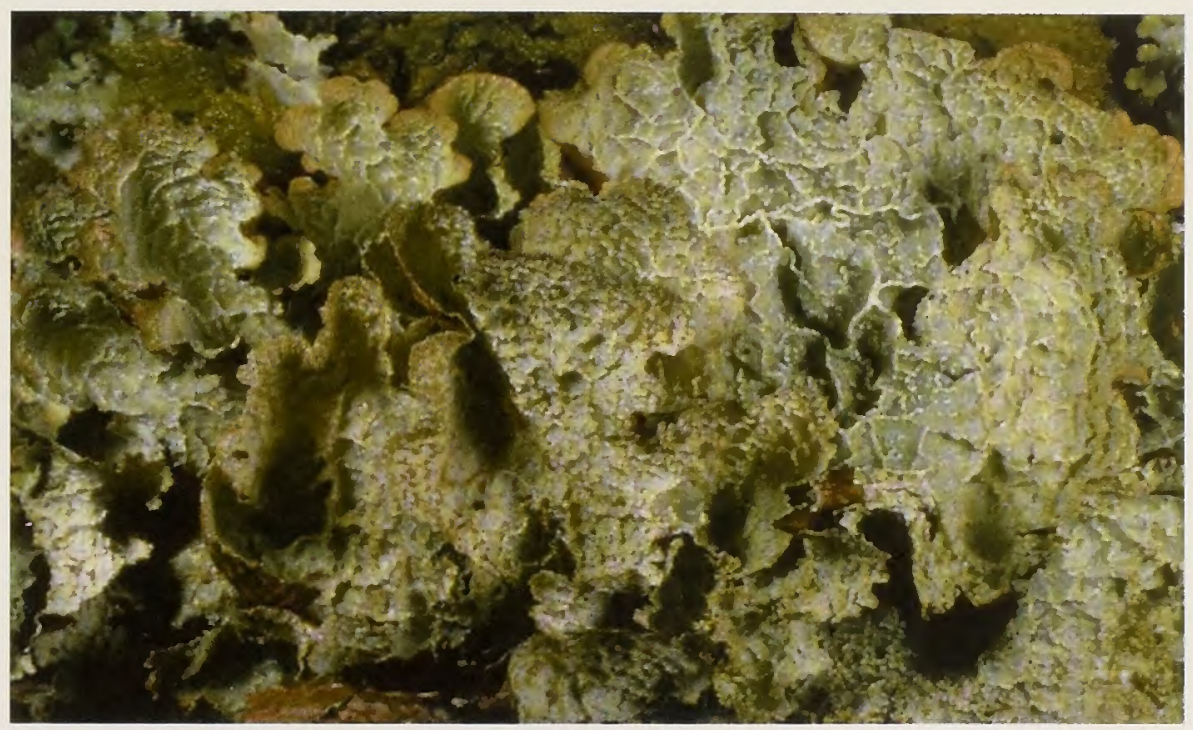

Figure 25. Platismatia norvegica

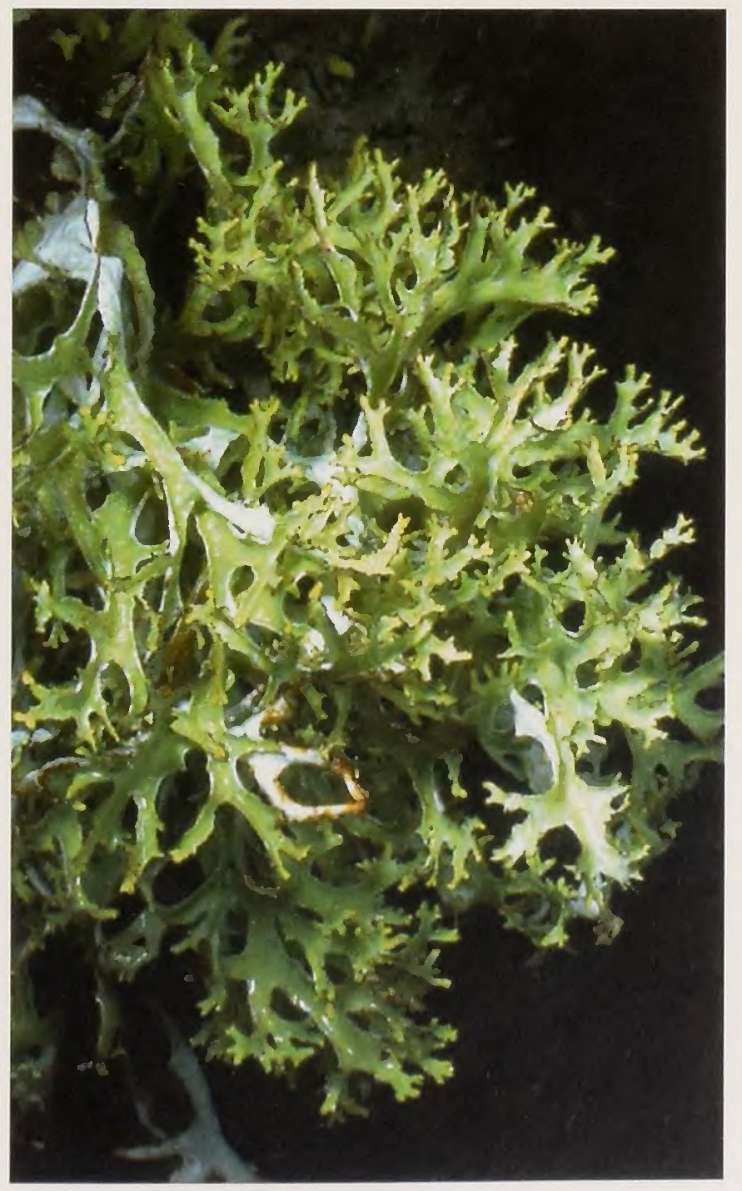

Figure 26. Platismatia stenophylla 


\section{Ramalina thrausta (Ach.) Nyl.}

\section{A. Identification in the Field}

Look for what appears to be a slightly off-color Alectoria sarmentosa, or pendant, unusually greenish Usnea, hanging from the branches and occasionally the boles of conifers and hardwood trees. It will also occur in understory shrubs such as rhododendron or huckleberry. Minute sorediate hooked branch tips may be visible with a hand lens.

\section{B. Technical Description}

\section{Morphology}

"Thallus fruticose, pendulous, to $30 \mathrm{~cm}$ long, pale greenish; branches filamentous, mostly $<0.5(1) \mathrm{mm}$ diam., the tips often hooked or curled and ending in a minute soralium" (McCune \& Geiser 1997). Although the delicate, pale green, hairlike branches with minute green hooked tips are distinctive, they can be poorly developed. The cortex is thin and translucent, smooth and even; pseudocyphellae are typically point-like, or somewhat elongated (Brodo et al. 2001). Brodo et al. (2001), McCune \& Geiser (1997) and Goward (1999) provide good keys, descriptions, line drawings and photographs for this and other similar species. Additional habitat information and a species list at known sites are available online from the Air Quality Database (USDA 1998).

\section{Chemistry}

All spot tests are negative. Ramalina thrausta (Figure 27) can, however, usually be distinguished from look-alike specimens of Alectoria spp. using spot tests. An iodine spot test detects the presence of lichenan in Alectoria spp., a substance not present in $R$. thrausta (Common 1991). In addition, $A$. sarmentosa is almost always $\mathrm{KC}+$ red (occasionally it is $\mathrm{KC}$-) and $A$. vancouverensis (superficially very similar to $A$. sarmentosa) is always $C+$ red.

\section{Reproductive Structures}

Apothecia are very rare (Brodo et al. 2001). This species primarily reproduces asexually by soredia and by fragmentation.

\section{Look-alikes}

Alectoria sarmentosa can easily be confused with $R$. thrausta, and the two often co-occur. When growing from tree boles, $R$. thrausta may grow alongside Alectoria, and in these cases, $R$. thrausta will look slightly more delicate, with thinner branches that appear a bit messy and tangled (rather like an unhealthy Alectoria). With close inspection, the diagnostic hooked, minutely sorediate branch tips can be detected (McCune \& Geiser 1997). The elongate pseudocyphellae characteristic of $A$. sarmentosa are lacking in $R$. thrausta, although shorter, almost point-like pseudocyphellae are present; there is some overlap in this characteristic between the two species (Brodo et al. 2001). Alectoria thalli often show some nonfilamentous, flattened areas, especially at branch junctions, whereas Ramalina branches are filamentous and consistently more rounded, with flattening occurring infrequently. When flattening does occur, it is only at 
branch bases (Brodo et al. 2001). The medulla of $A$. sarmentos is almost always $\mathrm{KC}+$ red, while all spot tests for $R$. thrausta are negative (Brodo et al. 2001).

Alectoria vancouverensis is morphologically identical to $A$. sarmentosa, so could be mistaken for $R$. thrausta. Alectoria vancouverensis is $C+$ red, while $R$. thrausta is negative, and $A$. vancouverensis tends to be more coastal, but does occur in the Oregon Cascades (A. Ruchty pers. comm).

Ramalina menziesii (Figure 28), when growing at coastal sites, is often finely filamentous and lacks well-developed nets and resembles $R$. thrausta. Check the lobe tips for tiny nets and no soredia; $R$. thrausta would have tiny hooked, minutely sorediate branch tips.

Ramalina farinacea (Figure 20) growing in deep shade can form hooked sorediate branch tips, but these thalli are always short $(<6 \mathrm{~cm}$ long) and usually some portion of the thallus is flattened (McCune \& Geiser 1997).

Pendant Usnea spp. growing in shaded habitats where the distinctive coloration from usnic acid is not well developed could be mistaken for $R$. thrausta; check for the presence of a central cord.

\section{Range}

The current known and suspected range of $R$. thrausta in the Northwest Forest Plan area is all Physiographic Provinces except Eastern Oregon Cascades, Eastern Washington Cascades and California Cascades. On the west coast of North America, this mainly circumboreal lichen occurs from the Chugach National Forest, Alaska (Derr 1997) south to central California (Sanders 1997, Tavares 2002, Tucker 2001) and east into northern Idaho and Montana.

Within the Northwest Forest Plan area, $R$. thrausta occurs infrequently in the Coast Range and Western Cascades (McCune \& Geiser 1997) south to Sonoma County (north of Santa Rosa) (Sanders 1997). In Washington it is known from the Gifford Pinchot National Forest and the Columbia River Gorge National Scenic Area. Although it is not yet reported from the Washington Olympic Peninsula, Washington Western Lowlands or northern part of the Washington Western Cascades, known sites in similar habitat both north and south of these areas suggest that this inconspicuous species may have been overlooked. In Oregon it occurs on the Suislaw, Willamette, and Umpqua National Forests, and the Salem, Eugene, Roseburg, Medford and Coos Bay Districts of the BLM. In California it is known from the Siskiyou National Forest (Del Norte County), and Sonoma County on lands of unknown ownership. It is suspected to occur infrequently at scattered locations in suitable habitat within its known range.

\section{Habitat}

Although Ramalina thrausta was originally thought to be a riparian species (USDA \& USDI 1994, 2001), recent information suggests that the species has a broader ecological amplitude. One central Oregon study found $R$. thrausta to be more frequent in riparian areas (Peterson \& McCune 2001); in another it occurred in riparian zones associated with fish bearing streams in the middle parts of the McKenzie R. watershed (McCune et al. 2001). In western Oregon, thalli at non-riparian sites may be larger, with thicker branches than 
individuals in riparian sites (A. Ruchty, pers. comm.). Generally speaking, this species occurs in moist low elevation conifer stands (sea level to $2250 \mathrm{ft}$.) that frequently have a hardwood component, where it grows on the branches and boles of conifers and hardwoods, as well as understory shrubs.

In Washington, on the Gifford Pinchot National Forest, it was found in two old-growth riparian sites at about $1500 \mathrm{ft}$. elevation on the flats along major drainages. At one site it was growing on the limbs of a riparian conifer, and at the other site was found as litter beneath large old cedar and western hemlock. It was also found at an upland site with Douglas-fir, western hemlock and silver fir co-dominants and vine maple, ocean spray, western dogwood, salal and Oregon grape, where it was growing on the smooth bole of a dogwood tree.

More habitat information is available for $R$. thrausta sites in Oregon. On the Willamette National Forest $R$. thrausta occurs in western hemlock plant associations with salal, Oregon grape and sword fern, between 200 and 2200 $\mathrm{ft}$. elevation. New habitat data from the Willamette and adjacent Eugene District BLM suggest that the species can be locally common there, where it is frequently found in low elevation riparian sites, and at non-riparian areas that appear to be 'moist', possibly due to landscape level influences such as topography, etc. (A. Ruchty, pers. comm.). In this area it also occurs on upland, exposed ridgetops, where it is most abundant and better developed at sites with mature trees and is also occasional at sites with younger trees $(\mathrm{J}$. Ponzetti, pers. comm). On the Siuslaw National Forest it occurs in moist western hemlock plant associations between 350 and $1400 \mathrm{ft}$. elevation. On the Umpqua National Forest it is known primarily from white fir/dry shrub stands with salal, Oregon grape and occasionally with incense-cedar, between 1200 and $2200 \mathrm{ft}$. elevation. In the Eugene District BLM, R. thrausta occurs in the Coast Range in an old-growth remnant patch of Douglas-fir surrounded by a 50-year-old stand, in a vine maple forest gap within a 50-year-old Douglas-fir stand that includes scattered old-growth remnant trees, and 50 year old Douglas-fir stands sprinkled with occasional filbert gaps and remnant old-growth Douglas-fir. All of these stands are under about $800 \mathrm{ft}$. elevation. In the Coos Bay District BLM it occurs at sea level in the dune and interdune wetland mosaic habitat that includes patchy shore pine and Sitka spruce forest with cyanolichen-rich willow and ericaceous shrub thickets. In Coos Bay District it also occurs on north-facing slopes of old-growth Douglas-fir/western red cedar forests with hardwood gaps of dogwood, vine maple and oceanspray, at about $800 \mathrm{ft}$. elevation. In the Roseburg District BLM it occurs between 240 and $2100 \mathrm{ft}$. elevation in Douglas-fir and western hemlock stands with salal and oregon grape in the understory, in white fir salal stands with and without incense-cedar, and in unspecified community types. In the Medford District BLM R. thrausta occurs between 1500 and 1700 $\mathrm{ft}$. elevation, at sites with north to north east exposures, in two different habitat types. One habitat type is a moist late-successional riparian Port Orford cedar/Douglas-fir/incense cedar stand with azalea, yew and white alder in the understory and a few Jeffrey pine nearby. This site is in a steep, high humidity, incised drainage under full shade. The other habitat type is the fairly open Oregon white oak/Douglas-fir/poison oak plant association. In this habitat type one site is riparian, near a small perennial stream, while the other is next to a tiny intermittent drainage that only provides increased humidity a few months out of the year. It is not reported from the Mount Hood National Forest. 
In Northern California, $R$. thrausta is known from an old-growth Douglas-fir forest in the Siskiyou National Forest (D. Glavich, pers. comm), and a coastal site near Fort Ross, Sonoma County, where it was found in an open grassland with scattered madrone (Sanders 1997). In Southeast Alaska it occurs on Sitka spruce on maritime beaches (Geiser et al. 1998); it is considered to be hygrophytic in British Columbia, and is best developed when growing in close proximity to standing water or wetlands (Goward 1999).

Stand age at known sites of $R$. thrausta is largely unknown. In the Air Quality database, it is reported from several old-growth Douglas-fir stands, usually with moist site characteristics; occasionally it was in riparian situations (USDA 1998). It was found in one 14 year old stand, where it had undoubtedly blown in from a nearby colonized site; it was also in a 30 year old thinned stand with remnant large Douglas-fir present (USDA 1998). On the Gifford Pinchot it grows in old-growth Douglas-fir stands and in a 111 year old stand. On Medford District BLM it occupies late-successional stands. The abundance of this lichen at most known sites is not known. 


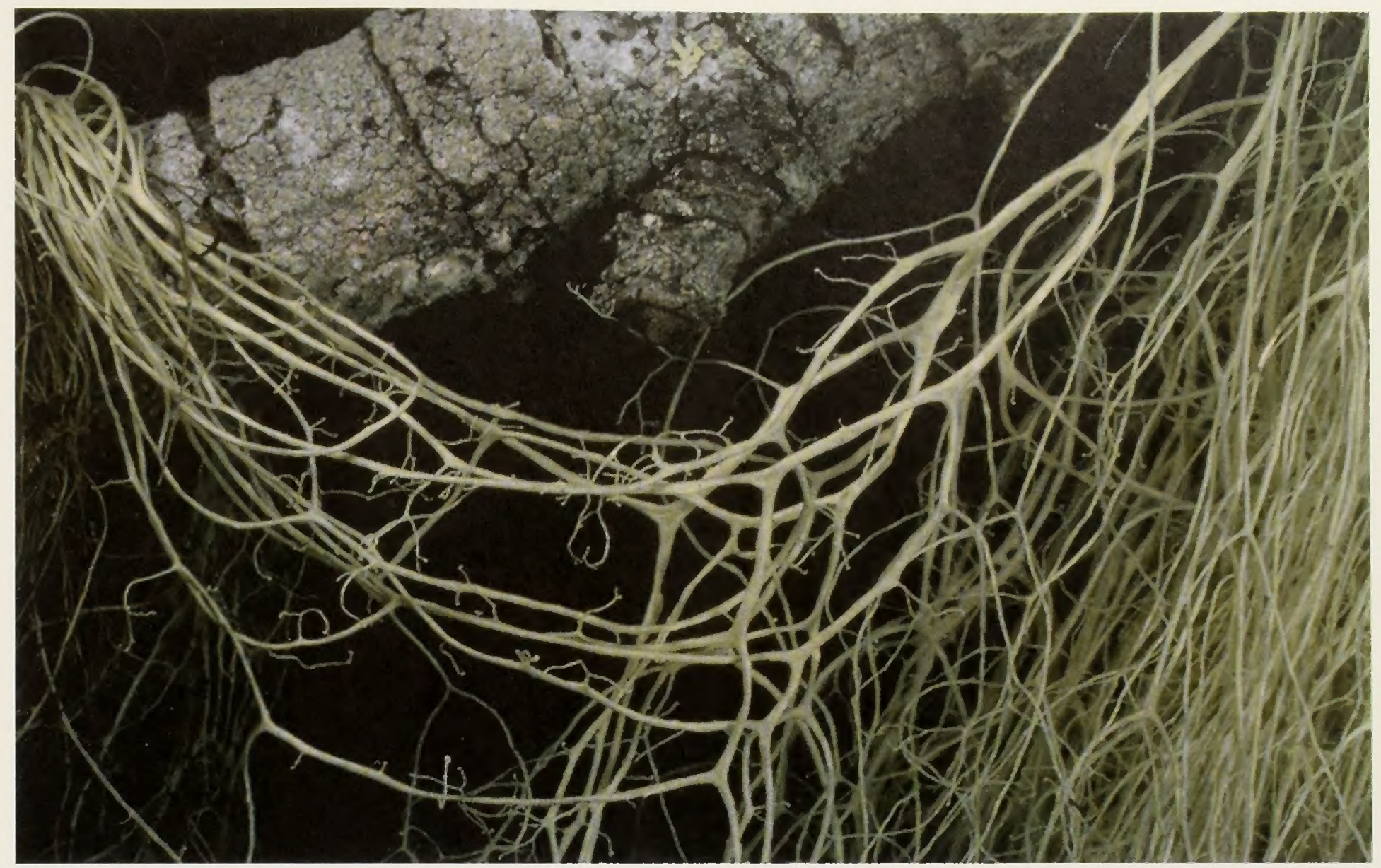

Figure 27. Ramalina thrausta

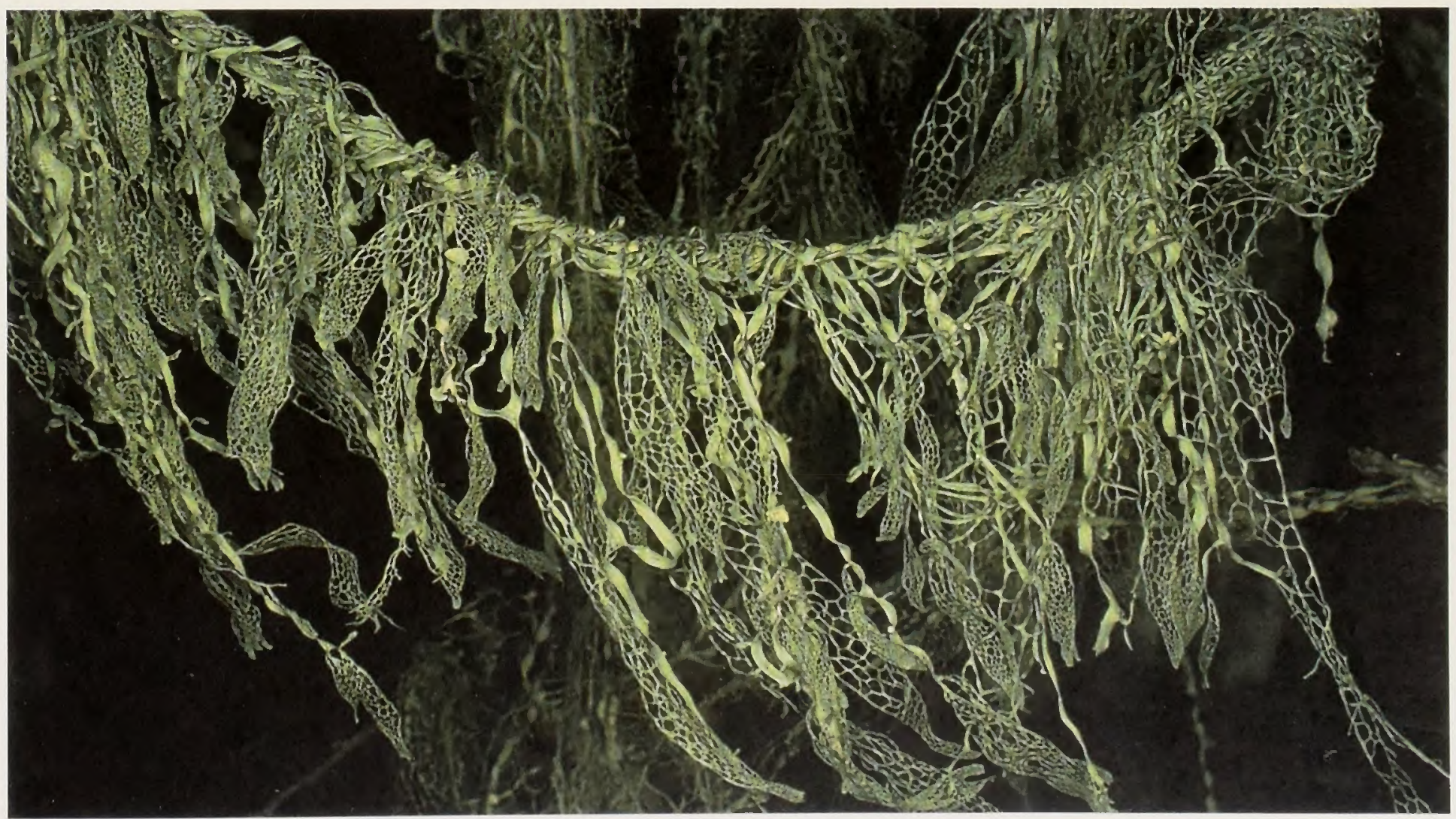

Figure 28. Ramalina menziesii 


\section{Teloschistes flavicans (Sw.) Norman}

\section{A. Identification in the Field}

Look for a distinctive bright orange, tufted, fruticose lichen that looks like a shrubby orange Usnea. It can be either epiphytic or growing on rocks.

\section{B. Technical Description}

\section{Morphology}

Teloschistes flavicans (Figure 29) is a conspicuous, small to medium sized (2-5 $\mathrm{cm}$ tufts), fruticose lichen. The thallus is tufted, erect and spreading or, rarely, pendent, and often vividly yellow to orange colored. It is occasionally greenish-yellow, or even pale greenish, when grown in the shade (McCune and Geiser 1997). It is composed of many elongated, entangled, somewhat compressed, more or less twisted, pitted or channeled, sorediate branches that have pointed tips and short pointed side branches. The soredia are yellowish and are produced in roundish soralia. This is the only sorediate Teloschistes in North America (Brodo et al. 2001).

\section{Chemistry}

Cortex $\mathrm{K}+$ purple-red; medulla spot tests are negative.

\section{Reproductive Structures}

Apothecia are rarely seen (Brodo et al. 2001). Asexual reproduction occurs via soredia and thallus fragmentation. In Britain T. flavicans can spread locally on an individual tree or boulder but disperses only very slowly to adjacent rocks or tree boles (Gilbert and Purvis 1996).

\section{Look-alikes}

Brodo et al. (2001) and McCune \& Geiser (1997) provide keys, descriptions and photographs.

Teloschistes contortuplicatus is a small to medium-sized fruticose or weakly foliose lichen with tufts of erect or semi-erect yellowish to orange or whitish grey ciliate branches, round in cross-section to irregular, slender to in part rather stout, often covered in a thin nap of erect tomentum. The branches are irregular and terminate in minute, globose, isidia-like outgrowths. Soredia and isidia otherwise unknown (T. flavicans is sorediate). Teloschistes contortuplicatus produces lateral apothecia that are often ciliate (ours rarely produces apothecia). This species occupies a drier habitat than $T$. flavicans, and grows on vertical rocks or trees in dry inter-montane locations at lower elevations. Known from western Northern Territories (Canada) south to Idaho, Montana and other western states (Goward 1999). It could occur in drier habitats in the southern part of the Northwest Forest Plan area.

Teloschistes exilis (Figure 30) is similar but is smaller, non-sorediate, and has apothecia; historically it has been collected in the Santa Cruz Mountains and the Channel Islands but is now very rare (Hale and Cole 1988). 
Usnea have a similar growth form but most are never bright orange; they always have a diagnostic central cord, which is lacking in Teloschistes.

Usnea rubicunda (Figure 31) is a tufted fruticose lichen with a reddish-brown hue produced by coalescing reddish cortical spots. This species usually has abundant fibrils and isidiate soralia; T. flavicans has small side branches and soralia. Check for the central cord which will be present in U. rubicunda.

Xanthoria have a similar orange coloration, but are foliose (some species minutely fruticose); they are much smaller in stature and more appressed than $T$. flavicans, which has an erect tufted growth habit.

\section{Range}

The current known and suspected range of Teloschistes flavicans in the Northwest Forest Plan area includes a five mile wide swath of coast in the Oregon and California Coast and Oregon Klamath Physiographic Provinces.

Teloschistes flavicans is rare throughout the range of the Northwest Forest Plan, occurring at five known sites in Oregon, where it reaches the northern limits of its current known range. In Oregon, the only substantial population is at Cape Lookout State Park. Minor populations occur at New River Area of Critical Environmental Concern (ACEC) (BLM), near Pacific City (BLM), Sand Lake, Cape Blanco State Park and Harris Beach State Park. In 2000, the coastal lichen study visited a total of 161 coastal sites from northern California to northern Washington. No new populations of T. flavicans were discovered (Glavich et al. 2000), and this species has never been found in Washington. Although there are no known sites in California in the Northwest Forest Plan area where suitable habitat exists, the presence of sites to the north and south suggests that it probably occurs in the California Coast Physiographic Province. Teloschistes flavicans is a widespread tropical and subtropical species that occurs sporadically along the west coast of the Americas from Ecuador to northern Oregon (McCune and Geiser 1997). It has become extremely rare along the eastern seaboard, but can still be found in the south and on the west coast (Brodo et al. 2001).

\section{Habitat}

In the Northwest Forest Plan area T. flavicans is confined to forested headlands and dunes of the coastal fog belt, especially on capes or peninsulas, at sites less than $200 \mathrm{~m}$ (600 ft) elevation (McCune et al. 1997). At Cape Lookout, T. flavicans is found on the twigs of Sitka spruce and is common in the litterfall of an old Sitka spruce forest on the long, forested headland of the peninsula. It grows on the boles and limbs of exposed Sitka spruce and Hooker's willow in an open Sitka spruce forest, on shore pine in a mature shore pine forest at the edge of a pasture, and in the twig litterfall of a small, old, mixed shore pine and Sitka spruce forest. In southern California (south of the Northwest Forest Plan area), T. flavicans grows on conifers and other trees (e.g. Quercus) in coastal scrub stands. One collection from San Mateo County is on sandstone. The abundance at known sites is unknown. 


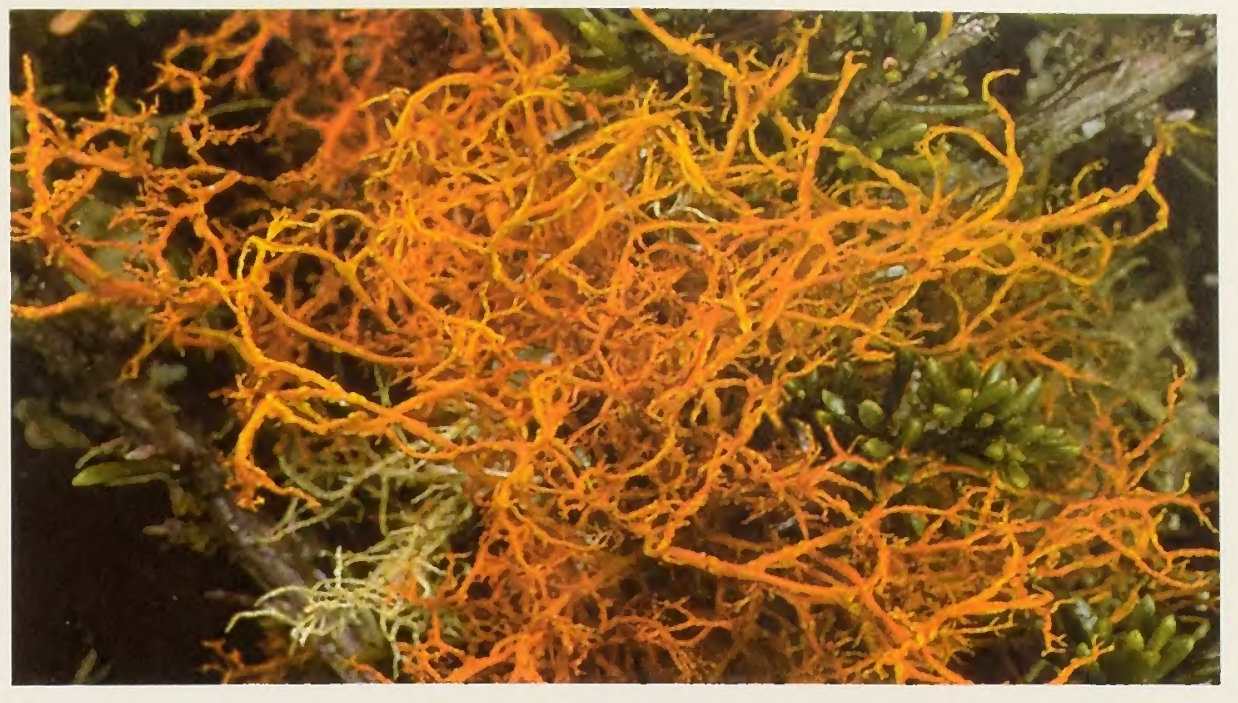

Figure 29. Teloschistes flavicans

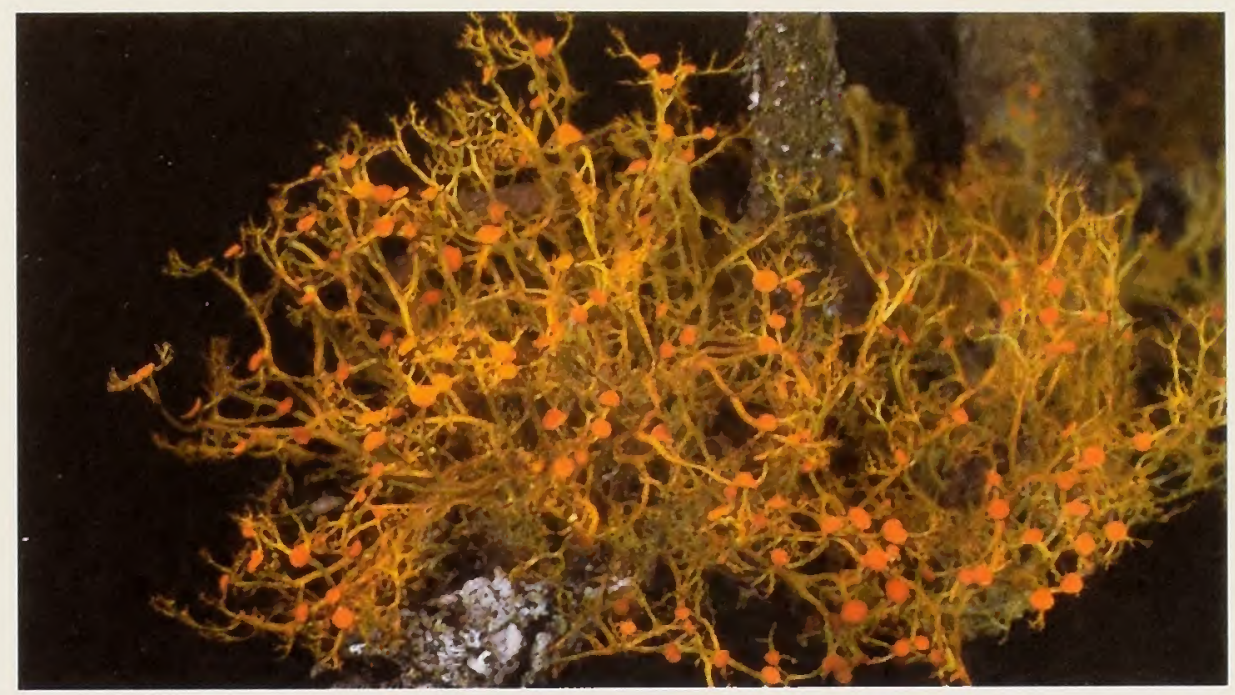

Figure 30. Teloschistes exilis

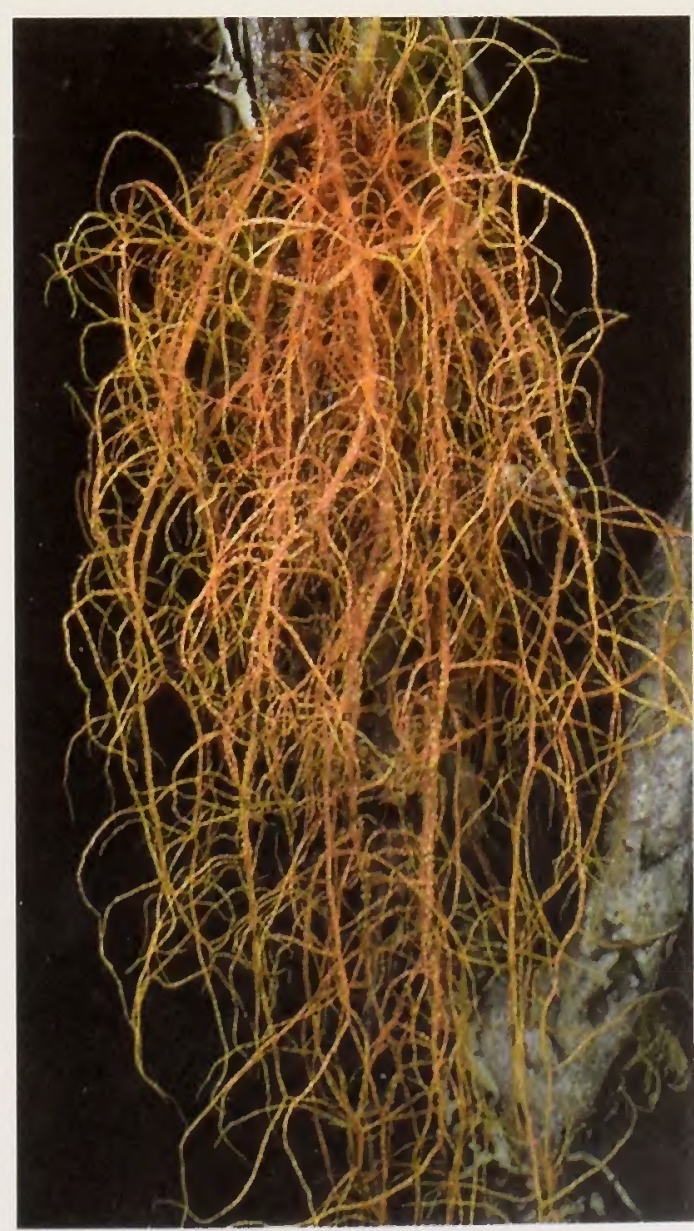

Figure 31. Usnea rubicunda 
2003 Survey Protocols for Category A \& C Lichens 


\section{Usnea longissima Ach.}

\section{A. Identification in the Field}

Usnen longissima (Figure 32) is usually easy to spot because of its distinct growth form. Look for a long, yellow-green fruticose lichen that looks like a $1 \mathrm{~cm}$ diameter living version of a feather boa. It often grows low in the canopy and on understory plants, but can also be high in the canopy. Some people mistakenly call it "Spanish moss" because, like that southern plant, it can festoon trees and shrubs with long billowing strands, and biomass can be quite high. The decorticate patches on the central stand are visible with a hand lens.

\section{B. Technical Description}

\section{Morphology}

Thallus fruticose, pendulous, to $3 \mathrm{~m}$ or more long, pale greenish or silveryyellowish green tinged; main branches very long and rarely dividing, with numerous dense, short perpendicular side branches and fibrils of about equal length $(3-40 \mathrm{~mm})$; papillae lacking; cortex smooth but disintegrating on the main stems, leaving rough patches of white medulla over the pinkish to brownish central cord; the central cord beneath the cortex is white (when exposed with a razor blade), but frequently turns pinkish or reddish brown in decorticate main branches; central cord very thick (usually making up about $60 \%$ of the diameter of the branch); soredia rarely present, emerging from raised pale spots; (Brodo et al. 2001, McCune 2000, McCune \& Geiser 1997).

\section{Chemistry}

Central axis I+B. Cortex and Medulla K-, C-, KC- PD- (with various combinations of evernic, diffractaic, barbatic, and 4-O-demethylbarbatic acids; sometimes with usnic acid only), rarely $\mathrm{K}+\mathrm{Y}-\mathrm{O}, \mathrm{PD}+\mathrm{O}$ (salacinic acid) (McCune 2000). Goward (1999) lists the chemistry for five different chemotypes, which may represent different species.

\section{Reproductive Structures}

Apothecia are extremely rare (Keon 2002); soredia are occasionally present, arising from raised pale spots (Doell \& Wright 2000, McCune 2000). This species primarily reproduces asexually by fragmentation of the main thallus, side branches and fibrils. The relatively large size of the propagules indicates an inherent dispersal limitation (Keon \& Muir 2002), with the majority of vegetative propagules dispersing only short distances, (i.e. typically less than 5 meters) from their source locations (Esseen 1985, Esseen et al. 1981). This species is considered to be dispersal limited at both stand and landscape levels across the Pacific Northwest (McCune \& Geiser 1997, Sillett et al. $2000 \mathrm{~b}$ ). Studies suggest that that the presence of populations in old-growth (i.e. tall) stands increases the possibility of dispersal and establishment of $U$. longissima onto adjacent substrates in suitable habitat, especially adjacent tree crowns where the species is most effective at continuing to disperse to other suitable habitats (Keon \& Muir 2002, Keon 1999). The finding that $U$. longissima transplants thrive in habitat that was predicted to be the least suitable (i.e. clear cuts) also suggests that dispersal limitations play a more 
significant role than the availability of suitable habitat in determining this species' distribution, and highlights the important role of colonized greentree retention in timber harvest areas (Keon \& Muir 2002, Keon 1999).

\section{Look-alikes}

The genus Usnea is notoriously difficult, with many of our North American species concepts being based on European material. Usnea longissima is one of a handful of (usually) easily recognizable Usneas, although it can be confused with other pendant species.

Alectoria sarmentosa contains usnic acid, giving it the same color as $U$. longissima. Typically their growth forms are very different, with $A$. sarmentosa having more pendants that lack perpendicular side branches, but single strands could be confused. It lacks the central cord which is diagnostic for all Usneas.

Ramalina menziesii (Figure 28) could be mistaken for U. longissima, particularly thin coastal specimens that lack the characteristic well-developed nets. Check for the presence of a central cord.

Small specimens of $U$. longissima can be confused with other pendant Usnea species, however $U$. longissima is the only species with an I+ violet or dark bluish central cord (McCune \& Geiser 1997). If you encounter one of these confusing pieces, continue to look for better developed material, and check for decorticate sections on the main axis.

The following references are invaluable to anyone wishing to better understand our rich Usnea flora:

- McCune \& Geiser (1997) provide an entry-level key to the common Usneas of the Northwest Forest Plan area. Since then, McCune (2000) has greatly reworked and updated his key to include the wealth of new information available for this difficult genus. This key is available online, under the heading "Download Updated Keys", at the following website: www.nwlichens.org

- Goward (1999) provides an easily to use comprehensive Usnea key with nice line drawings. A good companion reference is Halonen et al. (1998), the technical paper Goward is a co-author on; it expands on some of the species descriptions, habitat notes and ecology. Goward (1999) can be downloaded for free at: www.crownpub.bc.ca

- Tavares (1997) has written a preliminary key to Usnea in California, which can exhibit environmentally induced morphological variability. She also provides a glossary for many of the sometimes obscure features used to key Usneas.

- Brodo et al. (2001) provide a key to 79 species of North American Usneas, and excellent photographs for many of these species.

\section{Range}

The current known and suspected range of $U$. longissima in the Northwest Forest Plan area is all of Washington and Oregon except Eastern Cascades, and the California Klamath and Cascades Physiographic Provinces. Its distribution within its range is limited and patchy (Keon \& Muir 2002). In 
California, U. longissima is known from Del Norte, Humboldt, Siskiyou, Mendocino, Lake and Siskiyou, and Sonoma Counties, but not further south (Doell \& Wright 2000). Doell (1997) reported this species from Lake and Siskiyou Counties, however subsequent verification of those herbarium specimens indicated they were mis-identified (J. Doell pers. comm.). There are known sites on federal land in California at the Arcata field offices of the Arcata District BLM.

Due to a combination of anthropogenic influences such as habitat alteration and air quality degredation, $U$. longissima has declined significantly throughout its global range (Esseen et al.1981). This once-common circumboreal species is now considered endangered in many areas of Europe and Scandinavia (Ahti 1977). It was recently placed on the Red List of California Lichens, where it is considered rare (Doell \& Wright 2000).

\section{Habitat}

Although Usnea longissima was originally thought to be a riparian species (USDA \& USDI 1994, 2001), recent information (Keon 2002) suggests that the species has a broader ecological amplitude. Generally speaking, in the Northwest Forest Plan area, $U$. longissima occurs in old-growth and latesuccessional conifer stands, and in hardwood stands and riparian areas. It is typically infrequent but can be locally abundant in all habitat types. It can also grow in clear-cut and other young stands where there is suitable substrate (i.e. conifers and hardwoods) for colonization (Keon \& Muir 2002).

In the Oregon Coast Range, where extensive growth and habitat studies of $U$. longissima have been conducted (Keon \& Muir 2002; Keon 2002; Keon 1999), it tends to reach its greatest biomass in old-growth/late-successional stands on upper slopes or ridges (Keon 1999). In that study area, stand age was determined to be the most significant variable in predicting suitable habitat for $U$. longissima, with larger populations occurring in mature and old-growth stands (Keon 1999). However, concurrent transplant experiments using $U$. longissima revealed that transplants of this species into habitat predicted to be least suitable (i.e. very young clear cut stands) actually increased in biomass more than transplants into old-growth (Keon \& Muir 2002). This suggests that the presence of a nearby propagule source may be more important to dispersal and survival at both the local and landscape level than habitat characteristics (Keon \& Muir 2002). Remnant, or retention, trees (both conifers and hardwoods) function as sources of inoculum from which lichen propagules can disperse (Peck \& McCune 1997), and remnant trees also function as important "hotspots" of lichen diversity and abundance (Neitlich \& McCune 1997).

In British Columbia, $U$. longissima is frequent in localized areas in open, humid coastal localities, especially in old-growth forests at lower elevations where it primarily grows on conifers; it secondarily occurs on deciduous trees and shrubs (Goward 1999). Additional habitat information for mainly Washington and Oregon sites is available online from the Air Quality Database (USDA 1998): www.fs.fed.us/r6/aq

In California, U. longissima is distributed for the most part in old growth forests in the same ecological zone as the redwoods, although it does not necessarily grow on that substrate (Doell \& Wright 2000). Usnea longissima is found in the coastal mountains north of San Francisco, less than forty kilometers inland, at lower elevations (up to at least 2700 feet) where the 
climate is cool and moist (Doell \& Wright 2000). It may reach as far inland as $48 \mathrm{~km}$ in river canyons like the Van Duzen that receive a lot of coastal fog (D. Wright pers. comm.). Substrates include conifers, hardwoods and shrubs; this species reproduces by fragmentation and will grow on many substrates that it gets blown onto.

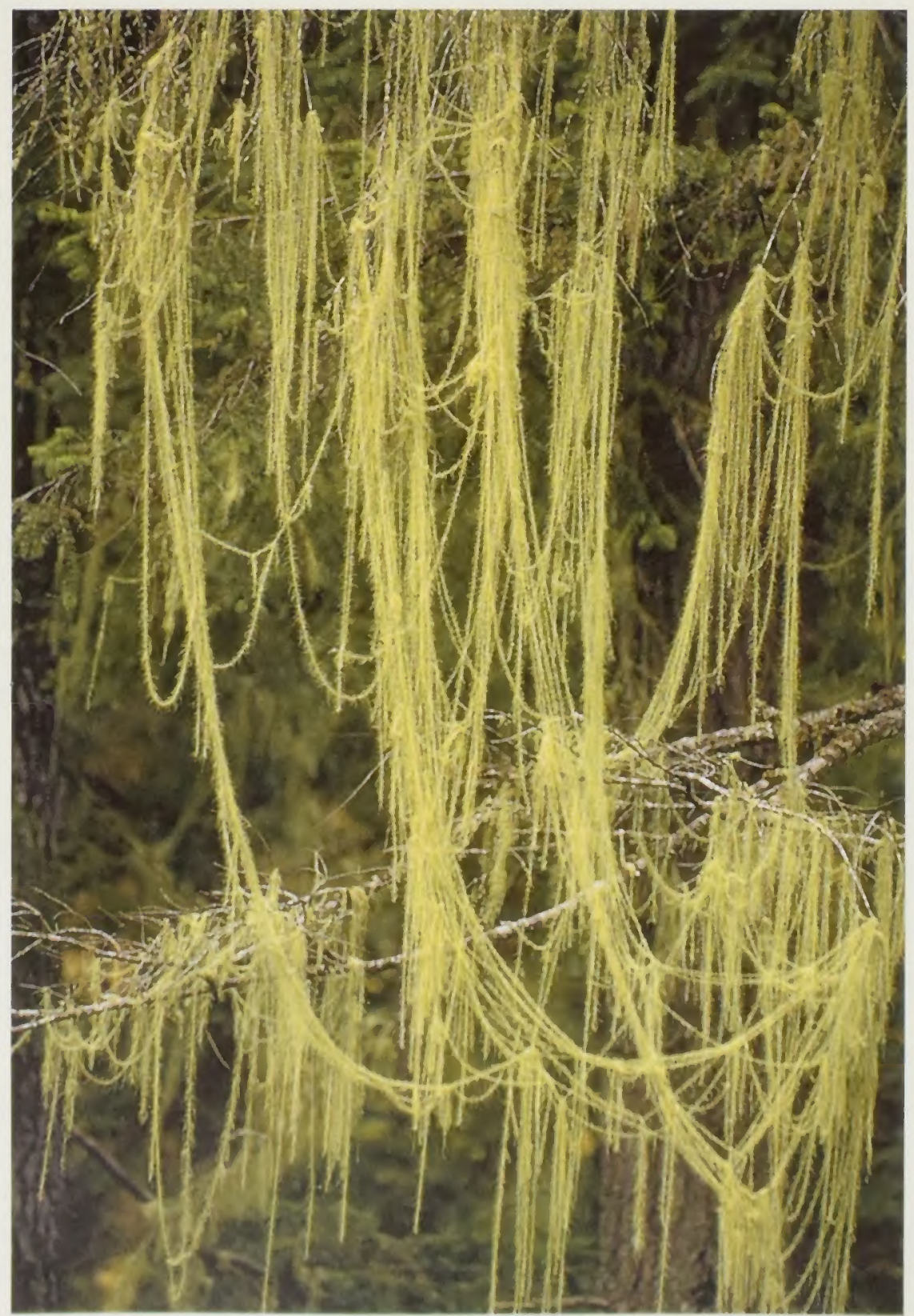

Figure 32. Usnea longissima 


\section{References}

Ahti, T. 1977. Lichens of the boreal coniferous zone. In: Seward, M.R.D. (ed.), Lichen ecology. Academic Press, New York, NY. Pp. 145-181.

Bowler, P.A. \& R.E. Riefner, Jr. 1995. Notes on the Ramalinaceae and current related research in California, USA. Bulletin of the California Lichen Society 2(1):1-5.

Brodo, I.M., S.D. Sharnoff \& S. Sharnoff. 2001. Lichens of North America. Yale University Press, New Haven, Connecticut. 795pp.

Brodo, I.M. \& D.L. Hawksworth. 1977. Alectoria and allied genera in North America. Opera Botanica 42:1-164.

Burnett, E. 2002. Personal communication. Seattle Lichen Guild.

Culberson, W.L. \& C.F. Culberson. 1968. The lichen genera Cetrelia and Parmelia (Parmeliaceae). Bulletin of the United States National Museum, Volume 34:449-558. Smithsonian Institution Press, Washington DC.

Derr, C.C. 1997. Air quality biomonitoring on the Chugach National Forest: Methods and baselines using lichens. Unpublished report, 113pp.

Dillman, K. 2002. Personal communication. Arizona State University, Tempe and Tongass National Forest, Ketchikan.

Doell, J. 2002. Personal Communication. California Lichen Society.

Doell, J. 1997. Usnea longissima Ach. In San Mateo County. Bulletin of the California Lichen Society. Vol. 4(1):6-7.

Doell, J. \& D. Wright. 2000. Usnea longissima in California. Bulletin of the California Lichen Society. Vol. 7(1):17-19.

Erwin, S. 2002. Personal communication. Shasta-Trinity National Forest.

Esseen, P.-A. 1985. Litter fall of epiphytic macrolichens in two old Picea abies forests in Sweden. Canadian Journal of Botany 63:980-987.

Esseen, P.-A, L. Ericson, H. Lindstrom \& O. Zackrisson. 1981. Occurrence and ecology of Usnea longissima in central Sweden. Lichenologist 13:177-190.

Esseen, P. and K. Renhorn. 1998. Edge Effects on an Epiphytic Lichen in Fragmented Forests. Conservation Biology 12(6), pp. 1307-1317.

Esslinger, T. L. 1997. A cumulative checklist for the lichen-forming, lichenicolous and allied fungi of the continental United States and Canada. North Dakota State University: http: / / www.ndsu.nodak.edu/ instruct/ esslinge/ chcklst/chcklst7.htm (First Posted 1 December 1997, Most Recent Update 27 August 2001), Fargo, North Dakota.

Geiser, L.H., K.L. Dillman, C.C. Derr \& M.C. Stensvold. 1998. Lichens and allied fungi of southeast Alaska. In: Lichenographia Thomsoniana: North American lichenology in honor of John W. Thomson. Eds: M.G. Glenn, R.C. Harris, R. Dirig \& M.S. Cole. Mycotaxon, Ithaca, NY. 1998.

Gilbert, O.L \& O.W. Purvis. 1996. Teloschistes flavicans in Great Britain: distribution and ecology. Lichenologist 28(6):493-506.

Glavich, D. 2002. Personal communication. California Lichen Society.

Glavich, D., L. Geiser \& A. Mikulin. 2000. Coastal lichen study. Corvallis, OR. Draft document.

Goward, T. 1999. The lichens of British Columbia, illustrated keys. Part 2, Fruticose species. Special report series (British Columbia Ministry of Forests); 9. 319pp.

Goward, T., McCune B. \& D. Meidinger. 1994. The Lichens of British Columbia. Part 1. Foliose and squamulose species. Ministry of Forests Research Program, British Columbia. 181 p.

Hale, M.E., Jr. \& M. Cole. 1988. Lichens of California. California Natural History Guides: 54. University of California Press, Berkeley, CA. 171 p.

Halonen, P., P. Clerc, T. Goward, I.M. Brodo \& K. Wulff. 1998. Synopsis of the genus Usnea (Lichenized Ascomycetes) in British Columbia, Canada. Bryologist 101:36-60. 
Harpel, J. 2002. Personal communication. Gifford Pinchot National Forest.

Hilmo, O. and H. Holien. 2002. Epiphytic Lichen Response to the Edge Environment in a Boreal Picea abies Forest in Central Norway. The Bryologist 105(1), pp. 48-56.

Holien, H. 1986. Bryoria tortuosa new to northern Europe. Lichenologist $18(3): 265-268$

Hoover, L. 2002. Personal communication. Six Rivers National Forest.

Jorgensen, P.M. 1973. On some Leptogium species with short Mallotiumhairs. Svensk Botanisk Tidskr 67:53-58.

Jorgensen, P.M. 1975. Contributions to a monograph of the Mallotium-hairy Leptogium species. Herzogia 3:433-460.

Jorgensen, P.M. 1994. Further notes on European taxa of the lichen genus Leptogium, with emphasis on the small species. Lichenologist 26: 1-29.

Jorgensen, P.M. 1997. Further notes on hairy Leptogium species. Symbolae botanicae Upsalienses 32: 113-130.

Jorgensen, P.M \& T. Goward. 1994. Two new Leptogium species from western North America. Acta Botanica Fennica 150: 75-78.

Jorgensen, P.M \& P.W. James. 1983. Studies on some Leptogium species of western Europe. Lichenologist 26: 109-125.

Jorgensen, P.M \& T. Tonsberg. 1999. Notes on some small species of Leptogium from Pacific North America. Bryologist 102: 412-417.

Keon, D.B. 2002. Fertile Usnea longissima in the Oregon Coast Range. Lichenologist 34:13-17.

Keon, D.B. \& P. S. Muir. 2002. Growth of Usnea longissima across a variety of habitats in the Oregon Coast Range. Bryologist 105:233-242.

Keon, D.B. 1999. Predicting presence of the sensitive lichen Usnea longissima in managed landscapes: a comparative multivariate anaylsis. Manuscript in prep. Oregon State University, Corvallis. 29pp.

Krog, H. 1968. The macrolichens of Alaska. Universitetsforlaget. Blindern, Oslo 3. 180pp.

Larsen, L. 2002. Personal communication. Humboldt State University.

McCune, B., J. Hutchinson, and S. Berryman. 2001. Concentration of Rare Lichens along Large Streams of the Central Cascades AMA. Unpublished report to USDA Forest Service, Willamette National Forest. 24 pp.

McCune, B. 2000. Usnea in the Pacific Northwest. 11pp. Available under "Download Updated Keys" at: www.nwlichens.org

McCune, B. \& L. Geiser. 1997. Macrolichens of the Pacific Northwest. Oregon State University Press, Corvallis, OR. 386 p.

McCune, B., R. Rosentreter, \& A. DeBolt. 1997. Biogeography of rare lichens from the coast of Oregon. pp. 234-241. In: T.N. Kaye, A. Liston, R.M. Love, D.L. Luoma, R.J. Meinke and M.V. Wilson (eds.). Conservation and Management of Native Plants and Fungi. Native Plant Society of Oregon, Corvallis, OR . 296 p.

McCune, B. \&T. Goward. 1995. Macrolichens of Northern Rocky Mountains. Mad River Press, Eureka, California. 208 pp.

McCune, B. 1993. Gradients in epiphyte biomass in three Psendotsuga-Tsuga forests of different ages in Western Oregon and Washington. Bryologist 96:405-411.

McFarland, J. 2002. Personal communication. Arcata Field Office, BLM.

Neitlich, P.N. \& B. McCune. 1997. Hotspots of epphytic lichen diversity in two young managed forests. Conservation Biology 11:172-182.

Peck, J.E. \& B. McCune. 1997. Remnant trees and canopy lichen communities in western Oregon: a retrospective approach. Ecological Applications 7:1181-1187.

Peterson, E.B. 2002. Personal communication. California Lichen Society. 
Peterson, E.B. \& B. McCune. 2001. Diversity and succession of epiphytic macrolichen communities in low-elevation managed conifer forests in western Oregon. Journal of Vegetation Science 12:511-524.

Ponzetti, J. 2001. Personal communication. Washington State Office, USDI Bureau of Land Management.

Rosso, A., B. McCune \& T.R. Rambo. 2000. Ecology and management of a rare, old-growth associated canopy lichen in a silvicultural landscape. Bryologist 103:117-127.

Ruchty, A. 2002. Personal communication. USDA Forest Service, Gifford Pinchot National Forest.

Rundel \& Bowler 1978. Niebla, a new generic name for the lichen genus Desmarieria (Ramalinaceae). Mycotaxon 6(3):497-499.

Sanders, W. 1997. Ramalina thrausta (Ach.) Nyl. in California. Bulletin of the California Lichen Society 4(1): 6 .

Sholars, T. 2002. Personal communication, California Lichen Society. College of the Redwoods, Fort Bragg, Califnornia.

Sierk, H.A. 1964. The genus Leptogium in North America north of Mexico. The Bryologist: 67:245-316.

Sillett, S. C. 1994. Growth Rates of Two Epiphytic Cyanolichen Species at the Edge and in the Interior of a 700-year-old Douglas fir Forest in the Western Cascades of Oregon. The Bryologist 97(3), pp. 321-324.

Sillett, S. C., B. McCune, J. E. Peck, and T. R. Rambo. 2000a. Four Years of Epiphyte Colonization in Douglas-fir Forest Canopies. The Bryologist 103(4), pp. 661-669

Sillett, S.C., B. McCune, J.E. Peck, T.R. Rambo \& A. Ruchty. 2000b. Dispersal limitations of epiphytic lichens result in species dependent on old-growth forests. Ecological Applications 10:789-799.

Smith, A. 2002. Personal communication. Willamette National Forest.

Spjut, R.W. 1995. Vermilacinia (Ramalinaceae, Lecanorales), a new genus of lichens. IN: Contributions to lichenology in honour of Gerhard Follmann. Edited by: Daniels, F.J.A., M. Schultz \& J. Peinne. Botanical Institute, University of cologne, Cologne, Germany: 337-351.

Spjut, R.W. 1996. Niebla and Vermilacinia (Ramalinaceae) from California and Baja California. Sida, Botanical Miscellany 14: 1-208.

Tavares, I.I. 2002. Personal communication. University of California, Berkeley.

Tavares, I.I. 1997. A preliminary key to Usnea in California. Bulletin of the California Lichen Society. Vol. 4:19-23.

Tucker, S. 2001. New reports for California in Lichens of North America. Bulletin of the California Lichen Society 8(2), 59-71.

USDA Forest Service. 1998. See website for lichens and air quality in the Pacific Northwest Region: www.fs.fed.us/r6/aq.

USDA Forest Service \& USDI Bureau of Land Management. 2001. Record of Decision and standards and guidelines for amendments to the survey and manage, protection buffer, and other mitigation measures standards and guidelines.

USDA Forest Service \& USDI Bureau of Land Management. 1994. Standards and guidelines for management of habitat for late-successional and oldgrowth forest related species within the range of the northern spotted owl.

White, F.J. \& P.W. James. 1985. A new guide to microchemical techniques for the identification of lichen substances. British Lichen Society Bulletin 57 (supplement)

Wirth, V. 1995. Die Flechten Baden-Wurttembergs. 2 vols. Eugen Ulmer GmbH \& Co., Stuttgart.

Wright, D. 2002. Personal communication. California Lichen Society. 
2003 Survey Protocols for Category A \& C Lichens 
Appendix A

Lichen \& Bryophyte Species Location Field Form \& Instructions 
2003 Survey Protocols for Category A \& C Lichens 


\section{Species Location Field Form}

Scientific Name:

LOC ID:

Flora Species Location Table

Survey Date:

Landform*:

Aspect (deg.):

Soil*: Admin, Unit*: Area(ac):

Elev:

Moisture*:
Sub Admin..*: Bedrock*:

Slope \%:

Flagging Color:

General Location:

LAND USE ALLOCATION: Matrix, AMA, LSR, Riparian Rsv, Wilderness, Admin. Withdrawn, Other:

Directions:

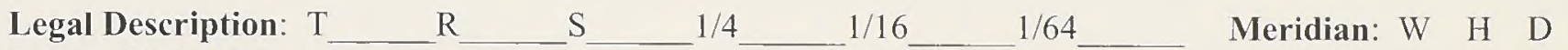

State: WA OR CA County: C USGS Quad: $\quad 7.5 \mathrm{~min} / 15 \mathrm{~min}$

UTM COORDINATES: $\quad$ E $\quad$ N Zone: 10

GPS Unit Used: $\quad$ Datum: NAD-27 Accuracy: \pm _ $\mathrm{ft}$

Notes:

\section{$\underline{\text { Surveys }}$}

Survey ID:

Project Name:

Protocol: $\mathrm{Y} / \mathrm{N}$

Survey Method: Casual Observation, Complete, Cursory, Incidental, Intuitive Controlled, Unspecified

Observers(s):

Notes:

\section{Community Observations}

Plant Community:

Community Age: ___ (Estimate? Tree core? Stand exam?) Light: full sun, partial shade, or full-shade

Stand Structure: even-aged, multi-aged, all-aged, even-aged w/residual trees, even-aged w/ legacy structure

Successional Stage: pioneer ( $<20 \mathrm{yrs})$, young (20-39 yrs) mid (40-79 yrs), late ( $80-200 \mathrm{yrs})$, old (200-500 yrs), very old $(>500)$

Stand Size (DBH): sapling (1-4.9"), pole(5-8.9"), medium(9-20.9"), large(21-31.9") giant(32-47.9") remnant(>48") Notes:

\section{Flora Species Observations}

Abundance: Rare (1-3/acre) Uncommon (4-10/acre) Common (11-40/acre) Abundant (>40/acre)

Substrate:

Distribution: isolated location, clumpy, scattered-even, scattered-patchy:

Associated Species:

\section{Flora Species Collections}

Collector:

Date sent to taxa expert:

Verified by:

Location of voucher:
Col. No.:

Date:

Ver. Date:

Attach specimen in completed voucher packet and send to Taxa Expert for Verification Attaeh maps showing speeies locations.

* fields have pick list in ISMS 


\section{Species Location Field Form}

\begin{tabular}{|c|c|c|c|c|c|c|c|}
\hline \multicolumn{4}{|c|}{ Flora Observations Table: } & \multicolumn{4}{|c|}{ Feature Observations Table: } \\
\hline $\begin{array}{c}\text { SPECIES } \\
\text { CODE }\end{array}$ & Species Name & $\begin{array}{l}\text { TOTAL } \\
\text { QUANT. }\end{array}$ & Phenology* & $\begin{array}{c}\text { Feature } \\
\text { Type }\end{array}$ & $\begin{array}{l}\text { Feature } \\
\text { Species }\end{array}$ & $\begin{array}{l}\text { Decay } \\
\text { Class }\end{array}$ & DBH \\
\hline & & & & & & & \\
\hline & & & & & & & \\
\hline & & & & & & & \\
\hline & & & & & & & \\
\hline & & & & & & & \\
\hline & & & & & & & \\
\hline & & & & & & & \\
\hline & & & & & & & \\
\hline & & & & & & & \\
\hline & & & & & & & \\
\hline & & & & & & & \\
\hline & & & & & & & \\
\hline & & & & & & & \\
\hline & & & & & & & \\
\hline & & & & & & & \\
\hline & & & & & & & \\
\hline & & & & & & & \\
\hline & & & & & & & \\
\hline & & & & & & & \\
\hline & & & & & & & \\
\hline & & & & & & & \\
\hline & & & & & & & \\
\hline
\end{tabular}

* Picklist items for Phenology: Bud, Dead, Dormant, Flower, Fruit, Imm. Flower, Imm. Fruit, Regrowth, Seed, Senescent, Spore/Cone, Vegetative, WO_Sporophyte, W Sporophyte 


\section{Species Location Field Form Instructions}

Listed below are instructions for completing the species Location Field Form. The form must be completed for each location where Survey \& Manage species are detected. A geographic co-ordinate is required to describe the location, either UTM or Latitude/longitude. This may be acquired directly with GPS units in the field or entered after the field visit by consulting aerial photographs, ortho-quad maps, or other maps. The map source field is used to document the method used to determine this coordinate pair. The center of a sample area may be used as the location coordinate when several species are located within a single sample area, so that all species can be recorded in a single location record. In ISMS, enter the data into the Flora Brief form.

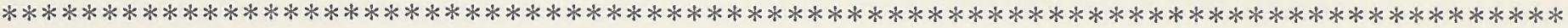

FLORA SPECIES LOCATION information captures spatial and physical information; which is used to identify and locate the site.

Scientific Name Use currently accepted scientific name.

SpeciesLocation ID- Assign a unique ID\# to each S\&M site. A suggested format is a 2-character value for project name; a 3 -character value representing the unit (use zeros to fill in where needed, e.g. unit 5 would be 005 ).

Survey Date

*Admin Unit-

*Sub Admin-

*Landform

$\operatorname{Area}(\mathrm{Ac})$

*Bedrock

Aspect $^{0}$

Elev.

Slope

*Soil-
Enter the day, month (in 3 letter code, e.g. Jan), and year, (e.g.05/Oct/1999).

Enter the ISMS code for the administrative unit responsible for managing this species location, (ie. Forest or BLM District). Refer to ISMS codes sheets or pick lists for values. Example: FS0510 = Forest Service, Region 5, Forest 10 (Six Rivers N.F.)

Enter the administrative sub-unit responsible for managing this species location (ie. Ranger district or BLM resource area). Refer to ISMS codes sheets or pick lists for values. Southriver $=$ BLM, Roseburg District, Southriver Resource Area

Use ISMS pick list to obtain the value that best describes the site position where the species observation was made.

Total area surveyed, in acres.

Use ISMS pick list.

Aspect is recorded using a compass. It is determined by the direction the general slope is facing and is recorded in degrees. Do not enter zero as a null value. Use $360^{\circ}$ for north.

Record the elevation of the species location site in feet.

Slope is measured in percent and determined using a clinometer, compass, or visual estimate. Record \% slope based on the general topography at the site.

Record the soil type at the species location. Refer to ISMS pick list of values. 
*Moisture- $\quad$ Use the pick list values in ISMS.

Flagging color If flagging is used to mark a site, record the color of the flagging.

General Location Provide a general description of the species location.

Land Use Allocation Circle the value that best represents the land use allocation where the species location occurs.

Directions Provide detailed directions to the species location, include driving directions and directions to the site off of the road.

Legal Description, State, County, USGS quad. Fill in appropriate response.

UTM Coordinates Record UTME and UTMN coordinates (to the nearest whole number).

Notes Provide any notes relevant to the species location.

SURVEY INFORMATION: Due to the structure of the ISMS database, each location record must be able to stand alone, and provide its own record of some required survey information. Some of the following fields duplicate fields found in the General Survey Data Form.

Survey ID- $\quad$ This is not a required field, due to the possibility that some locations may be documented which are not the result of a survey. For records that are the result of a survey, enter the same Survey ID \# as used on the Survey Data Form for this survey. In this way, information contained in either table can be used to describe a record and may be queried together for reports. It is imperative that similar numbers and letters be entered clearly.

Project Name

Enter the name of the project within which this survey was conducted. This name is designated by the local field unit, may be character and/or numeric.

Protocol

Circle $\mathrm{Y}$ or $\mathrm{N}$ to indicate whether the survey which resulted in this location record was done to protocol standards.

*Survey Method Circle the method used for this survey.

Observers - $\quad$ Enter the last names of surveyors conducting the survey, separated by a forward slash, up to 50 characters total.

Notes

Provide any notes relevant to the survey.

COMMUNITY OBSERVATIONS are used to document the plant community found within one tree height potential of the species location. If the plant community is significantly different closer to the actual site, conditions in this smaller area are described. To identify the plant association, use the appropriate Plant Association guide for the specific geographic region that you are surveying. 
*Plant Community Enter Ecoclass association and the plant/vegetation series or association which best matches the local site. Use the standard ISMS value list provided for plant series/subseries/association. The ISMS code for this community name will be automatically entered by the ISMS program, however you may record either name or code and the corresponding value will be entered.

Community Age Enter the age of the plant community within one tree height potential of the site location. This is generally determined to be the age of the oldest trees present at the site. Circle method for determining age.

*Light Circle appropriate response.

*Stand Structure Circle the number of tree canopy layers present at the site location from the list given.

*Successional Stage Circle the seral stage that best describes the average successional stage of the vegetation in the species location area. The stand age in parenthesis is provided as a general rule of thumb but may not be applicable in multiple-aged stands. Use whatever local standard is germane to the stand in question.

*Stand Size Circle the best response.

Notes

Provide any notes relevant to the vegetation community in which the species location occurs.

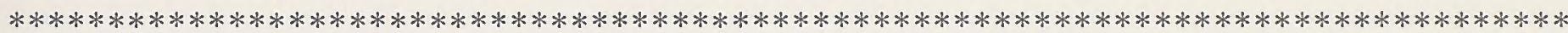

FLORA SPECIES OBSERVATIONS are recorded on individual rows of the field form table for each species located at a site. Additional information pertaining to each species is entered on the form in the same row. Explanations of these fields are given below.

*Abundance Circle appropriate value.

Substrate For lichens and bryophytes, record the immediate substrates(s) that the organism is on.

*Distribution Circle appropriate value.

Associated Species List other species of interest found in the stand.

\section{Flora Species Collections}

Complete the following fields for that record to describe the collection information. Enter this information in ISMS within the Collections table of the Affiliate section.

Collector Enter the name of the person(s) who actually collected the specimen.

Collection Number Enter the collector's collection number. This is usually a sequential number that is recorded for all collections made by that individual in their lifetime. It is usually recorded in a log book so that the collector may relate voucher verification with the specific specimen in question. 
Collection date Record date of collection in field.

Date sent to taxa expert Record date specimen was sent to taxa expert for verification for tracking purposes.

Verified by Enter the name of the person who does the final verification of the species.

Verification date Enter date that the specimen was verified

Location of voucher Enter location of the voucher. In most cases this should be a regional University Herbarium.

Go to table on back side of form and ender the following information:

*Species Code- $\quad$ Enter the four to five digit alphanumeric code for plants only as listed in the ISMS species codes list or the USDA PLANTS database. No other codes should be entered for any reason. Any species, including those not currently on the Survey and Manage list, but for which it may be important to keep records of known sites for future listing, may be recorded.

Species Name Enter the name of species at the site location. Unless the surveyor is absolutely certain of the species code this field should be completed.

Total Enter the number of stems or individuals described in this record.

*Phenology Use ISMS pick list values.

Feature observations:

Feature type

Determine the appropriate structure that best represents where the specimen was detected. The data entry program will only take one feature per record per site. For multiple detections of the same species, list the feature that describes the most

Feature species common associated feature. Select the feature type from the ISMS picklist.

Decay Class

If a plant is found in association with logs or woody_debris, list the appropriate decay class (Brown 1985). $0=$ Not applicable. $1=$ Log, recently fallen, bark intact or snag with fine limbs present. $2=$ Log, bark intact, small twigs absent or snag with $50 \%$ loose bark. $3=\mathrm{Log}$, trace of bark or snag with bole form intact. $4=\mathrm{Log}$, bark absent or snag, losing bole shape. $5=\mathrm{Log}$, decomposed or snag, form mostly gone.

DBH

If a plant is found in association with a tree, snag, log or woody debris feature, list the diameter at breast height (standing tree) or the largest diameter for down wood. This is an important indicator of late seral legacy association. 
Appendix B

Lichen \& Bryophyte General Survey Field Form \& Instructions 
2003 Survey Protocols for Category A E C Lichens 


\section{General Survey Field Form}

NOTE: All bold fields are to be completed on this form. All uppercase-bold fields are to be entered into the ISMS database. All fields marked by an * have a limited list of values (picklist) in the ISMS database.

General Survey Location

SURVEY LOCATION ID\#

ADMIN. UNIT*:

Landform*:

Soil*:

ELEV. (average) ft:

Location Directions
SURVEY DATE: SUB ADMIN*: Bedrock*: Moisture*: SLOPE:
\% Survey ID:

LEGAL DESCRIPTION: $\mathrm{T}$
$\begin{aligned} & \text { State: WA OR CA County: } \\ & \text { UTM COORDINATES: }\end{aligned}$
$\begin{aligned} & \text { GPS Unit Used: } \\ & \text { Accuracy: }+\end{aligned}$ ft. No. of Readings taken:

Accuracy: \pm ft. No. of Readings taken: No. of Satellites:

LAND USE ALLOCATION: Matrix/AMA, LSR, Riparian Rsv, Wilderness, Admin. Withdrawn, Other:

Location Notes:

\section{Survevs}

SURVEY TYPE*: Pre-Disturbance, Purposive, CVS FIA Strat Surv, Incidental, Known Site Strat Surv,

Monitoring, Other non-Strat Surv, Other Strat Surv, Species Specific, Unspecified Survey ID:

Project Name:

Protocol*: $\quad \mathrm{Y}$ N Unspecified

SURVEY METHOD*: Casual Observation, Complete, Cursory, Incidental, Intuitive Controlled, Unspecified

OBSERVER(S):

Survey Notes:

Species Table: This is a list of the Survey \& Manage species that were searched for. The Presence field should be marked with Y (yes), N (no), or U (unknown) to indicate whether or not the species was found.

\begin{tabular}{|l|l|l|l|l|l|l|l|l|}
\hline $\begin{array}{c}\text { SPECIES } \\
\text { CODE* }\end{array}$ & PRESENCE* & $\begin{array}{c}\text { Total } \\
\text { Quantity }\end{array}$ & $\begin{array}{c}\text { Species } \\
\text { Loc ID }\end{array}$ & $\begin{array}{c}\text { SPECIES } \\
\text { CODE* }\end{array}$ & PRESENCE* & $\begin{array}{c}\text { Total } \\
\text { Quantity }\end{array}$ & $\begin{array}{c}\text { Species } \\
\text { Loc ID }\end{array}$ \\
\hline & & & & & & & \\
\hline & & & & & & & & \\
\hline & & & & & & & & \\
\hline & & & & & & & & \\
\hline & & & & & & & & \\
\hline
\end{tabular}




\section{General Survey Field Form Instructions}

The General Survey Field Form should be completed for documentation purposes for each visit to a survey area (generally defined as a project unit or other similar-sized area which is surveyed at one time). A separate form should be used for separate portions of a project area, such as different units or portions of a unit, that are not physically adjacent (e.g. cannot be illustrated with a single polygon). A complete summary of the survey effort completed for one timber sale may, for instance, consist of several General Survey Field Forms, one for each visit to each unit, and possibly more if any unit requires multiple surveys to complete a single visit. The use of a regular format for the Survey Loc. ID (see below) will help to identify all records that pertain to a single project. This field form will need to be completed even if no target species are found in order to document that the survey effort was conducted to the correct protocol standards. Some fields require the use of a limited set of values used by the ISMS database. Additional fields are included for organization and tracking. For each individual site where a target species is found, an additional form (Species Locations Field Form) is completed with information pertinent to that location. Complete the General Survey Field Form in the field as surveys are done.

Neat and clean handwriting cannot be stressed enough. Please take a couple of extra seconds to ensure that your handwriting is clear and that unique letters and numbers are discernable.

$* * * * * * * *$

FLORA SPECIES LOCATION. Information in the Flora General Survey Locations Table captures the spatial and physical information which is used to identify and locate the survey area. This information is linked to the polygon in GIS which represents the survey area. Each visit to the same survey area should contain identical information in this section.

Survey Loc.ID- $\quad$ This is a unique ID\# for the survey area being documented. This may be character and/or numeric. A suggested format is: two-letter abbreviations identifying the Forest/BLM District, ranger district/resource area, and project name; plus a 2character value representing the unit (use zeros to fill in where needed, e.g. unit 5 would be 05) For example, Six Rivers National Forest, Mad River district, project Upper Mad, unit 5A is identified as SRMRUM05A.

\section{Survey Date}

*Admin Unit-

*Sub Admin-

\section{*Landform}

$\operatorname{Area}(\mathrm{Ac})$
Enter the day, month (in 3 letter code, e.g. Jan), and year, (e.g.05/Oct/1999).

Enter the ISMS code for the administrative unit responsible for managing this species location, (i.e. Forest or BLM District). Refer to ISMS codes sheets or pick lists for values. Example: FS0510= Forest Service, Region 5, Forest 10 (Six Rivers N.F.)

Enter the administrative sub-unit responsible for managing this species location (ie. Ranger district or BLM resource area). Refer to ISMS codes sheets or pick lists for values. Southriver = BLM, Roseburg District, Southriver Resource Area

Use ISMS pick list to obtain the value that best describes the site position where the species observation was made.

This field is be used to record the total number of acres in the survey area, individual unit of a sale or other identified survey area being recorded. This is the area of the polygon in GIS to which this survey location description is linked. This number may be equal to or larger than the actual number of acres surveyed during an individual visit. 
*Bedrock

*Soil-

Aspect $^{0}$

*Moisture-

ELEV(avg)

Min., Max.

Slope

Survey ID-
Use ISMS pick list.

Record the soil type at the species location. Refer to ISMS pick list of values.

Aspect is recorded using a compass. It is determined by the direction the general slope is facing and is recorded in degrees. Do not enter zero as a null value. Use $360^{\circ}$ for north.

Use the pick list values in ISMS.

Give the average elevation (feet) within the survey area. The average elevation is Required data. Elevation can be obtained from topographical maps or with calibrated altimeters.

Identify the lowest and highest point in the survey area.

Slope is measured in percent and determined using a clinometer, compass, or visual estimate. Record \% slope based on the general topography at the site.

Enter a unique ID \# for this survey visit. For tracking purposes, this should be the Survey Loc ID\# of the area being surveyed (above) plus a "1" or "2" which indicates the first or second visit to that area. There is additional space for indexing if needed. For example, Six Rivers National Forest, Mad River district, project Upper Mad, unit $5 \mathrm{~A}$, visit number one is identified as SRMRUM05A-1. Enter the same Survey ID as is used on the Species Locations Field Forms for this survey. In this way, information contained in either table can be used to describe a record and may be queried together for reports. It is imperative that similar numbers and letters be entered clearly.

Location Directions Provide detailed directions to the species location, include driving directions and directions to the site off of the road.

Legal Description Using a topographical map determine the Township, Range, and Section, Quarter Section, and Sixteenth Section of the survey area being documented. If the area is in more then one Section, quarter section, etc., record the one which represents the largest portion. If detail to the sixteenth section is not appropriate, limit data entry to the best quarter township.

UTM Coordinates Record UTME and UTMN coordinates (to the nearest whole number).

*Accuracy-

Estimate how close you think the map location is to the actual site on the ground. Use the pick list values in ISMS.

Land Use Allocation Circle the value that best represents the land use allocation where the species location occurs. 
Notes

Provide any notes relevant to the species location.

SURVEY INFORMATION: Due to the structure of the ISMS database, each location record must be able to stand alone, and provide its own record of some required survey information. Some of the following fields duplicate fields found in the General Survey Data Form.

*Survey Type Circle one of the values that best corresponds to the type of survey being documented. (ie. Pre-disturbance, Purposive, etc.)

Project Name Enter the name of the project within which this survey was conducted. This name is designated by the local field unit, may be character and/or numeric.

Protocol

Circle $\mathrm{Y}$ or $\mathrm{N}$ to indicate whether the survey which resulted in this location record was done to protocol standards.

*Survey Method Circle the method used for this survey.

Observers - $\quad$ Enter the last names of surveyors conducting the survey, separated by a forward slash, up to 50 characters total.

Notes

Provide any notes relevant to the survey.

FLORA SPECIES TABLE records all plant species that were searched for or encountered during the course of a survey visit. This list includes all Survey and Manage target species and may also be used to document any other common species found during the survey. These additional species observations help to document that a survey was done during appropriate weather.

*Species Code: $\quad$ Enter the four to five digit alphanumeric code (as listed in the attached ISMS species code list) for any species of vascular plant searched for or observed during the survey visit. This species list includes both Survey and Manage species for which surveys are required and other species. Additional species may also be documented in the Survey Notes.

Presence- $\quad$ For each species recorded, indicate if it was present or not (ie. a target S\&M species may have been searched for, but not found).

Total Quantity- $\quad$ Record the total number of stems or individuals found during the entire survey visit.

Species Loc ID- $\quad$ The Species Location ID (from the corresponding Species Location Field Form) can be recorded for Survey and Manage species as a cross-reference to those location records.

* fields with an asterisk have a pick list of values in ISMS 


\section{Appendix C}

Lichen \& Bryophyte Collection Packet Form for Voucher Specimens 
Notes:

BRYOPHYTES or LICHENS OF:

Admin. Unit:

Taxon:

State:__ County:___ Location:

T__ R_______ Meridian: D, H, w; UTM n:

UTM e:

Zone:

Substrate \& Site Characteristics (circle all that apply):

Soil: mineral soil, gravel, sand, loam, silt, clay, litter, duff, humus, peat, moss, or litter-fall

Rock type: granitie, serpentine, metamorphie, sedimentary, voleanie, or caleareous

Rock feature: outcrop, boulder, cliff, crevice, ledge, talus, or under-hang

Tree or Shrub: species:

location: base, trunk, branch, root, stump,

snag, recently fallen tree, rotten $\log$ (decay class: ), bark, wood, or tree root-wad

Light: full sun, partial shade, full shade Elevation: ft. Slope: $\%$ Aspect:

Topography: cut bank, ditch, meadow, roadside, ridge, slope, trail, or valley

Habitat: bog/fen, dense/open/eut forest, lake/pond, meadow, seep, spring, swamp, waterfall, stream/creek/river (intermittent), wetland, seasonally wet area, splash zone, or submerged

Site Moisture Regime: dry, mesie, moist, or wet

Coll. No.

Coll. Date:

Verified by:

Date: Notes: 


\section{Vouchering Policy for Purposive Surveys}

1. How much to voucher?

If there isn't very much material i.e. if there are only 1 or 2 bent setas ( $T$. geniculata) then it would be best to not remove any material. Instead look in and round the rest of the plot to see if more populations are present and if enough material is present then make a voucher. If a voucher is not collected it's very important to note that on the target species plot card. Often I use the 1 in 20 rule when vouchering a species.

2. Please use the voucher packet provided.

This will help us to keep the data consistent and it will also give us enough information to make each collection a valuable contribution to science. Finally the data on the packet corresponds to the ISMS database forms, which will make data entry easier.

3. You must assign a personal collecting number to each packet.

This can be any numbering system that you are already using but it should be a unique number for each packet. If you don't have a personal numbering system you could develop a system that includes your initials, the year and a number, i.e. JAHO0-1 etc. This unique collection number is important because it allows us to communicate about a specific collection.

4. Please fill in the blanks and circle the appropriate fields on each packet. It is important to be sure and put the CVS and S\&M plot numbers on each packet. 


\section{Appendix D}

Jan. 9, 2002 Memo: Centralized Process to Identify/Verify Survey \& Manage Specimens Collected While Conducting Surveys 
2003 Survey Protocols for Category A \& C Lichens 


\begin{tabular}{|c|c|c|c|c|c|}
\hline $\begin{array}{l}\text { United States } \\
\text { Department of } \\
\text { Agriculture }\end{array}$ & $\begin{array}{l}\text { Forest } \\
\text { Service }\end{array}$ & $\begin{array}{l}R-6 \\
R-5\end{array}$ & $\begin{array}{l}\text { OR/ } \\
\text { WA } \\
\text { CA }\end{array}$ & $\begin{array}{l}\text { Bureau of } \\
\text { Land } \\
\text { Management }\end{array}$ & $\begin{array}{l}\text { United States } \\
\text { Department of } \\
\text { Interior }\end{array}$ \\
\hline
\end{tabular}

\section{Reply Refer To: 2630(FS)/1736-PFP (BLM) (OR-935) P Date: January 29, 2002}

\section{EMS TRANSMISSION BLM-Information Bulletin No. OR-2002-}

To: $\quad$ USDA Forest Service Forest Supervisors: Regions 5 and 6; USDI Bureau of Land Management District Managers: Coos Bay, Eugene, Lakeview, Medford, Roseburg and Salem and Field Managers: Klamath Falls and Tillamook, OR and Arcata, Redding and Ukiah, CA

Subject: Centralized Process to Identify/Verify Survey and Manage Specimens Collected While Conducting Surveys

Pre-disturbance and strategic surveys are required for the majority of Survey and Manage (S\&M) species under the Record of Decision and Standards and Guidelines for Amendments to the S\&M, Protection Buffer and other Mitigation Measures. In recent years, a large number of known/suspected S\&M specimens have been collected as a result of these surveys. Many of these specimens/species are very difficult to identify and require identification/verification from taxonomic experts.

This memorandum describes a centralized process (Enclosure 1) for identifying known and suspected S\&M specimens (or those unknown specimens that cannot be identified) collected while conducting surveys. This procedure is essential to ensure that specimens are handled in a consistent manner and the data is standardized so it can be effectively used in the Annual Species Review process and amending management recommendations and survey protocols. Deviation from this procedure may lead to data not being considered in the Annual Species Review.

Field units conducting pre-disturbance and strategic surveys are asked to do the following with specimens collected from these surveys:

- Specimens (known/suspected S\&M species and those that cannot be identified) collected from these surveys must be sent to the interagency taxa expert for identification/verification. One specimen of lichens, bryophytes, and fungi should be collected at each potential site, whereas one mollusk specimen per survey area should be collected.

- Specimens collected from previous surveys, which have not been identified through the interagency taxa expert should be sent to them for verification. 
A centralized system for identifying/verifying and cataloging voucher specimens will greatly improve data quality and consistency. The taxa expert's role will include quality Survey and Manage control of specimen identifications to ensure consistency. Regional level contracts have been ore are in the process of being awarded; and qualified agency personnel have been hired to ensure that identifications are consistent and correct.

Centralized contracting through the regional offices is the most fiscally efficient method and also reduces competition for the limited number of available taxonomic experts.

It is expected that S\&M specimen identifications and field notification should take no longer than ten weeks (from the time they are received by the taxa expert). Field offices should include in enough project planning time for the identification of S\&M specimens.

Further questions can be directed to any of the interagency taxa experts (Enclosure 2) or Bruce Rittenhouse, Strategic Survey Coordinator, at 503-808-2984.

\section{is/ Terry Brumley}

TERRY L. BRUMLEY

Survey and Manage Program Manager

Enclosures 
cc:

FS Region 6

R. Huff

Richard Helliwell

T. Brumley

Kathleen Cushman

Judy Harpel

Mark Huff

Peggy Kain

Pat Ormsbee

Chiska Derr

Deb Quintana-Coyer
BLM Distribution

WO-230 (Room 204 LS) - 1

CA-330 (Paul Roush) - 1

CA-930 - 1

OR-930 (Ed Shepard) -1

OR-933 (Janis VanWyhe) - 1

OR-935 (Neal Middlebrook,

Russell Holmes, Kelli Van Norman,

Stephanie Sprague, Paul Hohenlohe,

Bruce Rittenhouse, Nancy Duncan) - 7

FS Region 5

Paula Crumpton

Jan Ford

David Diaz

Bob Mobley

Kathy Anderson

FS PNW

Randy Molina

Tina Dreisbach

Dede Olson

Mike Castellano

Brian Biswell

FWS:

Barbara Amidon, Laura Finley,

Monty Knudsen,

Steve Morey,

Heather Hollis

REO:

Jay Watson,

Debbie Pietrzak

K:Inrlserviccs\correspondencelbrumley\2630_centralizedprocesstoID_verify_SMspecime ns.doc

Edit: canderson: NR98: 1/25/02

Reedited per BLM 1/29/02 


\section{Enclosure 1 Specimen Processing Description}

The following requirements for voucher collections needing identification/verification will apply to all pre-disturbance and strategic survey fungi, lichen, bryophyte, and mollusk specimens. Field units are required to send all known or suspected S\&M specimens collected while conducting surveys (pre-disturbance and strategic surveys) in the above taxa groups to the Interagency Taxa Expert for identification/verification (Enclosure 2).

These specimens should include known or suspected S\&M species and other unknown specimens that cannot be identified at the field level. Common, non-S\&M species are not to be sent to the taxa expert. Once the specimen has been identified, the field unit will be notified on the species determination. At the discretion of the taxa expert, specimens may be returned to the field units to provide local reference material following species identification.

For lichens, bryophytes and fungi at least one voucher specimen should be collected at each potential known site. For mollusks, one specimen should be collected per survey area (e.g. timber sale unit). The best available mollusk specimen, preferably an adult, should be collected. Instructions for handling and sending specimens are available from the taxa expert.

In the case of lichens and bryophytes the field unit can request from the taxa expert that a duplicate specimen be returned (they should collect enough material so that a duplicate specimen be returned). The following information must accompany each specimen: date of collection, collector, collection number, location (including directions, UTM coordinates, type of survey, habitat, etc.) and preliminary species identification, if available.

Verification and documentation of voucher collections is also needed for strategic and pre-disturbance surveys that have already been completed. All existing voucher collections from previous surveys that have not been identified/verified by the taxa expert (or regional contracts administered by the taxa expert) should be sent to the respective taxa expert for identification/verification. As above, specimens may be returned upon request at the discretion of the taxa expert. Each specimen should be accompanied by the above information along with the name of the person who made the species determination. This does not apply to those specimens that were identified by contractors for which the contract specified that ownership of the specimen would transfer to the contractor. In this case the repository of the specimens and ISMS location ID number should be provided.

The identification/verification of specimens has varied among the different taxa groups. For example, fungi specimens to be identified typically have been sent to the S\&M mycology lab in Corvallis. Due to the large number of specimens collected while conducting pre-disturbance and strategic surveys, the time it took to identify specimens did not occur in a timely fashion. This resulted in delays of project planning and 
implementation. As a result some field units decided to use other contractors to identify their specimens. In some cases when the interagency taxa expert reviewed these identifications they found misidentifications or the contractors kept the specimens.

For mollusk species, the identification of specimens has varied by field unit. Many of the identifications have been done by field crews (who have taken mollusk identification training) or sent to regional experts (agency personnel or contractors). As a result the criteria used for identification and the reliability of mollusk identifications has been inconsistent and quality control is not possible without a collected voucher specimen (in many cases mollusk collections were returned to where they were collected). Accuracy of specimen identification has been shown to be as low as 9 percent (Data from Northern California "GOBIG" surveys).

It is expected that S\&M specimens will be identified in a timely manner. This is a result of no longer requiring pre-disturbance surveys for fungi, awarding centralized regional contracts with taxonomic experts that should allow for quality identifications and a quicker return of specimens, and having full time taxa experts for all taxa groups. It is expected that identifications should take no longer than 10 weeks for the field to be notified of identifications. Field offices should build in enough planning time to include the identification of S\&M specimens.

During the latest species review process many of the locations of species were disputed because of identification concerns. Members of the review panels were not sure of the reliability of the person who identified specimens thus negating several apparent known sites. A centralized process of identifying specimens will eliminate these concerns.

Additionally, voucher collections will serve as documentation in the event that species management and the data on which it relies are challenged. These collections will be housed in university herbaria/museums or other public locations. Field units can request from the taxa experts specimens for training purposes. Voucher collections provide reference material for future management to ensure consistency of identification, particularly as personnel change. 
Enclosure 2 List of Regional Interagency Taxa Experts

Fungi: $\quad$ Tina Driesbach

PNW Forestry Sciences

3200 SW Jefferson Way

Corvallis OR 97331

541-750-7404

tdreisbach@fs.fed.us

Mollusks: Paul Hohenlohe

PNW Forestry Sciences

3200 SW Jefferson Way

Corvallis OR 97331

541-750-7403

phohenlohe@fs.fed.us

Bryophytes: Judy Harpel

Gifford Pinchot National Forest

10600 NE $51^{\text {st }}$ Circle

Vancouver, WA 98682

360-891-5121

jharpel@fs.fed.us

Lichens: Chiska Derr

c/o Judy Harpel

Gifford Pinchot National Forest

$10600 \mathrm{NE} 51^{\text {st }}$ Circle

Vancouver, WA 98682

360-449-7853

cderr@fs.fed.us 

